A Report for Westinghouse Hanford Company

\title{
A SURVEY OF EXISTING AND EMERGING TECHNOLOGIES FOR EXTERNAL DETECTION OF LIQUID LEAKS AT THE HANFORD SITE
}

R. E. Lewis

S.S. Teel

October 1994

Prepared for the U.S. Department of Energy under Contract DE-AC06-76RLO 1830

Pacific Northwest Laboratory

Richland, Washington 99352 


\section{DISCLAIMER}

This report was prepared as an account of work sponsored by an agency of the United States Government. Neither the United States Government nor any agency thereof, nor any of their employees, make any warranty, express or implied, or assumes any legal liability or responsibility for the accuracy, completeness, or usefulness of any information, apparatus, product, or process disclosed, or represents that its use would not infringe privately owned rights. Reference herein to any specific commercial product, process, or service by trade name, trademark, manufacturer, or otherwise does not necessarily constitute or imply its endorsement, recommendation, or favoring by the United States Government or any agency thereof. The views and opinions of authors expressed herein do not necessarily state or reflect those of the United States Government or any agency thereof. 


\section{DISCLAIMER}

Portions of this document may be illegible in electronic image products. Images are produced from the best available original document. 


\section{SUMMARY}

This report presents a catolog of existing and emerging technologies that may be applicable for the detection of liquid leaks in the unsaturated subsurface external to storage and transfer facilities. The catalog was developed with the needs of the Hanford Site in mind, primarily those of tanks farms. The needs for external leak detection for other Hanford facilities were also considered (e.g., retention basins, pipelines).

A total of 29 technologies is described and rated in a Microsoft $\$$ Excel spreadsheet provided with this report. These technologies can be divided into the following groups: 1) borehole geophysics, 2) surface geophysics, 3) borehole.to.borehole geophysics, 4) soil moisture instrumentation, 5) in situ sensors, 6) moisture removal and analysis, and 7) vapor extraction analysis. General descriptions of these groups and the evaluated technologies are provided in the text.

The ratings are grouped into four categories: 1) technical feasibility, 2) implementation feasibility, 3) environmental/regulatory feasibility, and 4) economic feasibility. Evaluations are based on a literature review and conversations with vendors and independent technical experts.

In order to limit the number of technologies addressed in this catalog, several technologies applicable to leak detection were not addressed. These include internal leak detection, the use of tracers, and the use of sensors specific for volatile hydrocarbons.

Several promising technologies have been identified for use at tank farms; however, more development may be necessary before implementation. Several technologies were identified that might provide improvements in external leak detection at other Hanford facilities. 
•

•

• 


\section{ACKNOWLEDGMENTS}

The authors wish to acknowledge the help of D.F. Iwatate of Westinghouse Hanford Company for providing guidance during the course of this project. 
•

•

• 


\section{CONTENTS}

SUMMARY

.iii

ACKNOWLEDGMENTS

$\mathrm{v}$

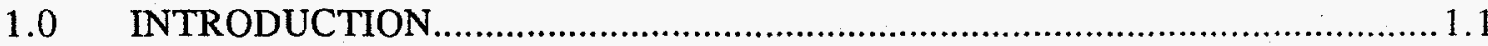

2.0 OVERVIEW OF CURRENTLY EMPLOYED LEAK DETECTION SYSTEMS.....2.1

2.1 FEDERALLY MANDATED LEAK DETECTION SYSTEMS FOR USTs .2.1

2.2 LEAK DETECTION FOR PIPELINES .............................................2.3

2.3 LEAK DETECTION AT THE HANFORD SITE

2.3.1 Hanford Tank Farms ................................................................ 2.4

2.3.1.1 Double-Shell Tanks.................................................2.4

2.3.1.2 Single-Shell Tanks..................................................2.4

2.4 LEAK DETECTION AT OTHER DOE SITES.........................................2.5

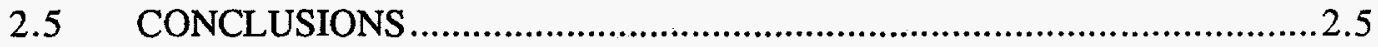

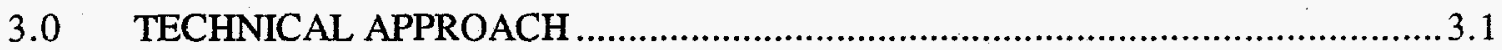

3.1 METHODS EMPLOYED FOR TECHNOLOGY SEARCH ….................... 3.1

3.1.1 Literature Search ............................................................. 3.1

3.1.2 Additional Sources of Information ........................................... 3.2

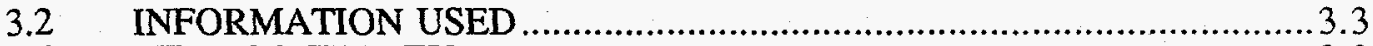

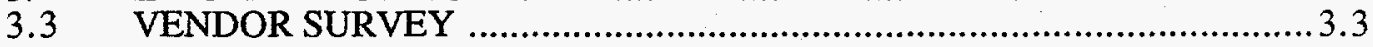

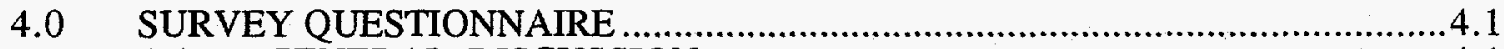

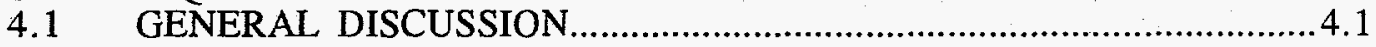

4.2 DETAILED DESCRIPTION OF SURVEY ............................................. 4.1

4.2.1 Assumptions ............................................................................. 4.1

4.2.1.1 SST Assumptions..................................................... 4.2

4.2.1.2 Subsurface Access Assumptions..................................4.2

4.2.1.3 Hanford Site Soils.......................................................... 4.2

4.2.1.4 Leak Assumptions ............................................... 4.2

4.2.1.5 Hanford Environmental Constraints..........................4.2

4.2.1.6 Noise ................................................................. 4.3

4.2.2 Survey Section 1: General Information........................................... 4.3

4.2.3 Survey Section 2: Technical Description...................................4.3

4.2.4 Survey Section 3: Technical Feasibility ......................................4.4

4.2.5 Survey Section 4: Implementation Feasibility ..............................4.5

4.2.6 Survey Section 5: Environmental/Regulatory Feasibility...............4.7

4.2.7 Survey Section 6: Economic Feasibility ...................................4.8

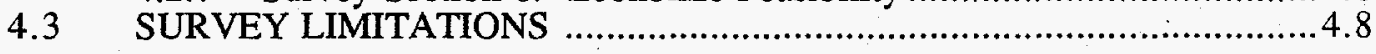

5.0 CANDIDATE TECHNOLOGIES FOR EXTERNAL LEAK DETECTION............5.1

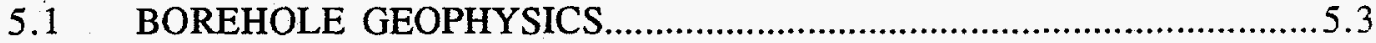

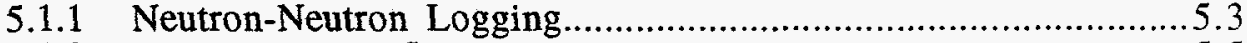

5.1.2 Pulsed-Neutron Spectroscopy Logging...................................5.5

5.1 .3 Electrical Induction Logging................................................5.6

5.1.4 Passive Gamma-Ray Logging ................................................5.6

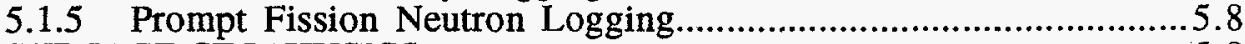

5.2 SURFACE GEOPHYSICS .............................................................. 
5.2.1 Surface Resistivity.............................................................5.9.

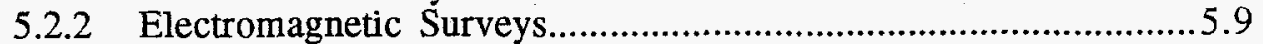

5.2.3 Ground Penetrating Radar ........................................................ 5.9

5.2.4 Seismic Boundary Waves ........................................................5.10

5.2.5 Surface Gamma Detection .......................................................5.10

5.2.6 Infrared Thermography......................................................... 5.10

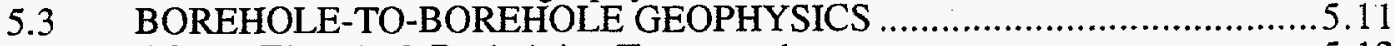

5.3.1 Electrical Resistivity Tomography............................................12

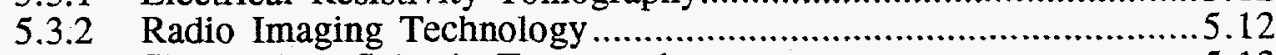

5.3.3 Shear-Wave Seismic Tomography............................................5.12

5.4 SOIL MOISTURE INSTRUMENTATION...........................................5.13

5.4 .1 Psychrometer..................................................................5.13

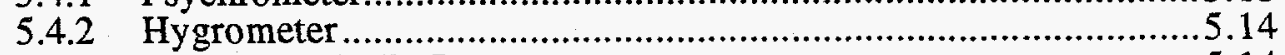

5.4 .3 Time-Domain Reflectometry …...........................................5.14

5.4 .4 Tensiometer.......................................................................5.14

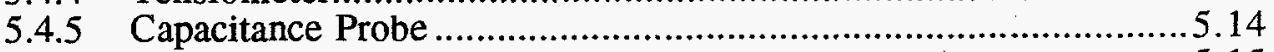

5.4.6 Resistivity Block .................................................................. 5.15

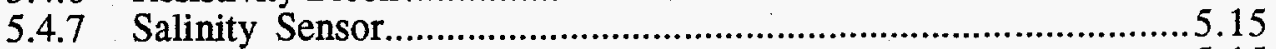

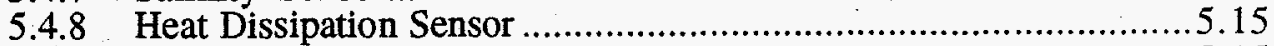

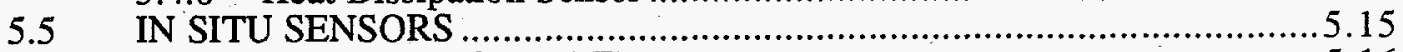

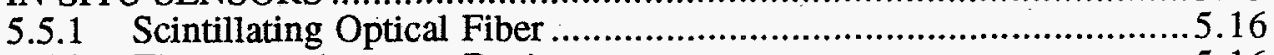

5.5.2 Thermoluminescent Dosimeter ..............................................5.16

5.5.3 Conductive Polymer ................................................................5.16

5.5.4 Acoustic Sensor ......................................................................5.17

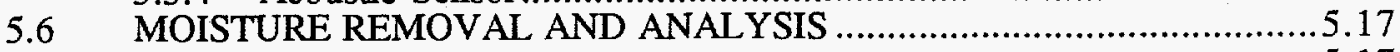

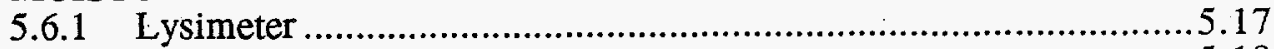

5.6 .2 Piezometer......................................................................... 18

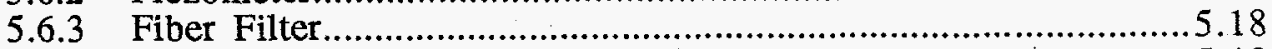

5.6.4 Membrane Filter................................................................... 5.18

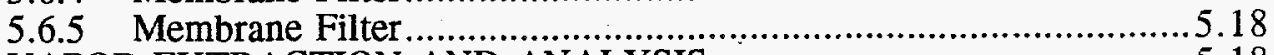

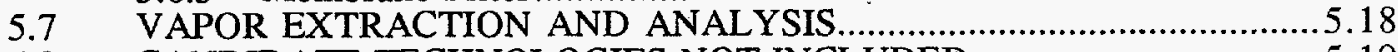

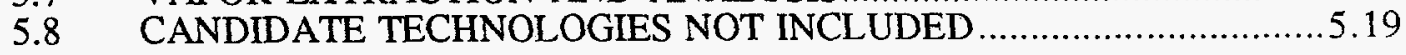

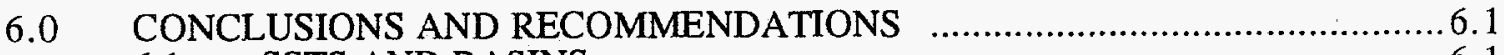

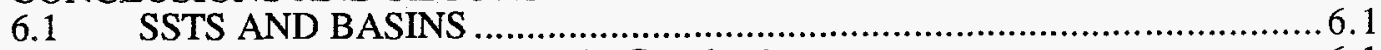

6.1.1 Borehole to Borehole Geophysics ................................................ 6.1

6.1 .2 Sensors........................................................................ 6.1

6.1 .3 Borehole Geophysics............................................................6.2

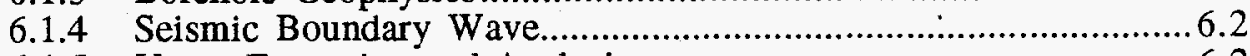

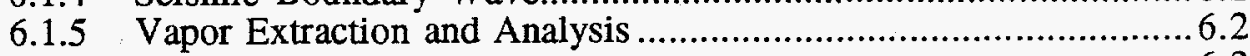

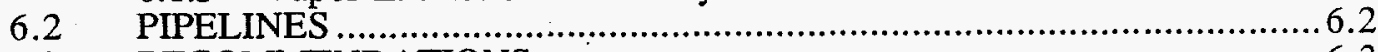

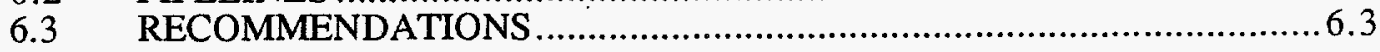

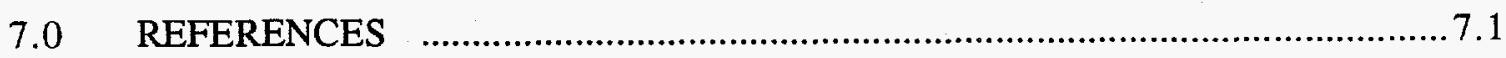

APPENDIX - SURVEY SPREADSHEET OF CANDIDATE TECHNOLOGIES …........ A.1 


\section{FIGURES}

1 Hanford Site Location Map

1.2

Underground Storage Tank System with Monitoring Wells ..................................... 2.2

Operational Regions of External Leak Detection Systems for SSTs

4.6

4 Borehole Geophysical Logging

\section{TABLES}

1 Candidate Technologies for External Leak Detection. 


\subsection{Introduction}

The U.S. Department of Energy's (DOE's) Hanford Site in southeastern Washington State (Figure 1) was acquired by the federal government in 1943 and for many years was dedicated primarily to the production of plutonium for national defense and the management of the resulting wastes (Woodruff et al. 1993). During the history of the Hanford Site, many structures were built that stored and transported liquids used for the production mission; some of these structures are still active. Active structures include underground storage tanks (single-shell tanks [SSTs] and double-shell tanks), retention basins, and pipes and pipelines. Many of the liquids stored and transported in these structures are potentially hazardous to human health and the environment. Any leakage of liquids from active structures, in addition, has the added potential to mobilize contaminants in the unsaturated zone. Therefore, it is beneficial to monitor these structures for leaks.

The purpose of this report is to catalog existing and emerging technologies that have potential for the external monitoring of liquid leaks. The report will focus primarily on the needs at the Hanford Site tank farms that are located in the 200 Areas (Figure 1), but will also be relevant to other Hanford Site facilities. Leak detection systems, both external and internal, are currently used at some Hanford facilities, and their use will be reviewed in Section 2 of this report. This report focuses on the detection of leaks as they migrate into the soils surrounding the facilities.

Section 3 discusses the technical approach used to develop the external leak detection technology catalog and describes the methods used to identify and report on the technologies. There is a large body of literature on external leak detection from underground storage tanks (USTs). To keep this catalog focused, several major assumptions were made to exclude several families of technologies. These assumptions are detailed in Section 3. Additional assumptions on the physical size of the facilities and the leaks detected are also described in this section.

Section 4 discusses the spreadsheet that summarizes the results of this effort. A description of the spreadsheet is included along with a discussion of the results. The promising technologies were divided into seven families. The general characteristics of each family are described along with their pros and cons, and a brief description of each technology is included. Several technologies were removed from the spreadsheet because of implementation issues. These technologies are described, and the reasons for exclusion discussed.

Section 5 lists the candidate technologies found for external leak detection. The principle of operation for each and advantages and disadvantages are discussed.

Section 6 summarizes the results of this project. The most promising technologies are listed, and recommendations for additional work are included. The Appendix contains digital and hardcopy versions of the technology spreadsheets.

This report was completed in a limited amount of time and, as such, it represents an initial attempt to catalog and evaluate external leak detection technologies. 


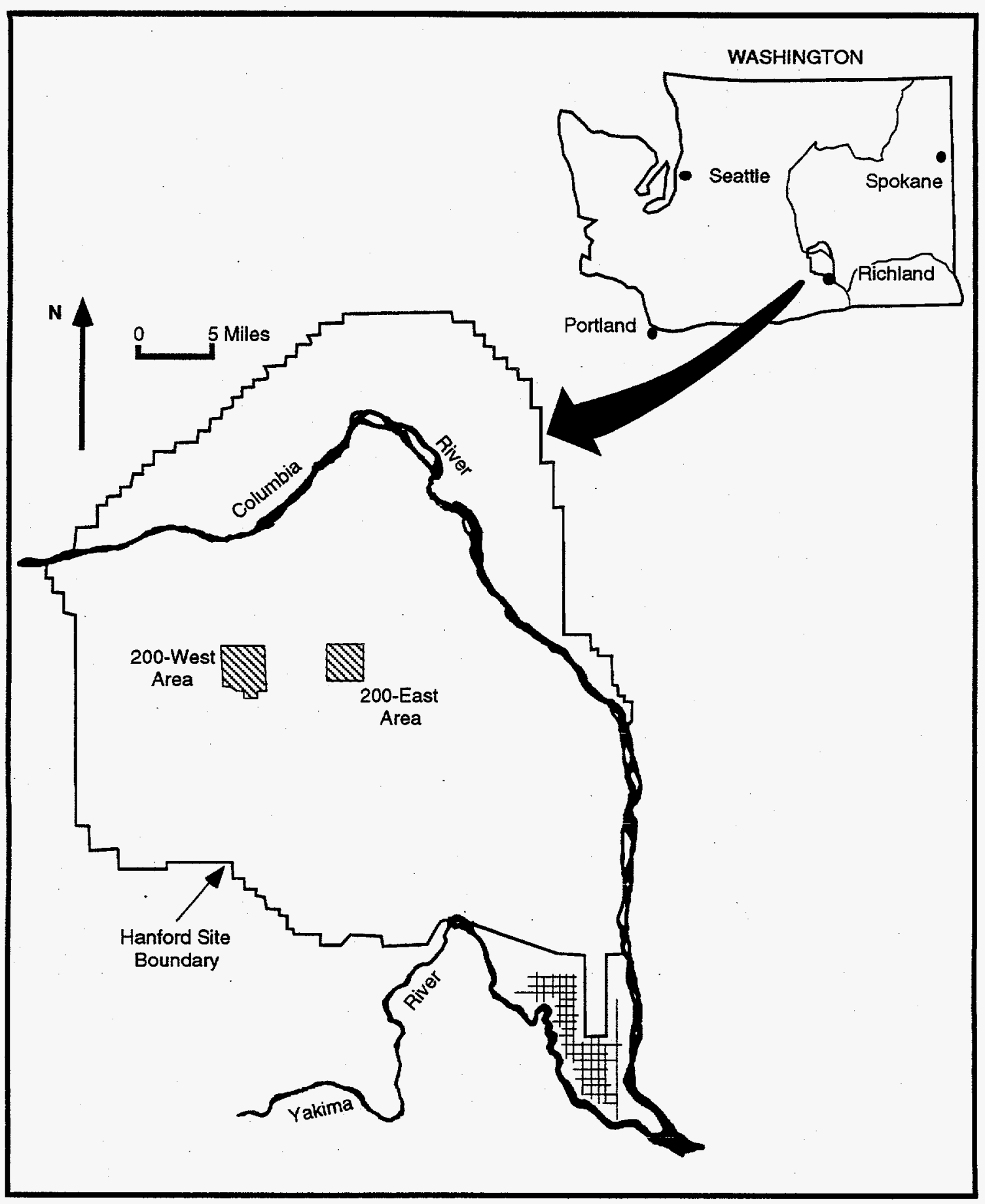

FIGURE 1. Hanford Site Location Map 


\subsection{Overview of Currently Employed Leak Detection Systems}

Leak detection technologies have developed into a mature industry. Most of these technologies were developed for one of two types of structures, 1) underground storage tanks (containing primarily petroleum products), or 2) utility pipelines (for natural gas or water). Leak detection for USTs is regulated under the Resource Conservation and Recovery Act (RCRA) and is administered by the U.S. Environmental Protection Agency. Individual states also regulate these tanks. Such regulations do not yet apply to long pipelines; however, prudent pipeline operators are using leak detection technologies to reduce financial and environmental liability.

\subsection{Federally Mandated Leak Detection Systems for USTs}

There are several million UST systems in the United States that contain petroleum or hazardous chemicals. Tens of thousands of these USTs, including their piping, are currently leaking. Many more are expected to leak in the future (EPA 1990). Leaking USTs can cause fires or explosions that threaten human safety. In addition, leaking USTs can contaminate nearby groundwater. Because much of the U.S. population depends on groundwater for potable water, in 1984 the federal government responded to the problem of leaking USTs by adding Subtitle I to RCRA. Subtitle I requires EPA to develop regulations to protect human health and the environment from leaking USTs.

UST regulations developed by the EPA define two categories of USTs:

- USTs installed after December 1988 (new) must meet the requirements for new USTs concerning correct installation, spill and overfill prevention, corrosion protection, and leak detection

- USTs installed before December 1988 (old) must meet requirements for corrosion protection and spill and overfill protection, and they must meet leak detection requirements.

EPA requires that new tanks are checked at least once a month for leaks. One (or a combination) of the following monthly monitoring methods must be used:

- Automatic tank gauging

- Monitoring for vapors in the soil

- Interstitial monitoring

- Monitoring for liquids on the groundwater

- Other approved methods.

Leak detection requirements are being phased in for old USTs. The operators of these tanks have three basic techniques for ensuring that their tanks are monitored at least monthly:

- For USTs that have corrosion protection or internal tank lining and devices that prevent spills and overfills, a combination of monthly inventory control with tank tightness testing every 5 years 
- For USTs that do not have corrosion protection or internal tank lining and devices that prevent spills and overfills, a combination of monthly inventory control with annual tank tightness testing

- Any of the monitoring systems described previously for new tanks.

EPA requirements for both new and old tanks do include external monitoring of leaks through 1) the monitoring of vapors in the soil, and 2) monitoring for liquids on the groundwater (Figure 2). Because of the need to install monitoring equipment in the large inventory of existing USTs, EPA has aided tank operators by publishing surveys and reviewing available external leak detection technologies available from vendors (Eklund and Crow 1988, EPA 1988).

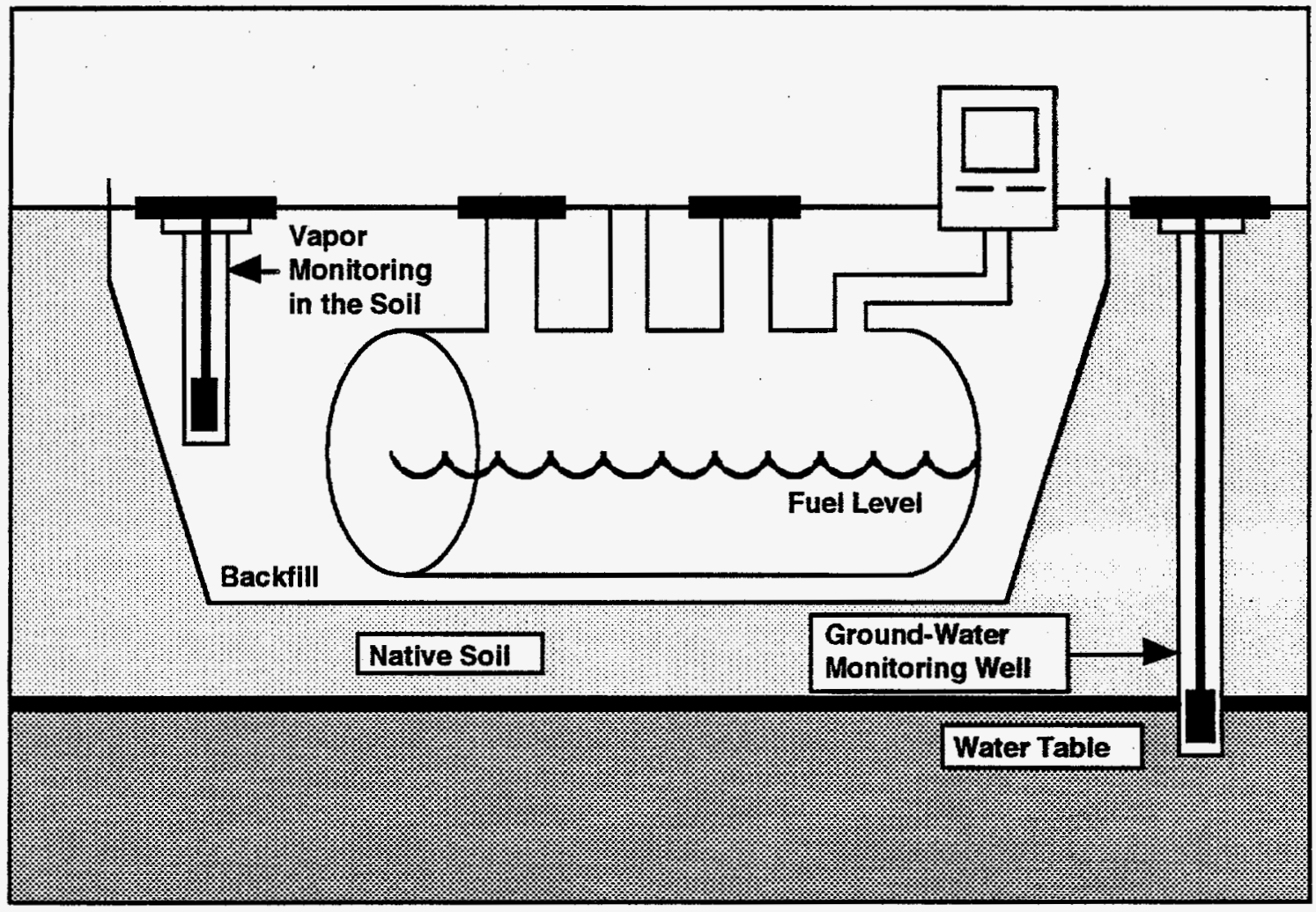

Figure 2. Underground Storage Tank System with Monitoring Wells (EPA 1989)

The external leak detection systems for USTs can be divided into four categories (Eklund and Crow 1988): intermittent liquid-phase detection, intermittent gas-phase detection, continuous liquid-phase detection, and continuous gas-phase detection. An examination of vendor survey data by Eklund and Crow (1988) yielded the following information:

- Commercial external leak monitors are designed primarily to detect leaks or spills of petroleum hydrocarbons 
- Most leak monitoring devices do not measure leak rates, although some devices (gaseous detectors) are capable of measuring hydrocarbon concentrations

- No uniform performance specifications exist for external leak monitoring devices

- Most leak monitoring systems require the installation of observation wells or boreholes

- Most leak monitoring systems can be retrofitted at existing UST installations

- Intermittent monitoring techniques are more labor-intensive than continuous techniques, but may be more reliable.

The first point is very important: commercially available leak detection systems are designed to detect petroleum hydrocarbons, not other products. Thus, much of the available technology may not be applicable to the materials stored and transported in Hanford Site facilities.

\subsection{Leak Detection for Pipelines}

There are few regulations pertaining to the establishment of leak detection systems for pipelines. Nevertheless, leak detection systems are currently employed for gas, water, and sewer pipelines. These leak detection systems include:

- Mobile surveys using portable instruments (e.g., flame ionization detector, combustible gas indicator ([Hennigar 1993])

- "Smart pigs" (monitoring within pipelines)

- Vapor monitoring adjacent to pipelines via dry wells (Raisanen 1991)

- Acoustic sensors (Fuchs and Riehle 1991, Kupperman 1990)

- Fiber optic acoustic sensor (Kurmer et al. 1993)

- Infrared thermography (Anon. 1989, Weil 1992)

- Ground penetrating radar (Graf 1990)

- Perfluorocarbon tracers (Dietz 1992).

\subsection{Leak Detection at the Hanford Site}

The Hanford site is a large DOE production facility that has been active since 1944. Its primary mission has been the production of plutonium, a process that has employed many structures that store or transport liquids. Currently, active structures include:

- Pipes and pipelines

- Underground storage tanks for high level wastes and other liquids

- Above-ground tanks for chemicals 
- Water treatment facilities

- Retention basins

- Storage pads

- Burial trenches

- Vaults.

Some of these structures have the potential for leakage, and external leak detection systems may be applicable. External leak detection systems are currently in use for underground storage tanks at the Hanford Tank Farms, which contain high-level wastes.

\subsubsection{Hanford Tank Farms}

Hanford Tank Farms comprise 177 underground storage tanks that contain high-level liquid radioactive waste. These tanks are grouped into 18 tank farms within the 200 East and 200 West areas. Of the 177 tanks, 149 are of single-shell design. Sixty-six of the single-shell tanks have been classified as suspected leakers (Woodruff et al. 1993). No double-shell tanks are known to have leaked. Leak detection systems are in use for both the single- and doubleshell tanks. These systems are described in detail in WHC (1989) and briefly summarized below.

\subsubsection{Double-Shell Tanks}

Double-shell tanks use the following leak detection systems:

- Leak Detection Pits that are designed to detect and recover solution leakage through the tank's steel liner. Three basic instrument systems are installed in each pit: 1) a radiation detection well, 2) instrument dip tubes for weight factor and specific gravity measurement, and 3) a thermocouple installed in a well that extends to within 3 inches of the bottom of the pit.

- Annulus Leak Detection channel leakage within the annulus to a space where conductivity probes are installed.

- Continuous Air Monitors (CAM) that monitor air that has circulated through the annulus. Any leaking liquid from the primary (inner) wall would contaminate the annulus air with radionuclides, which would activate an alarm.

\subsubsection{Single-Shell Tanks}

Single-shell tanks use the following leak detection systems:

- Surface Level Measurements are used for tanks that have liquid surfaces. The level is monitored either manually or automatically through the principle of electrical conductivity. The manual method uses reel-mounted tape or calibrated insulated wire that completes a circuit when the liquid surface is contacted. The automatic system uses an electrically driven plummet, and the level is recorded hourly.

- Liquid Observation Wells (LOWs) are fiberglass-cased drywells installed within solid-surface tanks that are used to monitor interstitial liquid levels with three probe types (gamma, neutron, and acoustic). 
- Drywells are vertical steel-cased boreholes that encircle the tanks and range in depth from 75 to 250 feet. There are 768 drywells at tank farms (Boomer et al. 1993), and they are monitored with gamma detection probes. The probes provide a continuous radiation profile (log) in the ground. The drywells are currently logged on schedules ranging from weekly to annually, depending on tank history (Isaacson and Gasper 1981). Drywells have also been monitored with a neutron (moisture) probe to detect possible changes in moisture levels in the soil.

The most commonly used gamma detection probe measures gross counts. It cannot distinguish between different gamma-emitting radionuclides. A high-resolution spectral gamma probe (radionuclide logging system [RLS]) has been developed by Westinghouse Hanford Company (WHC) and used to characterize some of the drywells. Weaknesses with the gross gamma systems currently used for leak monitoring have been noted (GAO 1992). Two probes similar to the RLS with associated support equipment (truck, cables, computers) have been ordered by tank farms.

- Laterals are horizontal drywells located around 10 feet below the concrete base of the tank. They are currently under 15 tanks and are monitored with radiation detection probes.

\subsection{Leak Detection at Other DOE Sites}

Leak detection systems are used at other DOE sites. However, only two reports describing current systems were received in time for consideration in this report. Neither site uses external methods for leak detection.

Douglas and Maresca (1993) provide a leak detection test plan and schedule for leak testing for the active portion of the liquid low-level waste (LLLW) system at the Oak Ridge National Laboratory (ORNL). This system entails the movement of low-level aqueous waste products through various pipelines and tanks, from a generator facility to a long-term storage facility. There are 41 ORNL LLLW tanks in active service; of these, 30 are doubly contained (i.e., the tank is in a vault), and 12 are singly contained. The LLLW tanks will be tested monthly using volumetric methods or visual inspection techniques. The primary leak detection methods for testing the tanks will be the "DP method." This method uses a differential-pressure sensor configured as a level sensor (a "bubbler") to sense liquid-level changes within the tank.

Galloway (1992) discussed conceptual designs and design recommendations for installing secondary containment and leak detection systems at three small sumps at the Fluorinel and Storage Facility (FAST) at the Idaho National Engineering Laboratory (INEL). The three sumps receive various materials from the FAST water treatment process. Currently, none of the sumps have secondary containment with leak detection capability. A leak detection pipe from the top of the sump provides access to where leaked materials would collect. A leak detection device with an alarm will be installed in this pipe.

\subsection{Conclusions}

There is little commonalty between commercially available external leak detection systems and the needs at the Hanford Site. This is due primarily to the differences in the materials stored. Most commercial systems are sensitive to petroleum hydrocarbons with high vapor pressure components (fuel and solvent tanks). Most liquids stored and transferred at the Hanford Site do not contain volatile petroleum hydrocarbons. 
The Hanford Site already has a history of external leak detection. A series of drywells and laterals have been installed around the SSTs, and they have been monitored regularly for leak detection since the 1970s. The current system does have its limitations: 1) the drywells are vertical, and because only a few of the SSTs have leak detection underneath the tank (laterals), leaks as large as 1500 gallons could go undetected (Key 1977);2) the logging systems employed for external leak detection are labor-intensive and do not provide continuous measurements; few wells are monitored more often than monthly (WHC 1989); and 3) the logging systems employed have been criticized as technically inadequate (GAO 1992).

The following chapter will discuss the methods used for determining if there are technologies, available or emerging, that can be employed to upgrade the existing external leak detection systems employed at the Hanford Site. 


\subsection{Technical Approach}

\subsection{Methods Employed for Technology Search}

The goal of this report is to identify existing and emerging technologies that could be used for external leak detection at the Hanford Site. Available technologies were discovered primarily through literature search; emerging technologies were discovered primarily through discussions with technical experts and the review of existing DOE proposals.

\subsubsection{Literature Search}

Because the liquids stored and transported at the Hanford Site are commonly not representative of those used in commercial industry, this project required a search for nonstandard uses of available technologies. The primary source for these technologies was a literature search conducted by the Hanford Technical Library (HTL).

HTL searched through the following databases:

- INSPEC Institution of Electrical Engineers

- NTIS National Technical Info Sves

- Ei Compendex*Plus Engineering Info. Inc.

- METADEX ASM/Inst. of Materials

- Enviroline1994 CIS, Inc.

- Pollution Abs Cambridge Scientific Abstracts

- TRIS Dialog Info. Svcs.

- Energyline CIS, Inc.

- FLUIDEX Elsevier Science Ltd.

- Energy SciTec

- Pascal INIST/CNRS

- TOXLINE Dialog Info. Svcs.

- WATERNET American Water Works Association

- ChemEng \& Biotec Abs RoySocChm, DECHEMA, FizChemie

- Scisearch Inst. for Sci. Info

- 3American Chemical Society.

A preliminary count was conducted for articles with the following keywords:

- Pipeline 
- Underground tank

- Storage tank

- Leak

- Detection.

Almost 3000 relevant articles were found in this initial search, more articles than could readily be sorted and ordered for this project. Much of this literature is directed towards the detection of leaks from USTs containing petroleum hydrocarbons. Because Hanford Site structures do not transport or store significant quantities of these liquids, especially when compared to other materials stored at the Hanford Site, the literature search was rerun, and it specifically excluded any articles with keywords of "oil" or "petroleum."

In addition, the search was subdivided into three categories. The first included the additional keywords of "Hanford" and "Richland." Twenty-six articles were found. The second search included the additional keywords of "Department of Energy" and "DOE." Twenty-seven articles were found; however, 10 discussed Hanford Tank Farms and most of the remainder discussed the LLLW at ORNL. The final search did not have any additional keywords, and it was limited to the last five years, since 1989. Three hundred sixty-two articles were found.

\subsubsection{Additional Sources of Information}

Additional technologies, especially emerging technologies, were discovered through discussions with experts in various technical fields, primarily vadose-zone monitoring, and through vendor lists compiled from advertisements.

Experts consulted included:

- Melvin Campbell (Pacific Northwest Laboratory [PNL]) In Situ Sensors

- Robert Engelman (PNL) Borehole Geophysics

- John Evans (PNL) In Situ Sensors and Fluid/Vapor Extraction

- Glendon Gee (PNL) In Situ Sensors and Soil Moisture Instrumentation

- Norman Harthill (Coleman Energy and Environmental Systems) Geophysics

- Randy Kirkham (PNL) In Situ Sensors and Soil Moisture Instrumentation

- Susan Narbutovskih (WHC) Surface Geophysics and Tomography

- Alan Rohay (PNL) Surface Geophysics. and Tomography

- Robert Riley (PNL) Vapor Extraction

- Gerry Sandness (PNL) Surface Geophysics

- Alan Schilk (PNL) Surface Geophysics

- David Stromswald (PNL) Borehole Geophysics and Vapor Extraction

- Robert Wilson (RUST GeoTech) Borehole Geophysics and Vapor Extraction. 
Advertisements in several trade journals (e.g., Pollution Engineering, Ground Water Monitoring and Remediation) were searched for promising technologies. In addition, catalogs of soil testing instrumentation were also searched for available technologies. These catalogs included Davis Instrumentation, Soil Test Materials Testing Catalog, Pollution Equipment, Ben Meadows Company, and GeoStore Environmental Testing Equipment.

\subsection{Information Used}

Most articles listed in the literature searches included detailed abstracts, and based on these abstracts the articles of interest were further reduced. The following technologies were not pursued further:

1) Pressure testing for leaks

2) In-tank or in-pipeline detection systems

3) Volumetric methods for leak detection

4) Flow and pressure measurements

5) Inventory methods for leak detection

6) Sensing for volatile vapors

7) Nondestructive testing of tanks or pipelines (e.g., mag flux, corrosion, acoustic waves in pipeline)

8) Tracers for leak detection.

These technologies were culled because they were either internal systems for leak detection (1 through 5), they relied on detection of volatile vapors (6), they required intimate contact with the storage vessel (7), or they required the addition of chemical tracers (8). The remaining articles of interest were ordered from HTL. Approximately 80 articles and patent descriptions were ordered.

\subsection{Vendor Survey}

Once a list of technologies was generated, a list of vendors and proposers (for emerging technologies) was developed. Appropriate vendors and proposers for each available technology were contacted and asked detailed questions about the technologies. Their names are included in the survey spreadsheet.

The survey questions used for each proposer and vendor are described in the following section. The results are in the survey spreadsheet in the Appendix, and they are summarized in Section 5. 


\subsection{Survey Questionnaire}

\subsection{General Discussion}

The results of the survey of technologies for external leak detection are based on a detailed set of questions that were applied to each technology. The survey questions were developed based on the results of EPA leak detection surveys (Eklund and Crow 1988, EPA 1988), the categorization of vadose zone monitoring techniques (Everett 1981, Wilson 1980, Everett et al. 1984), and the authors' personal experience.. The questions evolved as the survey progressed. The answers to these questions form the rows that populate the survey spreadsheet in the Appendix.

The questionnaire was initially filled out based on available literature (e.g., journal articles, patents, brochures, proposals). Follow-up included contacting the vendors or proposers for each technology. At least one individual was contacted for each technology, and that person or persons are named in the survey spreadsheet.

The survey questions were divided into six groups:

- General: Provides a short general description of the technology

- Technical Description: Provides a detailed technical description

- Technical Feasibility: Assesses the merits and limitations of the technology

- Implementation Feasibility: Assesses the practicality of implementing the technology at Hanford

- Environmental/Regulatory Feasibility: Assesses the environmental and regulatory limitations towards implementing each technology

- Economic Feasibility: Estimates the costs to implement each technology.

Most of the survey questions were designed to provide either a binary answer (yes/no) or a grade of 1 to 5 (with 5 the most desirable). The user will be able to sort the technologies based on binary responses and rate them by assigning weights to the grades.

The survey questionnaire is designed for all appropriate Hanford Site storage and transport facilities; however, many of the questions address Tank Farms in particular due to its welldefined specifications and documented needs.

The questions that were asked are detailed below.

\subsection{Detailed Description of Survey}

\subsubsection{Assumptions}

To fill out the survey, certain assumptions had to be made about Hanford Site facilities, geology, environment, and needs. The appropriate assumptions are discussed in this section. 


\subsubsection{SST Assumptions}

The primary focus of this survey is the Hanford tank farms. It was assumed that the typical tank is single-shell, 1,000,000-gallon capacity, 75 feet in diameter, with the top 6 feet below the surface and the base 50 feet below the surface.

\subsubsection{Subsurface Access Assumptions}

The primary access to the subsurface at the Hanford Site is existing boreholes. Tank farms currently have more than 700 drywells, and in this survey it is assumed that each tank is surrounded by six drywells that are separated from the formation by a single string of 6-inchdiameter steel casing. The casing is neither grouted nor is it screened or perforated. There is a cement plug at the bottom. Each drywell is 100 feet deep and 5 feet from the edge of the tank. The wells are 45 feet apart along the tank circumference.

An alternative method for subsurface access is the cone penetrometer. This system pushes a hollow rod into the subsurface. It is assumed that all pushes are vertical and that the internal diameter of the rod is 1.5 inches.

It is assumed that there are no drilling systems available at the Hanford Site that can routinely drill at shallow angles or horizontally. Thus, sensors cannot be emplaced beneath tanks or basins.

\subsubsection{Hanford Site Soils}

The soils underlying the Hanford liquid and storage facilities are assumed to be part of the Hanford formation. They have a moisture content of 5\% by volume of the total formation, a porosity of $30 \%$, and are a subarkosic sandy gravel. The depth to groundwater is assumed to be 200 feet.

\subsubsection{Leak Assumptions}

A typical leak is assumed to be a spherical blob 40 feet in diameter (approximately the distance between drywells). The leak is assumed to completely saturate the pore space (which comprises $30 \%$ of the volume).

The leak is assumed to be the typical interstitial liquid currently within the SSTs as defined by Boomer et al. (1993). This material consists primarily of (in descending relative concentration) water, $\mathrm{Na}^{+}, \mathrm{NO}_{2}^{-}, \mathrm{PO}_{4}^{-3}, \mathrm{Al}^{+3}$, organic carbon, $\mathrm{SO}_{4}^{-2}$, and $\mathrm{OH}^{-}$. The radionuclide components of SST wastes consist primarily of fission radionuclides, such as ${ }^{90} \mathrm{Sr}$ and ${ }^{137} \mathrm{Cs}$, and actinide elements, such as U, Pu, and Am (Cruse and Treat 1994).

Since many of the liquid storage and transport structures at the Hanford Site are not at tank farms, it is assumed that the primary constituent of all leaks will be water. Tank wastes are typically saline with high $\mathrm{pH}$.

\subsubsection{Hanford Site Environmental Constraints}

The average surface temperature at the Hanford Site is $53.4^{\circ} \mathrm{F}$ (Woodruff et al. 1993). The typical annual high temperature is $97^{\circ} \mathrm{F}$, and the typical annual low is $23^{\circ} \mathrm{F}$. The subsurface temperature is considered constant at $60^{\circ} \mathrm{F}$, although this value may be somewhat higher at the tank farms. Surface humidity ranges from $6 \%$ to $100 \%$. 


\subsubsection{Noise}

Acoustic and electromagnetic noise is present throughout much of the Hanford Site, especially at the tank farms. Sources of acoustic noise include vehicular traffic and stationary mechanical equipment. Sources of electromagnetic noise include high tension power lines, cathodic protection, and radio emissions.

\subsubsection{Survey Section 1: General Information}

The first section of the survey attempts to provide general information that can be used to initially focus the technology screening. The section contains:

- Name of Technology

- Source of Information: What individuals provided information on the technology.

- Vendor or Proposer: The vendor or proposer contacted and their employer.

- Principle of Operation: Provides a quick focus on the technology. Is it passive or active (interrogates the formation with energy) and is it emplaced at the surface or in the subsurface.

- Publications: List of applicable articles whose references are provided in Section 7.

- Service Performed by: Is the detection system performed by a private contractor or can Hanford provide it.

\subsubsection{Survey Section 2: Technical Description}

This section provides a description of the technology. The section contains the following subheadings:

- Media Monitored: Does the system monitor vapors or liquids?

- Sample/Measurement Volume: Describes the volume of the measurement. A point measurement refers to a sampling volume fist-sized or smaller. For a volume measurement, two values are provided, one for the volume of an individual measurement at a single station, the other the volume that a continuous measurement can provide (e.g., borehole geophysical systems can provide a continuous $\log$ ). Two-dimensional images provide the size of a single tomogram (assuming the system monitors a Hanford SST). Pixel size provides the area of each individual pixel obtained in the tomogram, and the size is a measure of the system resolution. The total volume refers to the volume of the entire survey (i.e., multiple tomograms).

- How System Detects a Leak: Provides a large series of binary answers that list various leak detection technologies. The technologies are divided into passive versus active where passive systems do not impart energy into the formation.

- Sampling Interval: Can the sampling instrumentation be left at the site to continuously monitor for leaks? If so, what is the minimum time (in hours) between measurements and the processing of results. If the system instrumentation cannot be left in place, then it samples at discrete intervals. 
- Detection Limit: Lists the lower and upper detection limit of the leak detection system. The limit is provided in units that the system measures, which may be a value that will have to be converted in order to determine the size of a leak. If the lower detection limit is adjustable, it is noted.

- Response Time: Lists the time from immersion of a sensor into a leak until it reaches steady state (hours).

- Data Collection System: If the data is collected by a person operating the leak detection system, then data collection is considered manual. Automatic data collection assumes that the system can record results to a system that can be periodically downloaded (e.g., data logger). Remote data collected assumes that the data can be sent (e.g., telemetered) to a central facility for processing and interpretation.

\subsubsection{Survey Section 3: Technical Feasibility}

This section of the survey provides an interpretation of the leak detection system. It provides our best attempt to judge the systems technical merits and weaknesses. The section contains the following subheadings:

- Direct versus Indirect Measurement: Does the system detect moisture (a direct measurement), or is it sensitive to another physical property that infers moisture (an indirect measurement). If the measurement is indirect, the strength of inference is assigned a grade.

- Data Ambiguity: How difficult is the interpretation of the data, and how nonunique is it? A grade is assigned.

- Level of Development: The first two rows provide a synopsis for the remainder of this section. These rows provide a grade for hardware maturity (including software control) and data interpretation software maturity. The remainder of the section is subdivided into three parts: is the system commercially available and readily adaptable for leak detection; is the system in development; or is the system in design phase. If the system is commercially available, how many years has it been on the market, has it ever been used expressly for leak detection, how reliable is the system (grade), and what is the anticipated lifespan of the system (grade)? If the system is in development, it is assumed that a prototype has been built. The rows address whether the system has been demonstrated, the number of years since demonstration (positive value) or the anticipated years until demonstration (negative value), the number of demonstrations, a grade for the technical obstacles till the system is marketable, and a grade for the anticipated reliability of the system. If the system is in design, it is assumed that no prototype has been built. The rows address the maturity of design (grade) from concept to laboratory tested subsystems, the technical promise (grade), and the anticipated level of effort until demonstration (grade that is dependent upon the resources of the proposer or vendor).

- Complexity: A grade is assigned to the complexity of the system hardware, the higher the value the less complex. A grade is also assigned to the complexity of the software and data interpretation.

- Reliability: System reliability is assigned a grade. The value is based on vendor experience, proposer estimates, and system complexity. If one system component is notably less reliable, it is named and its anticipated service life in years provided. 
- Interferences: Are there any known interferents that can cause the system to either respond positively to a non-existent leak (false positive) or not detect a leak (false negative). If so, the potential interferents are listed and the severity is graded. Note: For many of the systems, there is little data about interferents, especially for Hanford Site conditions.

\subsubsection{Survey Section 4: Implementation Feasibility}

This section of the survey provides an interpretation of the level of effort to install, maintain, and operate the leak detection system at the Hanford Site. This section primarily focuses on implementation at Hanford Tank Farms because of its well-defined specifications and documented needs.

- Depth Limitations: At what depths do the sensors for the leak detection system need to be installed? Surface is down to a depth of 6 inches, shallow subsurface is from 6 inches to 3 feet, and the two remaining options are cut off at 50 feet, the depth of a typical SST.

- Subsurface Access: If the system requires subsurface access, how is it accomplished? The response has been subdivided into boreholes and alternative subsurface means. If boreholes are required, then the minimum internal diameter in inches is provided. Can the system operate in a cased borehole (i.e., the system does not require intimate contact with the formation); if so, can the casing be either conductive (metallic) or nonconductive (e.g., fiberglass or PVC)? If boreholes are used, is screened or perforated casing required? Does the sensor require that the casing be yanked for operation? The last rows address whether the leak detection system will be operational in existing Tank Farm drywells (described in assumption section above). Are modifications to the drywells required and what are they? Alternative subsurface methods considered whether the sensors can be installed with a cone penetrometer or a backhoe. Cone penetrometer assumes that the penetrometer can either deploy sensors into the subsurface or the cone rod or alternative casing can remain in place with size limitations noted in the assumption section.

- Operational Regions for Tanks: What portions of a SST can the detection technology monitor for leaks? The letters within the spreadsheets are keyed to Figure 3 . It is assumed that there is no currently available method at Hanford to deploy sensors beneath a tank or basin, region 4 .

- Implementation Specifics: How many sensors or access points are necessary to adequately monitor one SST for an external leak? For systems that can use the drywells, it is assumed that six access points are adequate (i.e., the average number of drywells per SST). The depth of the sensor relative to the base of the tank is also estimated.

- Utility Service: What are the site power requirements for the leak detection system? The three primary responses are 1) no power needed, 2) self-contained power, and 3) external source required. If the power is self-contained, then what is used: a battery, a generator, or a portable air compressor? If an external source is required, is it AC or DC and what are the power requirements (watts)? The primary consideration for the latter is whether the current grid is sufficient.

- Operating Environment: Will the system be operational in typical Hanford Site environmental conditions? In particular, will it operate within the range of typical temperature (surface and subsurface depending on implementation scheme), 


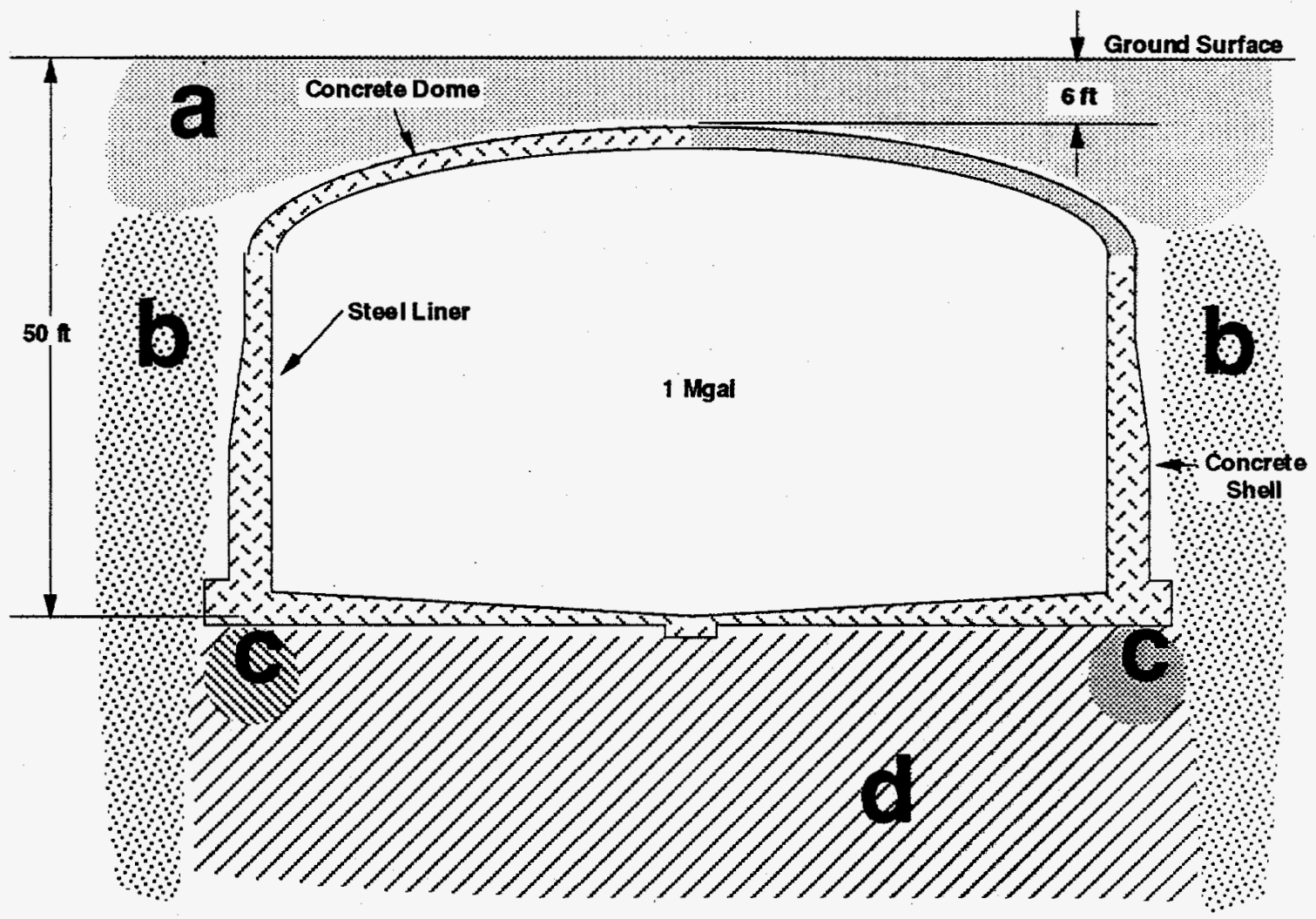

Figure 3. Operational Regions of External Leak Detection Systems for SSTs. The letters are keyed to the spreadsheets in the Appendix

surface humidity, and soil moistures encountered at the Hanford Site (the values are listed in the preceding assumption section)? Also, will the system operate effectively in a contaminated Hanford Site environment? The response is divided into the effect of radioactivity on the sensor, is the effect of radiation on the system known and what is this level of effect; is the effect of salinity on the sensor known (e.g., where it is in intimate contact with the formation), and what is the level of this effect; is the effect of atypical pH known, and what is the level of effect.

Assumptions on the range of these physical parameters are provided in Section 4.2.1 of this report. Note: Many vendors and proposers do not know the effect of the Hanford Site environment on their systems, especially radiation.

- Sensitivity to Local Noise: Is the leak detection system sensitive to local acoustic or electrical noise, as defined in the earlier assumption section? For many systems a simple yes/no answer is not available, so a grade has been assigned. If the system is believed to be sensitive, then the range of applicable frequencies is reported.

- Sensor Maintenance: Does the system require maintenance? If so, how often should it be maintained (months), how long does it take (hours), and can it be performed remotely? This section is primarily concerned with the maintenance of sensors that are emplaced into the subsurface, not ancillary or support systems that are readily removable from the surface. 
- System Calibration: Does the system require calibration? If so, how often should it be calibrated (months), how long does it take (hours), and can it be performed remotely? This section is primarily concerned with the calibration of sensors that are emplaced into the subsurface, not ancillary or support systems that are readily removable from the surface.

- Monitoring Time: How long does it take to monitor one tank for leaks (days)?

- Applicability to Active Sites: In general, will the leak detection system be implementable for the following Hanford Site storage and transport facilities: SSTs, basins, and pipelines?

\subsubsection{Survey Section 5: Environmental/Regulatory Feasibility}

This section of the survey provides an estimate for potential deleterious effects of the leak detection system on human health and the environment. The effect of the system on contaminant transport is also estimated.

- Permitting Required: Does the leak detection system require the introduction of a regulated material into the environment?

- Disposal/Dismantling Concerns: Will the system leave materials in the subsurface. If so, is there a potential to leave or deposit a hazardous substance (i.e., a radioactive source)?

- Risk during Installation: What is the risk to the worker during installation of the leak detection system? This risk is a function of the required installation. Is the system installed into surficial soils; if so, to what depth (feet)? Can the system use pre-existing boreholes or does it require new boreholes? Is the system in intimate contact with subsurface soils?

- Risk during Monitoring: Grades the risk to a worker during the monitoring of the leak detection system. If the worker is in intimate contact with contaminated materials, the risk is considered high. If the worker does not enter a contaminated zone, the risk is considered low. Also, is the presence of a Health Physics Technician (HPT) necessary during monitoring?

- Risk during Calibration: Grades the risk to a worker during calibration of the leak detection system. If the worker is in intimate contact with contaminated materials, the risk is considered high. If the worker does not enter a contaminated zone, the risk is considered low. Also, is the presence of a Health Physics Technician (HPT) necessary during calibration?

- Risk during Maintenance: Grades the risk to a worker during the maintenance of the leak detection system. If the worker is in intimate contact with contaminated materials, the risk is considered high. If the worker does not enter a contaminated zone, the risk is considered low. Also, is the presence of a HPT necessary during maintenance?

- Effect of Sampling/Measurement on Subsurface: Does the leak detection system have any effect on the current subsurface environment that might affect contaminant transport (e.g., does it alter the subsurface flow paths, alter subsurface moisture content, etc.)? 


\subsubsection{Survey Section 6: Economic Feasibility}

This section estimates the costs to install and operate a leak detection system at the Hanford Site. Determining these costs is difficult because 1) many of the systems are not designed for leak detection and will have to be adapted, 2) many of the systems are still in prototype or conceptual stage, 3) methods and costs for installation are uncertain, 4) the effects of Hanford Site contamination on the systems are generally unknown, 5) economy of scale-up is unknown, and 6) the costs of implementation at a DOE site are poorly constrained. Thus, if a numerical value could not be determined, a qualitative high, medium, or low was estimated.

- Capital Costs. What are the costs for the sensors that are emplaced into the formation? Also, what are the costs for the systems that control the sensors?

- Installation Costs. What is the cost to install or provide access for one sensor? Is the cost different if the service is provided by a vendor versus a Hanford Site contractor?

- Maintenance Costs. What is the cost to maintain the leak detection system if it can be applied to numerous sites? If the sensors are permanently emplaced, what are the maintenance costs for the equipment deployed for one SST? Is the cost different if the service is provided by a vendor versus a Hanford Site contractor?

- Calibration Costs. What is the cost to calibrate the leak detection system? Is the cost different if the service is provided by a vendor versus a Hanford Site contractor?

- Monitoring Costs. What does it cost to monitor one SST? Is the cost different if the service is provided by a vendor versus a Hanford Site contractor? What are the costs to process the data from the monitoring of one SST?

\subsection{Survey Limitations}

The production of this survey was subject to some limitations that may affect its completeness. The project was performed in a limited amount of time. This prevented the authors from 1) sending out formal questionnaires to vendors and proposers, 2) ordering more literature that may have suggested additional technologies, 3) following up literature reviews with more personal contacts.

The following parts of the survey were the most difficult to determine:

- Data Collection Systems: Many of the technologies do not have applicable data collection systems. These systems would have to either be developed or adapted from existing systems.

- Reliability: Many of the technologies will require significant adaptation, are still in the prototype stage, and are still conceptual. Thus, their reliability has not be proven nor quantified.

- Operating Environment: The Hanford Site presents unique challenges for emplaced sensors, and the ability of many of the technologies to be effective in this environment are unknown.

- Economic Feasibility: There are many unknowns because many of these systems have not be commercialized or have not been applied to leak detection. Also, operations at the Hanford Site present unique problems for which costs have not been quantified. 


\subsection{Candidate Technologies for External Leak Detection}

Based on the results of the literature search and discussions with technical experts, 32 technologies were identified as candidates for external leak detection. These candidate technologies are potentially capable of detecting a leak by monitoring for changes in one of the following:

- Moisture

- Radioactivity

- Temperature

- Bulk chemistry.

The candidate technologies have been divided into following categories, based on implementation and methods of analysis:

- Borehole Geophysics

- Surface Geophysics

- Borehole-to-Borehole Geophysics

- Soil Moisture Instrumentation

- In Situ Sensors

- Moisture Removal and Analysis

- Vapor Extraction and Analysis

The first three categories consider methods developed to study the earth through quantitative physical methods. Most were developed for the oil and mineral exploration industries, and they are generally in a mature state of development. Nevertheless, many of these technologies may require adaptation before they are applied to leak detection.

The Soil Moisture Instrumentation category considers several mature technologies that have been developed to provide point measurements of the moisture content or potential in the vadose zone. In situ sensors include technologies that provide point measurements of other parameters related to external leaks, primarily radioactivity.

The final two categories consider the removal of either liquid or vapor samples from the subsurface and their analysis either in the field or in the laboratory.

Table 1 lists the candidate technologies subdivided into these technology categories. A general discussion of each category follows with its strengths and weaknesses listed. Within each technology category, there is a brief description of each candidate technology.

Several of the technologies discussed in this section were not considered implementable at the Hanford Site because of technical limitations, and they were excluded from the survey spreadsheet. These technologies and the reasons for their exclusions are discussed in the end of this section. 
Table 1. Candidate Technologies for External Leak Detection

\begin{tabular}{|l||}
\hline Borehole Geophysics \\
\hline Neutron-Neutron Logging \\
Pulsed-neutron Spectroscopy Logging \\
Electrical Induction Logging \\
Passive Gamma Ray Logging \\
Prompt Fission Neutron Logging \\
\hline Surface Geophysics \\
\hline Surface Resistivity \\
Electromagnetic Surveys \\
Ground Penetrating Radar \\
Seismic Boundary Waves \\
Gamma Ray Detection \\
Infrared Thermography \\
\hline Borehole-to-Borehole Geophysics \\
\hline Electrical Resistivity Tomography \\
Radio Imaging Technology \\
Shear-Wave Seismic Tomography \\
\hline Soil Moisture Instrumentation \\
\hline Psychrometer \\
Hygrometer \\
Time Domain Reflectometry \\
Tensiometer \\
Capacitance Probe \\
Resistivity Block \\
Salinity Sensor \\
Heat Dissipation Sensor \\
\hline In Situ Sensors \\
\hline Scintillating Optical Fiber \\
Thermoluminescent Dosimeter \\
Conductive Polymer \\
Acoustic Sensor \\
\hline Moisture Removal and Analysis \\
\hline Lysimeter \\
Piezometer \\
Fiber Filter \\
Membrane Filter \\
Filter Candle \\
\hline Vapor Extraction and Analysis \\
\hline Tritium Detector \\
\hline
\end{tabular}




\subsection{Borehole Geophysics}

Borehole geophysical logging is a mature technology used for over 50 years in the petroleum industry. Logging is performed from a logging truck or van (Figure 4) that carries the downhole measuring instruments, the electric cable and winch needed to lower the instruments into the borehole, the surface instruments needed to power the downhole instruments and to receive and process their signals, and the equipment needed to make a permanent recording of the "log" (Schlumberger 1989).

The downhole measurement instruments are usually composed of two components. One component contains the sensors used in making the measurement, called the sonde. The other component is the cartridge that powers the sonde and preprocesses the data prior to transmission uphole.

Logging has been used at the Hanford Site for subsurface characterization since the 1950 s. It has been a primary leak detection method at Tank Farms since the 1970 s. Over 700 drywells have been installed at Tank Farms expressly for geophysical logging.

Logging has many strengths:

- It is a mature technology

- There are many different logging systems available that measure different properties of the subsurface

- The tools are well-calibrated for oil-field conditions, and most can be calibrated for Hanford Site applications after minor adaptation

- The data can be processed and displayed as acquired

- Drywells are already available

- The systems have good vertical resolution, typically from 2 to 12 inches.

Logging also has weaknesses:

- Boreholes are necessary for subsurface access

- The systems are labor-intensive and relatively expensive to operate

- Logging can only be used at discrete temporal intervals; the sonde is too expensive to leave in drywells

- The tools have a limited depth of investigation, typically from 2 to 12 inches

- Logging is not a particularly viable option for external monitoring of pipelines.

The remainder of this subsection discusses various logging systems that may have application for leak detection at the Hanford Site.

\subsubsection{Neutron-Neutron Logging}

Neutron-neutron logging systems determine the concentration of hydrogen (moisture) in the formation by measuring either the mean free path length or lifetime of neutrons emitted from a radioactive source in the sonde. These neutrons collide with nuclei of the formation 


\section{BOREHOLE GEOPHYSICAL LOGGING}

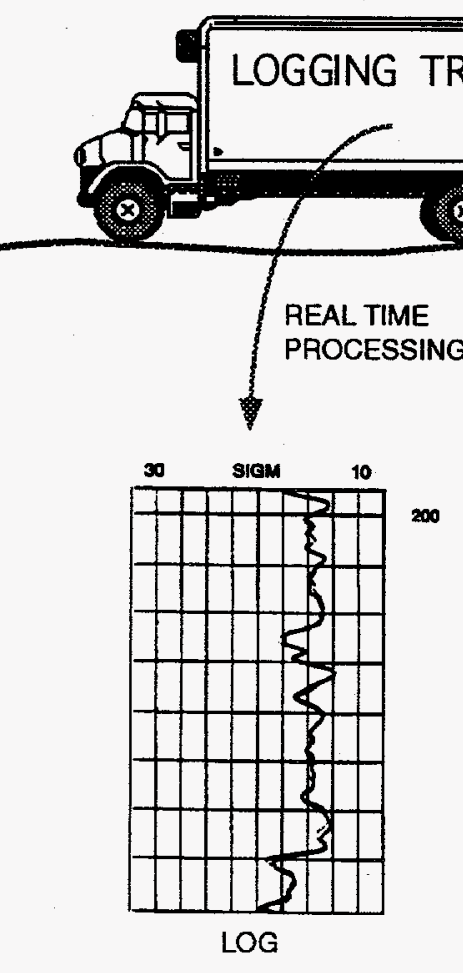

Log records physical property vs. depth

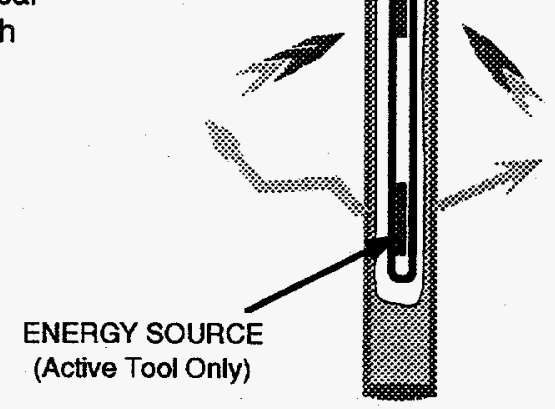

INTERACTIONS WITH FORMATION

Figure 4. Borehole Geophysical Logging 
materials, and with each collision, the neutron loses some of its energy. The greatest energy loss occurs when the neutron strikes a nucleus of practically equal mass (e.g., a hydrogen nucleus).

When the hydrogen concentration of the material surrounding the neutron source is large, most of the neutrons are slowed and captured within a short distance of the source. On the contrary, if the hydrogen concentration is small, the neutrons travel farther from the source before being captured. Accordingly, the counting rate at a neutron detector increases for decreased hydrogen concentration (Schlumberger 1989).

Borehole standoff is a concern for neutron-neutron tools. The response of the tools is affected significantly if they are not in direct contact with the formation; standoff is the distance that the tool is separated from the formation. Most commercial neutron-neutron tools compensate for borehole standoff by using two neutron detectors and using the count rate ratios to determine hydrogen concentration.

Two types of sources are available for these systems: chemical and generator. The most common chemical source is $\mathrm{AmBe}$, which provides neutrons with initial energies of several million electron volts (MeV). The sources are as large as 20 Curies (Ci). Neutron generators emit pulses of high-energy neutrons $(14.1 \mathrm{MeV})$ typically created by reactions between deuterium and tritium (Hearst and Nelson 1985).

The neutron generator has several advantages over the chemical source: 1) it can be turned off, so it is not hazardous when not in use; 2) the neutron energy is higher, so its depth of investigation is greater, and 3) it can be pulsed, and this permits an alternative way to measure moisture content. The epithermal neutron die-away technique, developed by Mobil Oil, uses a neutron generator to determine the lifetime of epithermal neutrons rather than the mean path length as the ratio tools do (Mills et al. 1988, Stromswold and Allen 1992). This tool currently does not have a correction for standoff. Schlumberger Well Services has developed a tool that used a neutron generator and measures both ratio porosity and neutron lifetime that is corrected for standoff.

Neutron-neutron tools show good promise for the detection of leaks in the vadose zone. The tools measure hydrogen, and because the Hanford formation has very few hydrous minerals (e.g., clays), the tool responds primarily to the moisture content of the formation. These tools are capable of detecting changes as șmall as 1 volume weight fraction of water in the formation. Neutron-neutron tools have been used around the SSTs in the past to detect leaks (WHC 1989).

These tools are well-suited for detecting leaks at the SSTs and basins. They can use existing steel-cased drywells.

\subsubsection{Pulsed-Neutron Spectroscopy Logging}

Pulsed-neutron spectroscopy tools measure the gamma rays resulting from interactions of neutrons with the different elements in the formation. The number of gamma rays and their energies form a spectrum that is recorded versus depth. These spectra are compared to signatures of the elements most commonly found in sedimentary rocks and their pore fluids. The number of gamma rays attributed to each of these common elements is presented as a percentage of the total gamma ray spectrum (relative yield). Common elements detected include $\mathrm{H}, \mathrm{Cl}, \mathrm{C}, \mathrm{O}, \mathrm{Si}, \mathrm{Ca}, \mathrm{S}$, and $\mathrm{Fe}$.

This logging system has the potential to not only measure hydrogen, thus moisture, but also to potentially detect hazardous wastes and provide a geochemical log. In addition, if the 
system is operated passively, without the generator turned on, the gamma detector could be used for spectral gamma logging.

Commercially available systems use two different types of detectors--scintillation and solid state (high-purity germanium). Scintillation detectors are used in the majority of the systems. Scintillation detectors are orders of magnitude less selective than solid state; solid state has the potential to accurately identify many more elements. However, solid state detectors are more difficult to operate, most must be kept at very low temperatures during operation, and they are less efficient. Logging runs with a system that has a scintillation detector may take one-half hour while those with a solid state detector can take over 6 hours.

Pulsed-neutron gamma spectroscopy logging systems have been used in the petroleum industry for over 15 years, and they are designed for use in steel-cased boreholes (Ellis 1987). Nevertheless, their precision may not be as good as other logging systems. They are more difficult to operate, and the data are much more difficult to process and analyze. The neutron accelerator source has advantages and disadvantages outlined in the previous section.

These tools can be used to detect leaks at the SSTs and basins. However, other logging systems, which are simpler to operate and whose data are simpler to analyze, can provide data that would be almost as useful for leak detection.

\subsubsection{Electrical Induction Logging}

Electrical induction systems use a high-frequency alternating current of constant intensity that is sent through a transmitter coil. The alternating magnetic field created induces currents in the formation surrounding the borehole. These currents flow in circular ground loops coaxial with the transmitter coils and creates, in turn, a magnetic field that induces a voltage in the receiver coil.

Because the alternating current in the transmitter coil is of constant frequency and amplitude, the ground loop currents are directly proportional to the formation conductivity. The voltage induced in the receiver coil is proportional to the ground loop currents and, therefore, to the conductivity of the formation (Schlumberger 1989).

The induction log would sense a leak through an increase in conductivity. The rock matrix is essentially an insulator, and the pore liquids are the conductors. A leak can increase the moisture content, and the leak may contain higher salinity liquid; both cases would increase conductivity.

The advantages of the induction logging system are: 1) it is a less complex tool than many of the nuclear logging systems, and 2) it can see farther into the formation than the other logging tools, as much as 6 feet. Disadvantages of this system include: 1) the system will not operate in steel-cased boreholes, and 2) the system cannot measure effectively when the formation resistivity is greater than 100 to $200 \mathrm{ohm}$-meters, values that may represent typical resistivities of the Hanford formation.

In summary, the disadvantages of the induction logging system outweigh its advantages. The system could be used to detect leaks at SSTs and basins; however, it would require the installation of new wells with nonconductive casing. This system is not particularly applicable to pipelines unless horizontal, nonconductive cased wells are placed under the pipes.

\subsubsection{Passive Gamma-Ray Logging}

Passive gamma-ray logging systems measure the intensity of gamma rays in the formation. Gamma rays are bursts of high-energy electromagnetic waves that are emitted spontaneously 
by some radioactive elements (radionuclides). The number and energies of gamma rays emitted are distinctive of the different radionuclides. These radionuclides can either be naturally occurring $(\mathrm{K}, \mathrm{U}, \mathrm{Th})$, or they can be created (e.g., $\left.{ }^{137} \mathrm{Cs},{ }^{60} \mathrm{Co}\right)$. In the Hanford formation, the naturally occurring radionuclides reside primarily in clay minerals and potassium feldspar.

A gross gamma system measures the total gamma-ray activity; it does not distinguish gamma-ray activity of different energies as a spectral gamma-ray system does. The spectral gamma system measures both the numbers of gamma rays and the energy level of each and permits the determination of the concentrations of naturally occurring and created radionuclides.

There are two principal types of detectors used by gamma logging systems: scintillation and solid state. Scintillators have been used for many years while solid state germanium detectors have seen limited commercial application. Germanium detectors provide a far superior spectral response at the expense of significantly decreased detector efficiency. Logging runs in a drywell with a spectral scintillation system may take one-half hour, while those with a solid state detector can take longer than 8 hours. Germanium detectors are also more costly and must be operated at or near liquid nitrogen temperatures (Wilson 1981). Nevertheless, solid state germanium detectors do provide a very important advantage of being able to resolve many peaks in gamma-ray spectra, thereby allowing numerous radionuclides to be identified (Koizumi et al. 1994). WHC has successfully developed a germanium detector spectral Radionuclide Logging System (RLS) that has been used to characterize wells at Tank Farms and other Hanford Site locales.

Gross gamma-ray logging has been used by Hanford Tank Farms as a primary means of external leak detection. Over 700 drywells have been logged periodically (WHC 1989). The GAO (1992) suggested improvements in the current system, and Tank Farms has responded by ordering two spectral logging systems that are similar to the current WHC RLS.

Passive gamma-ray logging provides many benefits for external leak detection. The systems have been used at the Hanford Site for over 15 years, and drywells for external leak detection are already in place. Gross gamma systems are very reliable, easy and quick to operate, and the data are straightforward to analyze. Spectral gamma systems present the benefit of radionuclide resolution at the expense of being more complex and acquiring data that are more difficult to analyze. Spectral systems with scintillation detectors are almost as fast to operate as a gross gamma system, and the tools are almost as reliable. Spectral systems with solid state detectors are less reliable, operations are more difficult, and logging speed is significantly slower. However, the data from these systems can be used to resolve many gamma-emitting radionuclides. A spectral system with a scintillation detector probably may have difficulty in resolving more than three created radionuclides.

The primary disadvantage to leak detection through passive gamma-ray logging is that many of the radionuclides that present a risk to human health (Buck et al. 1991) cannot be detected by this type of logging system. They emit either beta-particles or gamma rays that are too weak to be detected readily. In addition, gamma logging systems have a limited depth of investigation, typically around 8 inches.

Gross gamma systems have been successfully used to detect leaks at SSTs and basins; however, spectral gamma logging systems present the opportunity to provide significantly more information about the gamma-emitting constituents of the leak. The extended time required to $\log$ a drywell with a germanium spectral system may mitigate against many of its advantages, particularly if the system is used routinely for leak detection. A spectral system with a scintillation detector may present the best compromise among passive gamma-ray logging systems. 


\subsubsection{Prompt Fission Neutron Logging}

Prompt fission neutron (PFN) logging systems use a neutron generator (described in Section 5.1.1) to induce the fission of the appropriate radionuclides $\left(233 \mathrm{U},{ }^{235} \mathrm{U},{ }^{239} \mathrm{Pu}\right.$ ). A byproduct of fission is delayed high-energy neutrons (Hearst and Nelson 1985), which the logging system detects after they have slowed to epithermal energies (Givens and Stromswold 1989).

PFN systems have been commercially developed for U prospecting. They are more sensitive than passive gamma-ray logging when $U$ is not in secular equilibrium. The systems can detect $U$ down to $0.5 \mathrm{ppm}$ in a water-saturated formation.

The PFN system can readily detect several radionuclides that are difficult to detect with passive gamma-ray logging systems. In addition, two of these radionuclides are major risk drivers $\left({ }^{235} \mathrm{U},{ }^{239} \mathrm{Pu}\right)$ at the Hanford Site. However, this system can not distinguish between the fissionable nuclides. This logging system probably would not have the widespread use presented by neutron-neutron and passive gamma-ray logging systems; however, it could fill a niche at selected SSTs and other structures.

\subsection{Surface Geophysics}

This category considers technologies that remotely determine physical conditions of the subsurface from surface (sensors emplaced at depths of less than 3 feet) or airborne instrumentation. Most of these techniques are very mature; they have had extensive use in the petroleum and mineral exploration industry. The candidate technologies are:

- Surface Resistivity

- Electromagnetic Survey

- Ground Penetrating Radar

- Seismic Boundary Waves

- Surface Gamma-Detection

- Infrared Thermography.

The advantages of the above systems include:

- They are mature technologies

- They do not require contact with contaminated subsurface soils and liquids

- They have the potential to image underneath structures.

Their disadvantages include:

- Solutions may be non-unique

- Systems are affected by noise

- Resolution decreases as depth of investigation increases 
- Systems are designed for exploration, not monitoring, so measurements are discrete

- Data acquisition may be labor- and processing-intensive.

All of the surface systems, except passive gamma-ray detection, will be most effective if they monitor for change due to leaks. They are less effective if they attempt to locate a leak after the fact, due to intrinsic constraints in data analysis and interpretation.

\subsubsection{Surface Resistivity}

Surface resistivity is a geophysical prospecting method that observes electric fields caused by the active introduction of current into the ground to study earth resistivity. The method is usually restricted to using very low frequency or direct current to measure the apparent resistivity (Sheriff 1973). Resistivity measurement typically requires the use of four electrodes that are emplaced at the surface. Current is applied to the earth through two electrodes, and the potential across the ground is measured using two other electrodes.

The true resistivity value in any rock type is dependent upon the moisture content of the rock and the salinity of the moisture. Almost all rock-forming minerals are effective insulators; they will not conduct electricity in the normal sense. Therefore, all rocks, if absolutely dry, will not conduct electricity. In the earth, the pore spaces of the rocks usually contain water. The resistivity of a rock is directly related to the porosity (if the rock is saturated) or the moisture content (if the rock is unsaturated) of the rock. Increased salinity of a fluid decreases its resistivity so that rocks filled with saline solutions have lower resistivities than those filled with fresh water (Hallof 1992).

This method is not recommended for leak detection where conductive (metallic) structures are in the shallow subsurface. These structures will shunt away most of the applied current, preventing it from investigating the formation. Because metallic structures are present at both the SSTs and pipelines, little application can be seen for this method, as described above, at the Hanford Site.

\subsubsection{Electromagnetic Surveys}

Electromagnetic prospecting is based on the induction of electric currents in buried conductors, by the magnetic components of electromagnetic waves generated at the earth's surface. The waves originate from alternating currents at frequencies ranging from a few hertz to a few megahertz, which are passed through loops of wire on the ground. When the waves pass through a conducting body, they induce alternating electric currents in the conductive materials. These currents become the source of new electromagnetic waves that can be detected by suitable pickup coils (Dobrin 1976). System response is a function of the absolute resistivity. The relationship of this response to leak detection is discussed in Section 5.2.1.

Electromagnetic surveys are sensitive to ambient electrical noise (e.g., power lines) and inductive noise due to coupling with metallic structures. Inductive noise cannot be removed; it can only be minimized by selecting locations away from metallic structures (Hoekstra et al. 1992). Because of the sensitivity of these methods to ambient and inductive noise, they are not recommended for leak detection at the Hanford Site.

\subsubsection{Ground Penetrating Radar}

Ground penetrating radar (GPR) is an electromagnetic technique in which a single low-power broadband impulse of a 1- to 6-second nanosecond duration is transmitted into the earth. 
The transmission is followed by a listening interval of 20,000 nanoseconds. The impulses are directed into the ground through a moving antenna that has an extremely wide viewing angle. Return times of these impulses are then measured (3-D view capability is currently in development). Extensive GPR surveys have been performed on the Hanford Site (e.g., Sandness 1991).

GPR has a depth limitation at the Hanford Site of about 15 feet. It is also time-consuming to perform surveys, especially in areas with many artificial structures or obstacles. GPR is also somewhat affected by cultural noise. Above-ground or buried structures may complicate the interpretation of the results. Therefore, it is not recommended for use at the SSTs.

GPR is most effective at locating buried drums and pipelines and in performing archaeological surveys. GPR has also been used successfully to detect leaks from natural gas pipelines (Graf 1990) and for ground-water exploration and contaminant plume mapping, site investigations in karst regions, unexploded ordnance detection and mapping, subsurface mine detection, geotechnical investigations, and soil stratigraphic studies (Butler 1992). This technology may be applicable for leak detection at basins or pipelines at the Hanford Site; however, testing would be required to confirm this.

\subsubsection{Seismic Boundary Waves}

Leak detection of large above-ground storage tanks using seismic boundary waves has been described by Halabe and Maser (1993). Stonely waves (generated by a hammer) propagate along the boundary between the above-ground tank bottom, the soil, and the tank liquid. Transmission paths that encounter tank liquids in the soil have different arrival characteristics than those that do not, and a different pattern of arrivals will be observed over time as a larger soil area is affected by leakage. A two-dimensional image is generated. The location of a leak-affected zone is determined by a computer-aided tomography (CAT) scan.

Seismic boundary waves are probably not practical for leak detection at the SSTs due to the large number of boreholes that would be required (at least 22 per tank). and the difficulty of placing geophones within boreholes. Seismic boundary waves may be well suited for leak detection at basins or above-ground tanks.

\subsubsection{Surface Gamma-Detection}

Detectors of gamma radiation are commercially available for ground surveys. The systems have been developed for the mining industry, and there are two general models of operation. One is the continuous recording of data from a moving vehicle. The second mode is stationby-station survey by hand-held or back-pack mounted equipment (Hansen 1992). The detectors used are typically either scintillators or solid state (their advantages and disadvantages are described in Section 5.1.4).

These systems are usually placed from several inches to 5 feet above the ground. The radius and depth of investigation for a detector placed 2.5 inches above the ground for $60 \%$ of the signal are 16 and 5 inches, respectively (Hansen 1992).

Surface gamma-detection shows little promise for leak detection at the SSTs and basins due to its shallow depth of investigation. It may be applicable for pipelines buried at shallow depths.

\subsubsection{Infrared Thermography}

This technology uses infrared cameras to track the rate at which the surface soil temperature changes. This rate is a directly correlative to the thermal properties of the soil and any buried objects or anomalies. Images are viewed via patented processing and interpretation software. 
The system has been used to successfully detect hydrocarbon and water leaks in pipelines and shallow underground tanks. It is not recommended for use at the SSTs because temperature changes at the base of the tanks ( 50 feet below ground surface) would probably not be sensed at the surface. This device would be very effective at detecting near-surface leaks from pipelines, tanks, or basins. A disadvantage of this system is that it is it is labor-intensive (discreet monitoring that requires manual operation) and relatively expensive.

\subsection{Borehole-to-Borehole Geophysics}

Borehole-to-borehole geophysical technologies show great promise for external leak detection. They can provide direct measurements of the formation's physical properties beneath a structure in two or three dimensions. This is undertaken by placing sources and receivers in the subsurface (usually boreholes), transmitting signals between them, and measuring the response.

A tomogram is created by varying the positions of the source and receiver; either up and down within a pair of boreholes, by using different pairs of boreholes at the same depth, or by a combination of the two. The actual tomogram is created using geophysical inverse theory.

Three different borehole-to-borehole technologies are discussed:

- Electrical Resistivity Tomography

- Radio Imaging Technology

- Shear-Wave Seismic Tomography

These techniques actively investigate the formation by measuring its response to an electric (first two technologies) or an acoustic impulse.

The advantages to technologies within this category include:

- Ability to remotely image formation beneath surface and underground structures

- Potential to image a volume

Potential disadvantages include:

- The electrical techniques require nonconductive boreholes

- Adequate resolution may necessitate additional boreholes

- The later two technologies, as listed above, do not provide continuous measurements

- These technologies do not provide a direct measurement of a leak.

The promise of these systems for subsurface characterization and leak detection is so great that all three have been tested at the Hanford Site during FY1994.

The advantage of imaging beneath the SSTs for leaks has been apparent for some time. Key (1977) describes efforts at the Hanford Site to develop electrical methods to answer this need. Several promising technologies were identified for development but they were not considered cost-effective. 


\subsubsection{Electrical Resistivity Tomography}

Electrical resistivity tomography (ERT) measures the DC resistivity of a subsurface area. The measurement is made with pairs of electrodes placed into boreholes, each in electrical contact with the formation. Two electrodes are driven by a known current and the resulting voltage difference is measured between other pairs of electrodes, similar to surface resistivity discussed earlier. Each voltage to current ratio is called a transfer resistance. Transfer resistance is measured repeatedly until multiple linear combinations have been measured. Numerical inversion is then used to calculate the resistivity distribution in the vicinity of the boreholes (Daily et al. 1992).

ERT is a very promising method of leak detection at tanks, pipelines, and basins because small changes in moisture, especially if it is saline, should be identifiable. The system is currently designed to image a plane that is parallel to the ground surface, yet underneath the structure. Because the downhole equipment is inexpensive and robust, ERT has the potential to provide continuous measurements (less than 3 hours between measurements).

The primary technical concern is the effect of buried metallic objects (e.g., tank walls, pipes) on the response. The system will be tested at a simulated tank at the Hanford Site this year. In addition, the system requires direct contact between the electrodes and the formation. Drywells, as currently completed, cannot be used.

\subsubsection{Radio Imaging Technology}

RIMtech has developed a radio imaging method that could be used to detect leaks. The process consists of sending radio signals from a source to a receiver (Borns et al. 1993). These signals are absorbed (attenuated) as they propagate through the earth. The source units must be removed from the boreholes at the end of a test because they have a down-hole battery power source. Receivers can be placed at the surface or in PVC-cased boreholes. Leaks would be detected if they are a large enough target whose conductivity would sufficiently contrast with the surrounding soil.

Radio imaging is a very promising method for leak detection at SSTs, pipelines, and basins. It is especially advantageous in that it has the ability to "see" beneath the SSTs and other structures. Further, the system is readily deployable and requires little setup before data acquisition. A disadvantage to this method is that it is labor-intensive (discreet monitoring that requires manual operation), it requires nonconductive boreholes, and it is relatively expensive. Radio imaging was tested at the Hanford Site in FY1994.

\subsubsection{Shear-Wave Seismic Tomography}

Seismic cross hole tomography has been used for a number of applications (e.g., mineral exploration, fault detection, stress monitoring, cave and dam investigation) for over 10 years (Ivansson 1987) to investigate the formation between two boreholes (or a series of boreholes). In shear-wave seismic tomography, a shear wave is transmitted from a source located downhole in one borehole, and it is detected by receivers in other boreholes. Moving the source and receivers up and down the borehole and retransmitting an acoustic pulse creates a data set that can be inverted to create a tomographic image. Shear wave transmission is sensitive to water saturation, so this method can be used to monitor for saturation changes that may be due to leaks.

This system currently uses a single source and one receiver per well, which are moved as data are collected. Seismic tomography currently provides discrete measurements because the measurements are labor-intensive, and the sources are expensive. In addition, data reduction and analysis require significant resources. Nevertheless, the system is currently undergoing 
testing at the Hanford Site, and preliminary results indicate that good data can be acquired in steel-cased boreholes .

The technology is a promising method for leak detection for tanks, pipelines, and basins. Like ERT and RIMTech, it has the ability to image beneath the SSTs and, unlike those systems, it can use existing boreholes.

\subsection{Soil Moisture Instrumentation}

Soil moisture instrumentation systems are primarily used in agricultural and soil scientific studies. They are not generally used for leak detection. However, because they can accurately measure water content or potential in the vadose zone, they were examined for their potential for leak detection. Soil moisture instrumentation include the following:

- Psychrometer

- Hygrometer

- Time-domain reflectometry

- Tensiometer

- Capacitance probe

- Resistivity blocks

- Salinity Sensor

- Heat Dissipation Sensor.

The advantages or these technologies include:

- Technologies are mature and commercially available

- Sensors are inexpensive

- Sensors provide a direct measurement of soil moisture or potential

- Many sensors provide continuous measurements.

The disadvantages are that sensors:

- Must be in direct contact with formation

- Provide point measurement

- Have limited range of accurate measurements

- Some have limited sensor or calibration lifespan.

\subsubsection{Psychrometer}

Psychrometers measure negative soil water pressure (water potential) in very dry areas where tensiometers are ineffective. They measure the relationship between negative soil-water potential and the relative humidity of soil water. The system consists of a porous bulb 
chamber to sample relative humidity of a soil, a sensitive thermocouple, heat sink, reference electrode, and associate electronic circuitry. They provide very accurate measurements in very dry soils $(-0.5$ to $-70 \mathrm{bar})$. The primary limitation of psychrometers is that they are not designed for wet conditions, and they are severely affected by near-surface temperature gradients. Saturated conditions commonly cause the sensor to fail. They are also affected by hysteresis. Because of these limitations they are not recommended for use in leak detection.

\subsubsection{Hygrometer}

Hygrometers are very similar to psychrometers and have the same detection range. In a hygrometer, an excitation voltage is applied to the sensor and the resistance, which is a function of electrical current, is measured. Micro-changes in relative humidity are detected as large resistance changes. Wescor produces a dual-purpose hygrometer/psychrometer. Hygrometers are probably not practical for use in leak detection for the same reasons outlined in the psychrometer section.

\subsubsection{Time-Domain Reflectometry}

Time-domain reflectometry (TDR) involves two steps: the measurement of the propagation velocity of an electromagnetic pulse along a transmission line and the conversion of this measurement to an estimate of soil water content (i.e., calibration) (Hook and Livingston, in press). Precision Moisture Instruments, Inc. produces a 4-foot-long TDR probe that can be driven into the ground surface; this probe has been successfully demonstrated at the Hanford Site as part of the protective barriers program.

TDR is probably the best of the soil moisture sensors. TDR measures very accurately over a large moisture range. The main disadvantage to this sensor is that it requires a large number of boreholes to effectively monitor the SSTs. However, it would be well-suited for monitoring pipelines or basins. Another disadvantage is that it is the most expensive of the soil moisture instruments.

\subsubsection{Tensiometer}

A tensiometer measures the soil water potential directly by measuring the soil water pressure with a porous ceramic cup that is buried in the soil. The cup is attached to a pressure gauge or manometer. The main disadvantages to tensiometers are 1) they are limited to a depth of less that 15 feet, 2) they have a limited working range, and 3) they are difficult to use in sandy soils (Jones and Gee 1984). Another disadvantage to tensiometers is that the ceramic tip is fragile and is easily broken during installation (Everett et al. 1984). They are not recommended for monitoring the SSTs, primarily because of the depth limitation. They are also not recommended for use at pipelines or basins because of limited working range and because they work poorly in sandy soils, which compose much of the Hanford formation.

\subsubsection{Capacitance Probe}

Capacitance probes measure changes in the dielectric constant of soil materials. Because the dielectric constant of water (78) is much higher than that of soil materials (from 2 to 4 ), changes in dielectric constant can be directly correlated to changes in moisture content. The Troxler Inc. probe is designed to be used in a 2-inch PVC access tube. It can be lowered to any depth and can measure a 10-inch diameter around the probe. The capacitance probe provides fast, accurate measurements over a wide range of moisture contents. The capacitance probe would be well-suited for leak detection at the SSTs or basins. The main disadvantage to this sensor is that it requires installation of small-diameter, PVC-cased boreholes and that it is labor-intensive (discreet monitoring that requires manual operation). 
They are probably not practical for pipeline monitoring due to the large number of boreholes that would be required.

\subsubsection{Resistivity Block}

Resistivity blocks consist of two electrodes that are embedded in a porous material (e.g., fiberglass or gypsum). When buried in soil, the block absorbs and loses water until the water potential in the block is equal to the water potential in the surrounding soil. As the water content and water potential of the block changes, the electrical resistance measured between the electrodes changes; this change is used to infer the water potential of the soil. Resistivity blocks are advantageous because they are relatively inexpensive and are simple to use. However, disadvantages include their relatively short life span (5 years or less) and the fact that they work poorly in coarse-grained soils . Because of the high cost of borehole installation and the relatively short lifespan of these sensors, they are not recommended for use at the SSTs. They may be useful for monitoring at basins if the soil type is compatible with the sensor. They are probably not practical for pipeline monitoring due to the large number of blocks that would be required.

\subsubsection{Salinity Sensor}

Salinity sensors measure the specific electrical conductance of the soil water (Everett et al. 1984, Rhoades 1979). Conductance values can then be related to total salt content. The sensor consists of electrodes that are embedded in a porous ceramic material. The porous nature of the ceramic material allows the soil water to contact the electrodes. The main disadvantages to salinity sensors are that they are temperature dependent and they have a depth limitation of 30 feet. They are not recommended for monitoring use for the SSTs, primarily because of the depth limitation. They are also not recommended for use at pipelines or basins because of their temperature sensitivity.

\subsubsection{Heat Dissipation Sensor}

Heat dissipation sensors are based on the principle that the rate of heat dissipation in a fixed porous medium is dependent on the water content (Jones and Gee 1984). A porous cup is used to measure water potential based on heat dissipation. A limitation of heat dissipation sensors is that they have difficulty in detecting increases in moisture content above $15 \%$ by volume. Because of this limitation they are not recommended for leak detection.

\subsection{In Situ Sensors}

This category includes sensors that do not have to be placed into intimate contact with the formation. The in situ sensors are:

- Scintillating Optical Fiber

- Thermoluminescent Dosimeter

- Conductive Polymer

- Acoustic Sensor.

The advantages or these technologies include:

- Sensors provide continuous measurements

- Sensors need not be in direct contact with formation. 
The disadvantages are:

- Sensors provide point measurements

- Several sensors are still in the conceptual stage.

\subsubsection{Scintillating Optical Fiber}

Optical fibers with cores that scintillate when a passive gamma ray interacts with it are commercially available. They are currently used at the Hanford Site and other sites in radiation detection systems. The systems present potential for use in downhole passive gamma-ray detection, although this has not yet been done. The concept would be to insert nested sections of scintillating optical fiber (maximum length of each fiber is about 8 feet), photomultiplier tubes, and amplifiers into existing drywells.

The benefits of using an optical fiber system is that an automated system can be developed that continuously monitors gamma-ray flux in existing boreholes. The potential pitfalls in the engineering and deployment of such a system include the complex and expensive equipment needed downhole to covert the light pulses to digital signals. Scintillating optical fiber for leak detection should be investigated for use in SSTs and basins. The cost of photomultiplier tubes probably obviates their use for pipelines.

\subsubsection{Thermoluminescent Dosimeter}

The use of thermoluminescent dosimeters (TLDs) to detect alpha- beta- and gamma-emitting radionuclides in the subsurface has been proposed (Durham 1994). The TLDs can either be emplaced into existing drywells (gamma detection only) or directly into the formation via cone penetrometer. They would be connected to the surface by a shielded fiber optic cable, and a laser would be used to periodically read and clear the dosimeter. The system would require at least 4 hours collection time, possibly many more hours, before readout for a lowlevel contamination leak. Readout time is less than 1 minute per dosimeter.

The system has the potential to provide a promising method to continuously monitor for changes in subsurface radioactivity. The downhole system is very simple with no moving parts, and the dosimeters are commercially available and inexpensive. However, the concept is still conceptual, it has not been demonstrated, and there are technical hurdles: 1) the sensitivity of the dosimeter may have to be increased, 2) a portable readout system needs to be developed. If successfully developed and implemented, this system would be applicable to SSTs and basins. Implementation for pipelines would require many TLDs.

\subsubsection{Conductive Polymer}

Conductive polymer cables are sensing cables that have the ability to detect and locate the presence of any conductive fluid anywhere along its length. They are widely used in doubleshell tank monitoring and in secondary containment monitoring. The main disadvantage to these cables is that they are designed to operate under saturated conditions only, and they need to be replaced or maintained (dried) after they have been exposed to a leak. This would not be possible if they were permanently installed in a borehole. They could be used in leak detection only if the cables could be removed for maintenance and if they were placed in a location were water could collect and form saturated conditions. 


\subsubsection{Acoustic Sensor}

Acoustic sensors have been successfully used in monitoring pipelines and for internal tank monitoring (Kupperman 1990; Fuchs and Riehle 1991; Nordstrom 1990). For pipeline applications, the sensor needs to be in contact with the pipeline. A fiber optic acoustic sensor (Kurmer et al. 1993) has also been demonstrated that is placed within the pipeline. For internal tank monitoring, either the sensor needs to be submerged in the liquid or the tank must be pressurized and the sensor placed in the air space above the liquid. Because the SSTs are buried, attaching acoustic sensors to the tank is not an option. Also, because of the hostile nature of the wastes in the tank, internal monitoring was not considered an option. Therefore, acoustic sensors were judged as not appropriate for SST monitoring.

\subsection{Moisture Removal and Analysis}

Moisture removal and analysis devices are designed to collect samples of soil pore water that can be then be characterized by laboratory analytical methods. Analysis could either be performed at the site using portable analytical equipment (e.g., Viking Gas Chromatograph/Mass Spectrometer [GC/MS]). These devices include:

- Lysimeter

- Piezometer

- Fiber filter

- Membrane filter

- Filter Candle.

The advantages provided by these systems include:

- There is minimum data ambiguity due to direct analysis of subsurface pore water

- EPA-approved analytical methods can be used.

Disadvantages of these systems include:

- Provide only a point sample

- Require direct contact with formation

- Have long sample turnaround time if contract laboratories are used.

\subsubsection{Lysimeter}

Lysimeters (suction samplers) are designed to collect pore water samples from either the vadose or saturated zone. A constant pressure source draws pore water into the lysimeter through a porous membrane. An upper chamber stores collected fluids. They are most effective in collecting samples from moist soil (tension less than $300 \mathrm{mbar}$ ). A moisture sensor could be used within the lysimeter to also detect the presence of water. Lysimeters are probably not practical for use as the primary means of leak detection. However, they could play an important secondary role in monitoring at tanks and basins because of their ability to collect samples for analysis. They are probably not practical for pipeline monitoring due to the large number of lysimeters that would be required. 


\subsubsection{Piezometer}

Piezometers are small diameter pipes that are installed in a saturated zone or a zone where saturation is expected. The end of the pipe is screened to allow water to enter. Piezometers do not have a separate chamber for collecting water as do lysimeters. Piezometers are not recommended for use in leak detection because they have no provision for containing fluids.

\subsubsection{Fiber Filter}

Suction samplers constructed of cellulose-acetate hollow fibers have been used in soil column studies (Everett et al. 1984). However, they are more practical for laboratory studies rather than field applications. Therefore, they are not recommended for use in leak detection.

\subsubsection{Membrane Filter}

Membrane filters are suction-type samplers that use glass fibers to "wick" pore water samples via capillary action with the aid of a suction that is applied to the assembly. They are limited to a depth of approximately 13 feet and are therefore not recommended for use in leak detection at the SSTs. They may be applicable to basins and pipelines.

\subsubsection{Filter Candle}

A filter candle, as described by Everett et al. (1984), is designed to collect water below plant roots. It consists of a manhole access from which a lateral extension contains a trough for collecting water. Because the bottoms of the SSTs are approximately 50 feet below ground surface, a filter candle was considered to be impractical for the tank farms; they may be applicable to basins and pipelines.

\subsection{Vapor Extraction and Analysis}

The extraction of vapors from the vadose zone beneath storage and transfer structures provides an alternative method to borehole-to-borehole geophysics for extending the range of sensors. Ideally, a liquid leak would lead to increases in certain indicator vapors. Existing drywells could be perforated and a low-flow soil vapor extraction system installed. The vapors could then either be collected for analysis or analyzed in real time by sensors. The system is analogous to the continuous air monitors (CAMs) that are operational at the Hanford Site double-shell tanks.

An effort is currently underway to characterize the vapors within the SSTs, and only a few tanks have been characterized to date. Initial results indicate that the vapors within tanks are highly variable. Potentially viable vapors include tritium, ammonia, and nitrous oxide.

The advantages provided by a vapor extraction system include:

- Potential to sample under tanks

- Potential to provide real time data

- Minimum data ambiguity due to direct analysis of vapors

- Use of EPA-approved analytical methods. 
Disadvantages of these systems include:

- Vapor extraction may perturb the current subsurface environment

- System requires direct contact with formation

- Vapors may be contaminated

- Sample turnaround time is long if contract laboratories are used.

If a vapor sample is extracted, various analytical methods can be considered. For onsite analysis, a tritium detector was the only sensor considered in the survey. The apparent lack of volatile organic compounds negates the utility of a portable GC/MS.

Tritium detectors present a mature technology that is currently used at the Hanford Site and other nuclear facilities. The detectors are robust and there are Hanford staff who are very familiar with their use, maintenance, and calibration. The system detects the beta-emission of the tritium nuclide, and it requires the introduction of low flow rates of gas. Systems are available that can run continuously and store results on a data logger. However, in order for this technology to be successful, better characterization of tank vapors is necessary, the vapor extraction system would have to be engineered, the issue of dealing with exhausted contaminated vapors needs to be addressed, and the system must be tested.

\subsection{Candidate Technologies Not Included}

Several of the technologies described in this section were not continued into the survey spreadsheets because they were either not implementable or they had already been tested unsuccessfully at the Hanford Site. These technologies are:

- Surface Resistivity

- Electromagnetic Surveys

- Acoustic Sensors

- Filter Candle. 


\subsection{Conclusions and Recommendations}

Thirty-three available and emerging technologies have been identified that have potential for external leak detection at the Hanford Site. All but 4 of these technologies have been evaluated in detail in the spreadsheets within the Appendix. The reader is encouraged to rate the technologies by sorting the spreadsheets and weighing the grades to determine which technology best suit their needs. This section will summarize the spreadsheets and earlier parts of this report and will present the authors' recommendations for promising external leak detection systems.

It is doubtful that any one external leak detection system will provide the ultimate solution. A layered approach, in which several families of sensors are employed, would be the ideal. This approach promotes both synergy and redundancy. Many of the systems respond to physical properties that can only infer a leak. The use of multiple systems, which respond to different physical properties, will strengthen the inferences required for leak detection. Furthermore, if any sensor or family of sensors malfunctions or is affected by an interferent, other operational systems will provide backup.

\subsection{SSTs and Basins}

Based on the survey, general recommendations can be made for potential layered systems for external leak detection for SSTs and basins.

\subsubsection{Borehole-to-Borehole Geophysics}

Borehole-to-Borehole Geophysical systems present the greatest promise for external leak detection because they are capable of remotely detecting a leak under a tank or basin. Of the three technologies identified, ERT is the most promising because the system can be engineered to operate almost continuously and the physical property it measures, resistivity, is sensitive to small changes in liquid concentrations, especially where it is saline. However, because the technology is not mature, there is one major technical concern: Will the system operate effectively where buried conductive bodies (e.g., metallic tanks and pipelines) are present? A field demonstration planned for this fiscal year should provide an answer. An additional concern is the emplacement of electrodes into the subsurface. The existing steelcased drywells cannot be used, so either new wells will have to be drilled or alternative technologies for subsurface access considered. ERT electrodes have been emplaced by cone penetrometer at another site. The other two borehole-to-borehole technologies (radio imaging technology and shear-wave seismic tomography) are not currently suitable for continuous measurement. Shear-wave seismic tomography shows good potential because it can be use existing drywells. However, acquisition and processing of the data are timeconsuming, and it would be best to baseline structures before a leak is suspected.

\subsubsection{Sensors}

TLD and scintillating optical fiber systems have the potential to continuously monitor for leaks by measuring gamma radiation within the drywells. Although both types of sensors are commercially available, neither is currently configured for use in external leak detection. Extensive engineering may be required before either sensor type could be implemented. Scintillating optical fiber systems could be expensive because of necessary ancillary equipment (e.g., photomultiplier tubes). TLD shows promise but sensors should be developed with greater sensitivity and surface equipment should be developed.

Most other sensors are inappropriate because they require direct contact with the formation, they perform point measurements only, and they do not provide benefit over the recom- 
mended systems unless they can be installed beneath the SSTs and basins. There are no currently available, operational systems than can emplace sensors beneath structures at the Hanford Site.

\subsubsection{Borehole Geophysics}

Borehole geophysical logging systems were initially developed to characterize the subsurface for the petroleum industry. For this use, these systems are very effective, and their success has spawned a large commercial industry. These systems, however, are not as ideally suited for leak detection. They have a limited depth of investigation, they do not provide continuous measurements, and each logging system, as currently configured, requires a dedicated truck or van plus staff.

Logging systems have been used at SSTs as a primary means of leak detection for more than 15 years because better systems were not available when they were initially deployed. To that end, over 700 drywells have been installed at Tank Farms. Logging systems still show significant potential as a system to verify that leaks have occurred. For example, if a leak is indicated by an in situ sensor, the sensors could be pulled out of a drywell and logs run for confirmation and quantification. Because they represent a mature industry, reliable, sophisticated systems are available that can provide calibrated subsurface information. The addition of neutron-neutron logging to the gamma ray systems would enhance the technology and permit the detection of leaks that do not contain detectable gamma-emitting radionuclides. GAO (1992) has recommended that the gross gamma-ray logging systems at Tank Farms be upgraded or replaced. Replacement with scintillation spectral systems may be the best compromise. They are not nearly as selective as systems with germanium detectors; however, they are more efficient and thus can log more drywells per day. PFN logging systems may fulfill a niche where the liquids stored contain fissionable radionuclides.

Full suites of geophysical logging tools can provide good subsurface geohydrologic characterization data and information that might prove invaluable prior to onset of a suspected leak.

\subsubsection{Seismic Boundary Wave}

Seismic boundary wave technology may be applicable for leak detection at the basins.

\subsubsection{Vapor Extraction and Analysis}

If borehole-to-borehole geophysical techniques do not prove implementable, then vapor extraction systems could be considered because they present the potential to sample under storage structures, and they can use the existing drywells with minimum modifications.

\subsection{Pipelines}

Perhaps the best way to monitor pipelines is with "intelligent" pigs. These are commercially available sensors, developed for the gas pipeline industry, that run through pipelines and monitor for corrosion. They have two different methods of operation: magnetic flux leakage and ultrasonic. Both types of systems are self-contained and are either pushed through the pipeline by liquids or are pulled by wireline. The advantages of these systems are they can detect a problem before a leak actually occurs.

Infrared thermography services are commercially available for leak detection and may be applicable for pipelines. These systems acquire data rapidly from airborne systems; this is conducive to the lateral extent of pipeline systems. They have a shallow depth of investigation that should not pose an obstacle for shallow pipelines. 


\subsection{Recommendations}

- Data Quality Objectives need to be specified for external leak detection systems (e.g., minimum leaks detectable, rate of leakage) in order to design, test, and evaluate systems

- Which constituents of liquid leaks pose the greatest threats to human health and the environment must be determined. The determination could be made through fate and transport modeling and risk assessment. Based on these results, leak detection systems can be selected, tuned, or modified to respond to these constituents. This will allow the systems to detect not only leaks, but also monitor their migration through the subsurface.

- Borehole-to-borehole geophysical systems (electrical resistivity tomography, RIMtech, and shear wave seismic tomography) should be demonstrated at the Hanford Site under realistic conditions. The systems show great promise, especially ERT, but need successful demonstration before implementation can proceed.

- In situ sensors that can continuously monitor gamma radiation through existing drywells should be developed.

- Gross gamma logging system at tank farms should be upgraded to scintillation spectral gamma and neutron-neutron systems added. Consider PFN systems where applicable.

- The vapors within the tanks must be characterized to determine if vapor extraction analysis is a viable option for leak detection.

- Methods to emplace sensors under SSTs and basins must be developed.

- Methods must be developed to extract samples from beneath SSTs and basins. Confirmation of suspected leaks can be best provided by physical samples and laboratory analysis. 


\subsection{References}

Anonymous. 1992. "Thermal Video Detects Pipeline Leaks." Materials Evaluation, v 47, no. 11, p. 1273.

Boomer, K.D., S.K. Baker, A.L. Boldt, J.D. Galbraity, J.S. Garfield, C.E. Goldberg, B.A. Higley, L.J. Johnson, M.J. Kupfer, R.M. Marusich, R.J. Parazin, A.N. Prage, G.W. Reddick, J.A. Reddick, E.J. Slaathaug, L.M. Swanson, T.L. Waldo, and C.E. Worcester. 1993. Tank Waste Technical Options. WHC-EP-0616, Rev. 0, Westinghouse Hanford Company, Richland, Washington.

Borns, D.J., G. Newman, L. Stolarczyk, and W. Mondt. 1993. "Cross Borehole Electromagnetic Imaging of Chemical and Mixed Waste Landfills." RIMtech, Denver, Colorado.

Buck, J.W., M.S. Peffers, S.T. Hwang. 1991. Preliminary Recommendations on Design of the Characterization Program for the Hanford Site Single-Shell Tanks--A System Analysis. PNL-7573, vol. 2, Pacific Northwest Laboratory, Richland, Washington.

Butler, D. K. 1992. Proceedings of the Government Users Workshop on Ground Penetrating Radar Applications and Equipment 26-27 March 1992, Vicksburg. Mississippi. U. S. Army Corps of Engineers, Miscellaneous Paper GL 9240.

Cruse, J.M., and R. Treat. 1994. Subsurface Barrier Demonstration Test Strategy and Performance Specification. WHC-SD-WM-SP-001, Westinghouse Hanford Company, Richland, Washington (Draft).

Daily, W., A. Ramirez, D. LaBrecque, and J. Nitao. 1992. "Electrical Resistivity Tomography of Vadose Water Movement." Water Resources Research, vol. 38, no. 5, pp. 1429-1442.

Dietz, R. N. 1992. "Commercial Applications of Perfluorocarbon Tracer (Pft) Technology." Government Reports Annoucements and Index (GRA\&I), Prepared for the U. S. Department of Energy by Brookhaven National Laboratory, New York.

Dobrin, M.B. 1976. Introduction to Geophysical Prospecting. McGraw-Hill, New York, New York.

Douglas, D. G., and J.W. Maresca. 1993. "Detailed Leak Detection Test Plan and Schedule for the Oak Ridge National Laboratory LLLW Active Tanks." DOE/OR/01-1129-D1, Prepared or the U. S. Department of Energy by Vista Research, Inc., Mountain View, California.

Durham, J.S. 1994. "Subsurface Characterization and Monitoring of Radioactive Contaminant Plumes." Technical Task Plan submitted to Characterization, Monitoring, and Sensor Technology Integrated Program, U.S. Department of Energy, Washington, D.C.

Eklund, B. and W. Crow. 1988. Survey of Vendors of External Petroleum Leak Monitoring Devices for Use with Underground Storage Tanks. EPA/600/4-87/016. U.S. Environmental Protection Agency, Environmental Monitoring Systems Laboratory, Office of Research and Development, Las Vegas, Nevada.

Ellis, D.V. 1987. Well Logging for Earth Scientists. Elsevier, New York, New York.

EPA. 1988. Leak Lookout. EPA/530/UST-88/006. U.S. Environmental Protection Agency, Office of Underground Storage Tanks, Washington, D.C. 
EPA. 1989. Detecting Leaks: Successful Methods Step by Step. U.S. Environmental Protection Agency, Office of Underground Storage Tanks, Washington, D.C.

EPA. 1990. Musts for USTs. EPA/530/UST-88/008. U.S. Environmental Protection Agency, Office of Underground Storage Tanks, Washington, D.C.

Everett, L.G. 1981. "Monitoring in the Vadose Zone." Ground Water Monitoring Review, Summer Edition.

Everett, L. G., L. G. Wilson, and E. W. Hoylman. 1984. Vadose Zone Monitoring for Hazardous Waste Sites. Noyes Data Corporation, Park Ridge New Jersey.

Everett, L. G., L. G. Wilson, and L. G. McMillion. 1982. "Vadose Zone Monitoring Concepts for Hazardous Waste Sites." Ground Water, vol. 20, no. 3, pp. 312-324.

Fuchs, H. V. and R. Riehle. 1991. "Ten Years Experience with Leak Detection by Acoustic Signal Analysis." Applied Acousics, vol. 33, pp. 1-19.

Galloway, K. J. 1992. Conceptual Design Report for the Project To Install Leak Detection in FAST-FT-534/548/549. EGG-ME-10324, prepared for Westinghouse Idaho Nuclear and the U. S. Department of Energy by Idaho National Engineering Laboratory, Idaho Falls, Idaho.

General Accounting Office (GAO). 1992. "Improvements Needed in Monitoring Contaminants in Hanford Soils." GAO/RCED-92-149. U.S. General Accounting Office, Washington, D.C.

Givens, W.W. and D. C. Stromswold, 1989, "Prompt Fission Neutron Logging for Uranium." Nuclear Geophysics, vol. 3, pp. 299-307.

Graf, F. L. 1990. "Using Ground-Penetrating Radar to Pinpoint Pipeline Leaks." Materials Performance, vol. 29, no. 4, pp. 27-29.

Halabe; U. B., and K.R. Maser. 1993. "Leak Detection from Large Storage Tanks Using Seismic Boundary Waves." Journal of Geotechnical Engineering, vol. 119, no. 3, pp. 563583.

Hallof, P.G. 1992. "Electrical: IP and Resistivity." in Blaricom, R.V. (ed.) Practical Geopysics II for the Exploration Geologist. Northwest Mining Association, Spokane, Washington, pp. 39-176.

Hansen, D.A. 1992. "Radiometrics." in Blaricom, R.V. (ed.) Practical Geopysics II for the Exploration Geologist. Northwest Mining Association, Spokane, Washington, pp. 1-38.

Hearst, J.R, and P.H. Nelson. 1985. Well Logging for Physical Properties. McGraw-Hill, New York.

Hennigar, G. W. 1993. "Leak Detection: New Technology that Works." Gas Industries, January 1993, pp. 16-18.

Hoekstra, P., R. Lahti, J. Hild, C.R. Bates, and D. Phillips. 1992. "Case Histories of Shallow Time Domain Electromagnetics in Environmental Site Assessment." Ground Water Monitoring Review, Fall Issue, pp. 110-117. 
Hook, W. R., and N.J. Livingston. 1994. "A Model for the Description and Accuracy Evaluation of Time Domain Reflectometry Measurements of Soil Water." Journal of the Soil Science of America (in press).

Isaacson, R. E., and K.A. Gasper. 1981. A Scientific Basis for Establishing Dry WellMonitoring Frequencies. RHO-ST-34, Rockwell Hanford Operations, Richland, Washington.

Ivansson, S. 1987. "Crosshole Transmission Tomograph." in Nolet. G. (ed.) Seismic Tomograph With Applications in Global Seismology and Exploration Geophysics. pp. 159 188.

Jones, T. L., and G.W. Gee. 1984. Assessment of Unsaturated Zone Transport for Shallow Land Burial of Radioactive Waste: Summary Report of Technology Needs, Model Verification, and Measurement Efforts (FY78-FY83). PNL-4747, Pacific Northwest Laboratory, Richland, Washington.

Key, K. T. 1977. Nuclear Waste Tank and Pipeline External Leak Detection Systems. ARH-ST-127, Atlantic Richfield Hanford Company, Richland, Washington.

Koizumi, C. J., J. R. Brodeur, R. K. Price, J. E. Meisner, and D.C. Stromswold. 1994. "HighResolution Gamma-Ray Spectrometry Logging for Contamination Assessment." Nuclear Geophysics, vol. 8, no. 2, pp. 149-164.

Kurmer, J. P., S.A. Kingsley, J.S. Laudo, and S.J. Krak. 1993. "Applicability of a Novel Distributed Fiber Optic Acoustic Sensor for Leak Detection." Proceedings of the SPIE - The International Society of Optical Engineering, vol. 1797, pp. 63-71.

Kupperman, D. S. 1990. "Detector Relies on Sound to Locate Underground Pipe Leaks." Power, vol. 134, no. 2, pp. 61-62

Mills, W.R., L. S. Allen, and D. C. Stromswold, 1988, "Pulsed Neutron Porosity Logging Based on Epithermal Neutron Die-Away," Nuclear Geophysics, vol. 2, pp. 81-93.

Nordstrom, D. S.. 1990. "Direct Tank Bottom Leak Monitoring with Acoustic Emission." Materials Evaluation, vol. 48, pp. 251-254.

Raisanen, W. R. 1991. "Pipeline Leak Detection by Aspirated Vapor Monitoring." Pipeline Engineering, vol. 34, pp. 41-44.

Rhoades, J. D. 1979. "Inexpensive Four-Electrode Probe for Monitoring Soil Salinity." Journal of the Soil Science Society of America. vol. 43, no. 4, pp. 817-820.

Sandness, G. A. 1991. Report on Geophysical Surveys in the 300-FF-1 Operable Unit. EMO-1032, Prepared by Battelle Environmental Management Operations for the U. S. Department of Energy, Richland, Washington.

Schlumberger. 1989. Log Interpretation Principles/Applications. Schlumberger Educational Services, Houston, Texas.

Sheriff, R.E. 1973. Encyclopedic Dictionary of Exploration Geophysics. Society of Exploration Geophysics, Tulsa, Oklahoma.

Stivers, H. W. 1958. Leak Detection System for Self-Boiling, High-Level, Radioactive Wastes Storage Tanks (Scope and Design Criteria). HW-57289, General Electric Hanford Atomic Products Operation, Richland, Washington. 
Stromswold, D. C. and L. S. Allen. 1992. "Epithermal Neutron Lifetime Logging in Partially Saturated Formations and Large-Diameter Holes." IEEE Transactions on Nuclear Science, vol. 39, n. 4, pp. 997-1001.

Weil, G. J. 1992. "Infrared Thermographic Sensing of Sewer Pipeline Problems." 1992 National Conference on Water Resources Planning and Management, ASCE, pp. 890-895.

Westinghouse Hanaford Company (WHC). 1989. Waste Storage Tank Status and Leak Detection Criteria. WHC-SD-WM-TI-357. Westinghouse Hanford Company, Richland, Washington.

Wilson, L. G. 1980. Monitoring in the Vadose Zone: A Review of Technical Elements and Methods. EPA-600/7-80-134, Prepared by General Electric Company for the Environmental Protection Agency, Las Vegas, Nevada.

Wilson, R.D. 1981. "Fundamentals of Gamma-Ray Logging." Gamma-Ray Logging Workshop, Grand Junction, Colorado.

Woodruff, R.K., R.W. Hanf, and R.E. Lundgren. 1993. Hanford Site Environmental Report for Calendar Year 1992. PNL-8682, Pacific Northwest Laboratory, Richland, Washington. 


\section{APPENDIX}

SURVEY SPREADSHEETS OF CANDIDATE TECHNOLOGIES FOR EXTERNAL LEAK DETECTION AT THE HANFORD SITE 


\section{APPENDIX}

\section{SURVEY SPREADSHEETS OF CANDIDATE TECHNOLOGIES FOR EXTERNAL LEAK DETECTION AT THE HANFORD SITE}

This appendix contains both a hardcopy and a digital copy of the spreadsheets that describe and grade 29 candidate technologies for external leak detection. The hardcopy is as a series of tables that follow. The digital copy is a Microsoft ${ }^{\circledR}$ Excel spreadsheet on a $31 / 2$ " DOS formatted diskette.

Explanations of the spreadsheet rows are provided in Section 4 of this report. The Operational Regions discussed under Technical Feasibility are depicted in Figure 3. Brief descriptions of the candidate technologies are in Section 5. 
Table A.1. Borehole Geophysical Systems (Part 1)

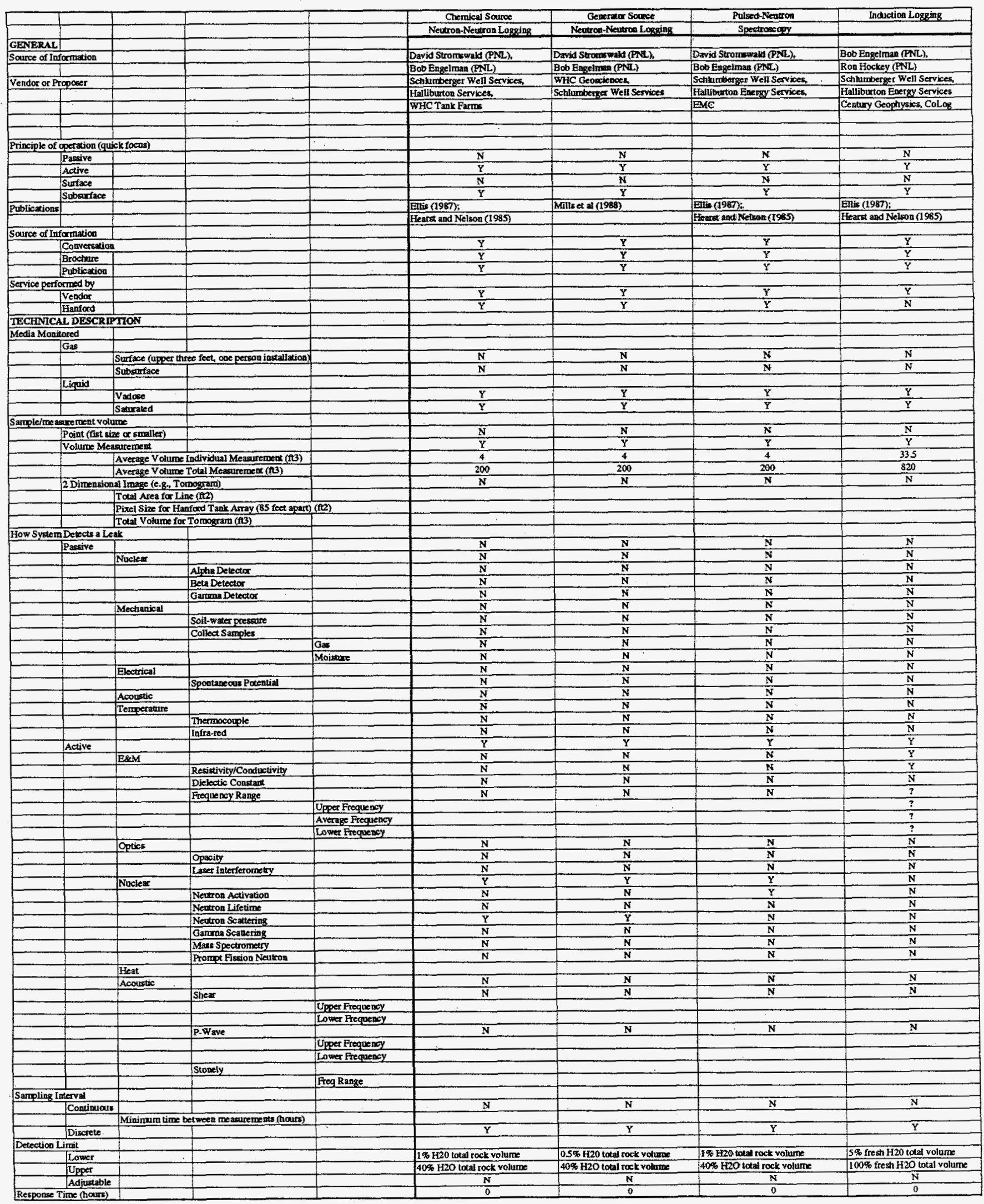


Table A.1. Borehole Geophysical Systems (Part 1)

\begin{tabular}{|c|c|c|}
\hline & & \\
\hline & & \\
\hline Data Colleces & cion System & \\
\hline & Mannal & \\
\hline & \begin{tabular}{|l|} 
Automatic \\
Autan
\end{tabular} & \\
\hline & Remocte & \\
\hline TECHNICA & AL FEASIBI & $\frac{1}{\text { nITY }}$ \\
\hline Direct Me ass & garement & \\
\hline Endired Meas & astreme int & \\
\hline & Strengtat of & $\frac{1}{\text { Inference (indrect }}$ \\
\hline Data Antigy & nuity how diff & fricall to inteppret re \\
\hline Cevel of Dev & velopment (yy) & ynopsis) \\
\hline & J Hardware fin & inclondes software co \\
\hline & Softwiare $(\mathrm{d} t \mathrm{a}$ & ta inleppretetion) \\
\hline & Expeciences & \\
\hline & & Syzem Commenere \\
\hline & & \\
\hline & & \\
\hline & & \\
\hline & & \\
\hline & & \\
\hline & & Sysem in Develo \\
\hline & & \\
\hline & & \\
\hline & & \\
\hline & & \\
\hline & & \\
\hline & & System in Desigg \\
\hline & & \\
\hline & & \\
\hline & & \\
\hline Inverse degre & ree of complex & xity for user/vendor \\
\hline & Handware & \\
\hline & Softwracefot doc & terpretation \\
\hline Reliabilky In $^{\prime}$ & most diffilcult & to replace compone \\
\hline & Service life o & of most difícull to \\
\hline & & Thame corgponent \\
\hline Imetrferencer & monitcring f & for change, dont car \\
\hline & Interferents $\mathrm{Y}$ & Known \\
\hline & & Pontential Interferent \\
\hline & False Positivi & ves (delects non -exi \\
\hline & False Negativ & ive (miss a leak) \\
\hline & Inverve seve & ertity of Interferenth \\
\hline MPLEMER & NTATTON F & FASIBLITY \\
\hline Depth Limita & ations (nteres & does it coprate) \\
\hline & Sulfiace & \\
\hline & Shallow subs & surface $\left(6^{1}\right.$ to 3 ) \\
\hline & & \\
\hline & $\frac{0^{\circ}}{250^{\circ}}$ & \\
\hline Subsurface & Access & \\
\hline & Bonetholes & \\
\hline & & Mjinimura D (inch \\
\hline & , & Operative in Caseo \\
\hline & + & \\
\hline & & \\
\hline & + & Require Perforatio \\
\hline & + & Necessary to Yank \\
\hline & & |vilize existing dr \\
\hline & & \\
\hline & & \\
\hline & Alternative S & Subsurface \\
\hline & & Cone Penetrometer \\
\hline & & Bachioge \\
\hline Operational B & $\frac{1}{\text { Regions (Figg }}$ & we 3) \\
\hline & (1) & \\
\hline & 2 & \\
\hline & 3 & \\
\hline & 4 & \\
\hline Inglemenentet & tion Specifics & assume $50^{\prime}$ spacio \\
\hline & Location to T & Tank \\
\hline & & Depth \\
\hline & & Nurber of sensort \\
\hline Ứlility Servic & & \\
\hline & TNone & \\
\hline & Self Containe & ed \\
\hline & & Battery \\
\hline & & Generator \\
\hline & & Air Compressor \\
\hline & External Sor & \\
\hline & & $A C$ \\
\hline & & $\mathrm{DC}$ \\
\hline & & Watts (does cystem \\
\hline Qperzoting En & 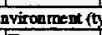 & ypicas Hanford corer \\
\hline & Tempecatare & \\
\hline & Surface Fium & \\
\hline & Soil Moisture & \\
\hline & Affected by & Contarringtion \\
\hline & & Radiactive focotot \\
\hline & & \\
\hline & & \\
\hline & & Saline (ryplem con \\
\hline & & th \\
\hline & & \\
\hline & & $\mathrm{Ph}$ hoyserm contract \\
\hline & & 年 \\
\hline & & \\
\hline
\end{tabular}




\section{Table A.1. Borehole Geophysical Systems (Part 1)}

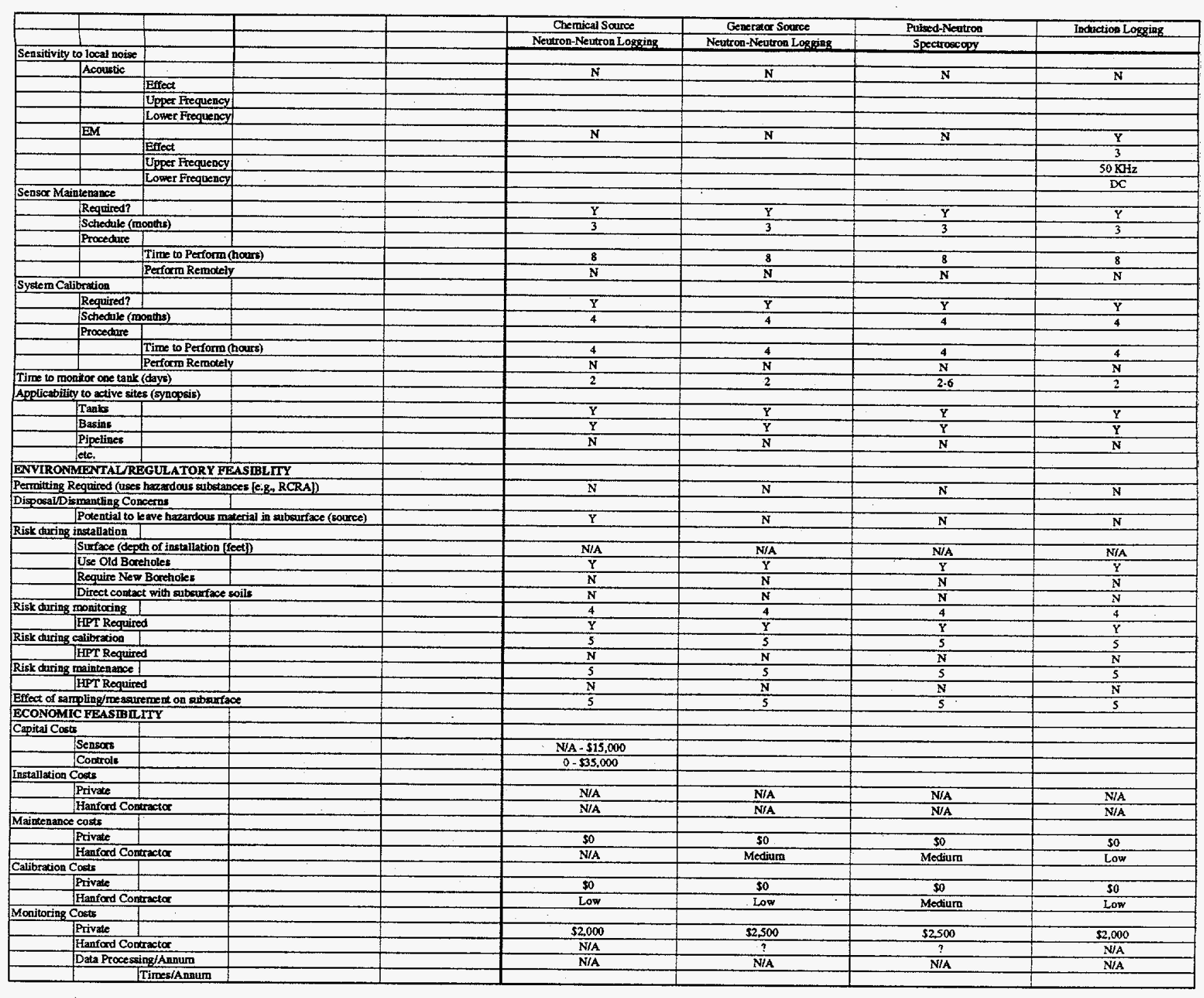


Table A.1. Borehole Geophysical Systems (Part 2)

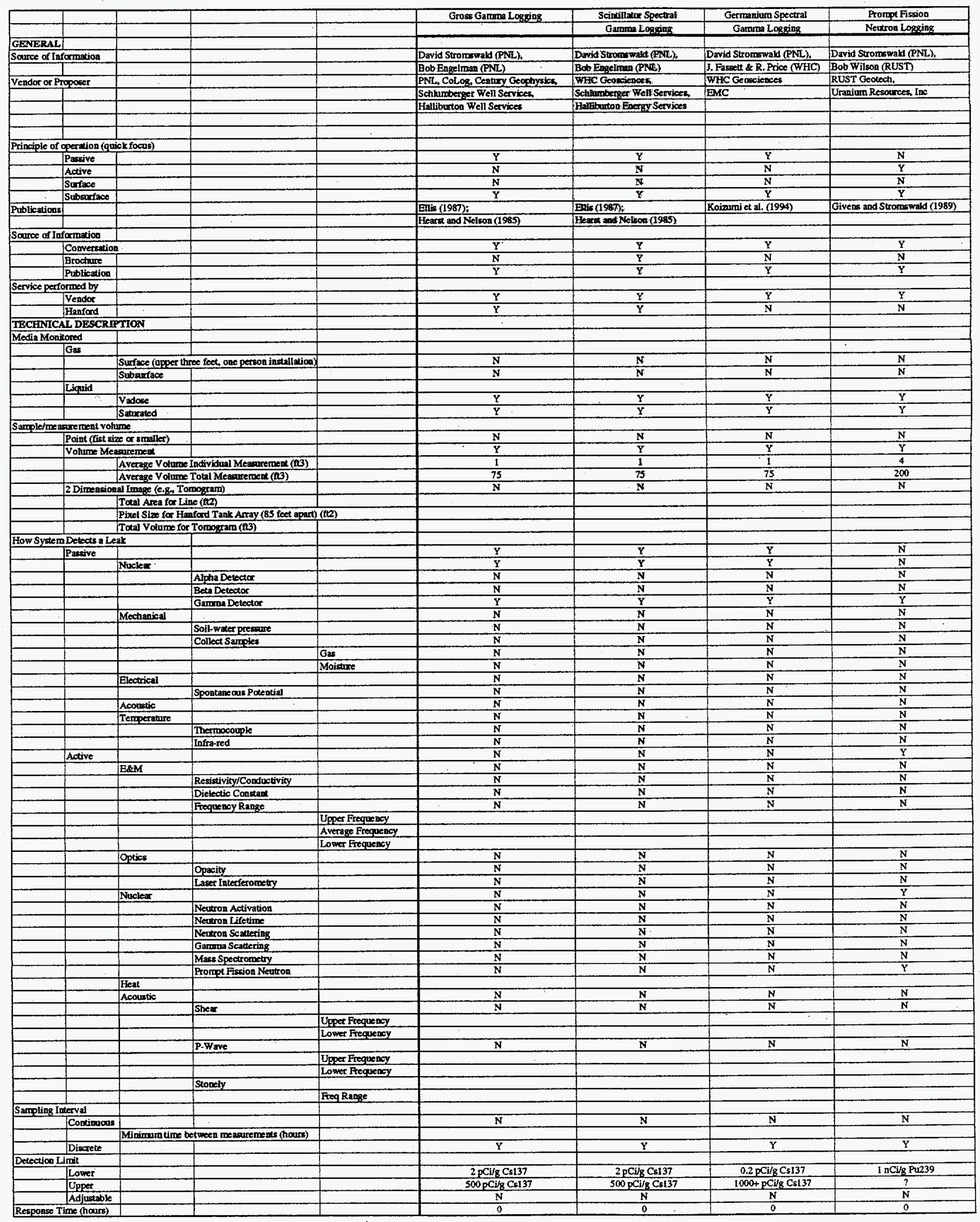




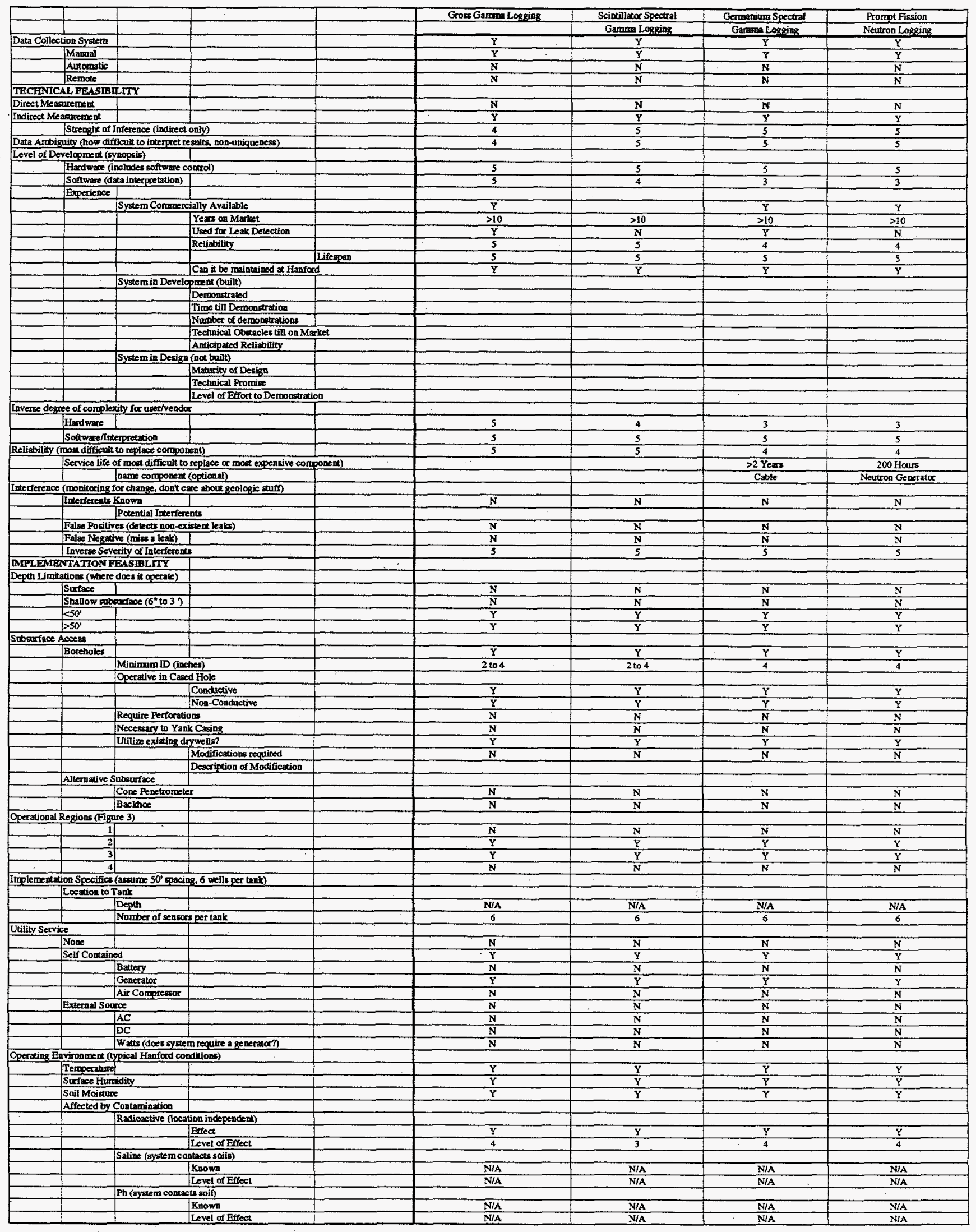


Table A.1. Borehole Geophysical Systems (Part 2)

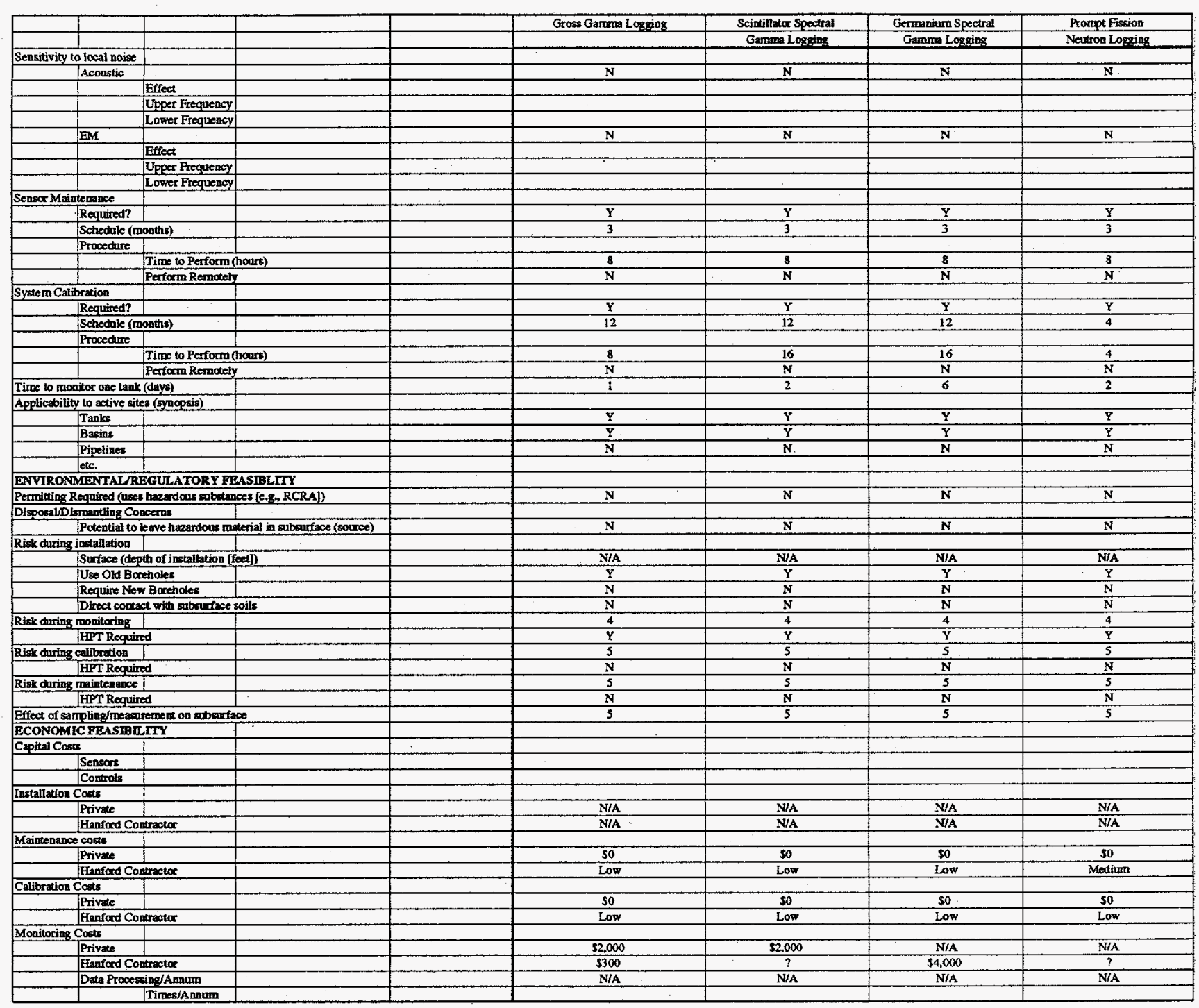


Table A.2. Surface Geophysical Systems

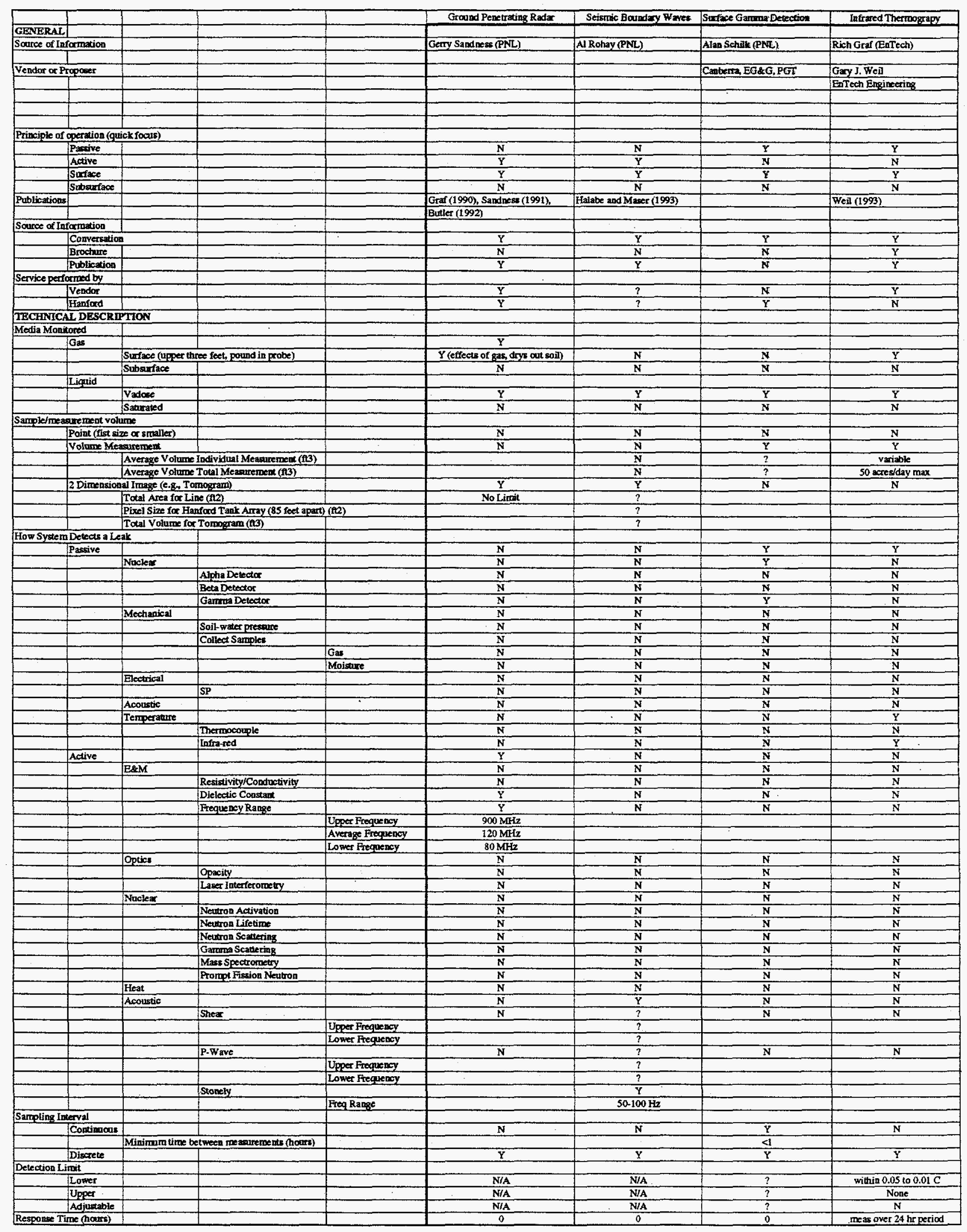


Table A.2. Surface Geophysical Systems

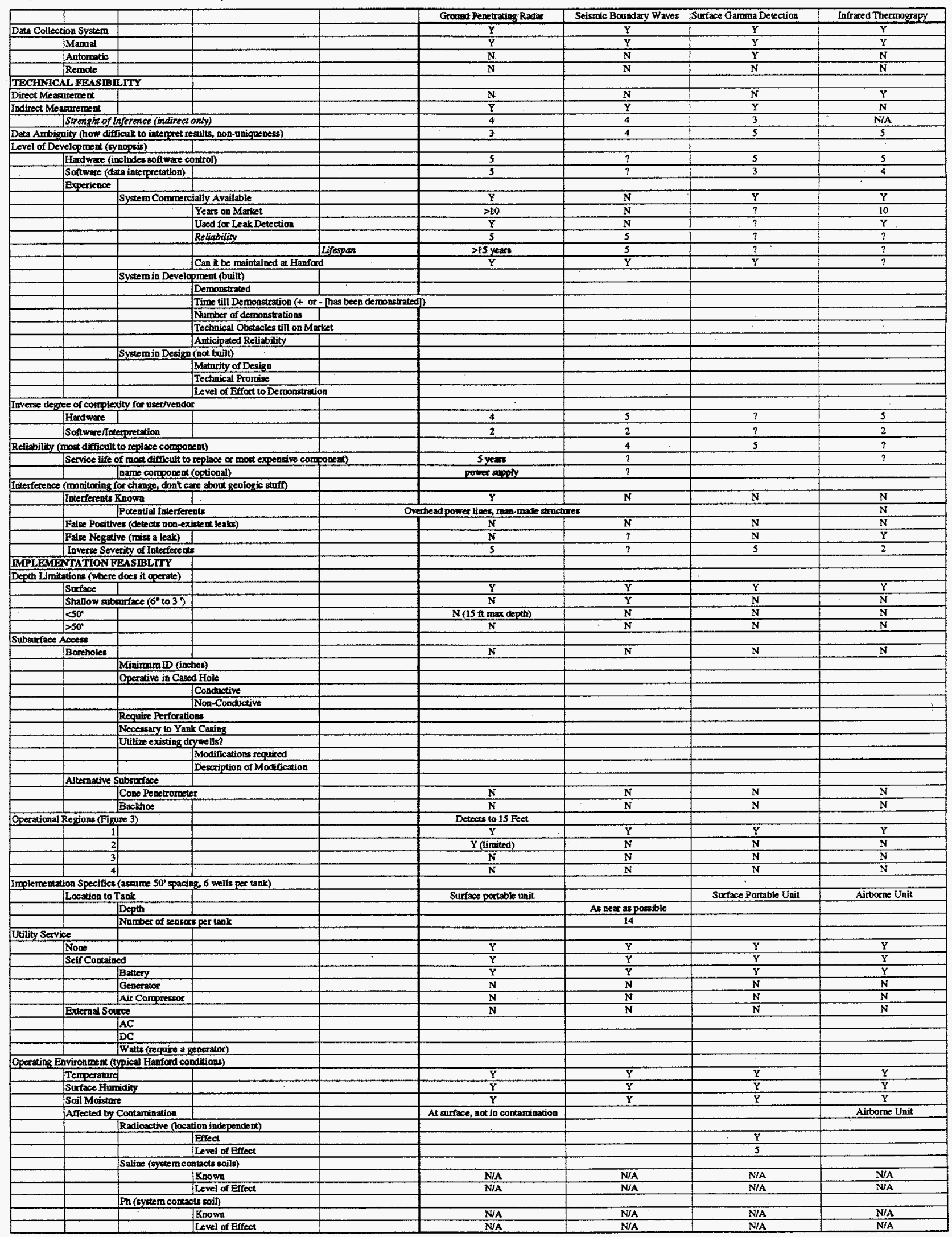


Table A.2. Surface Geophysical Systems

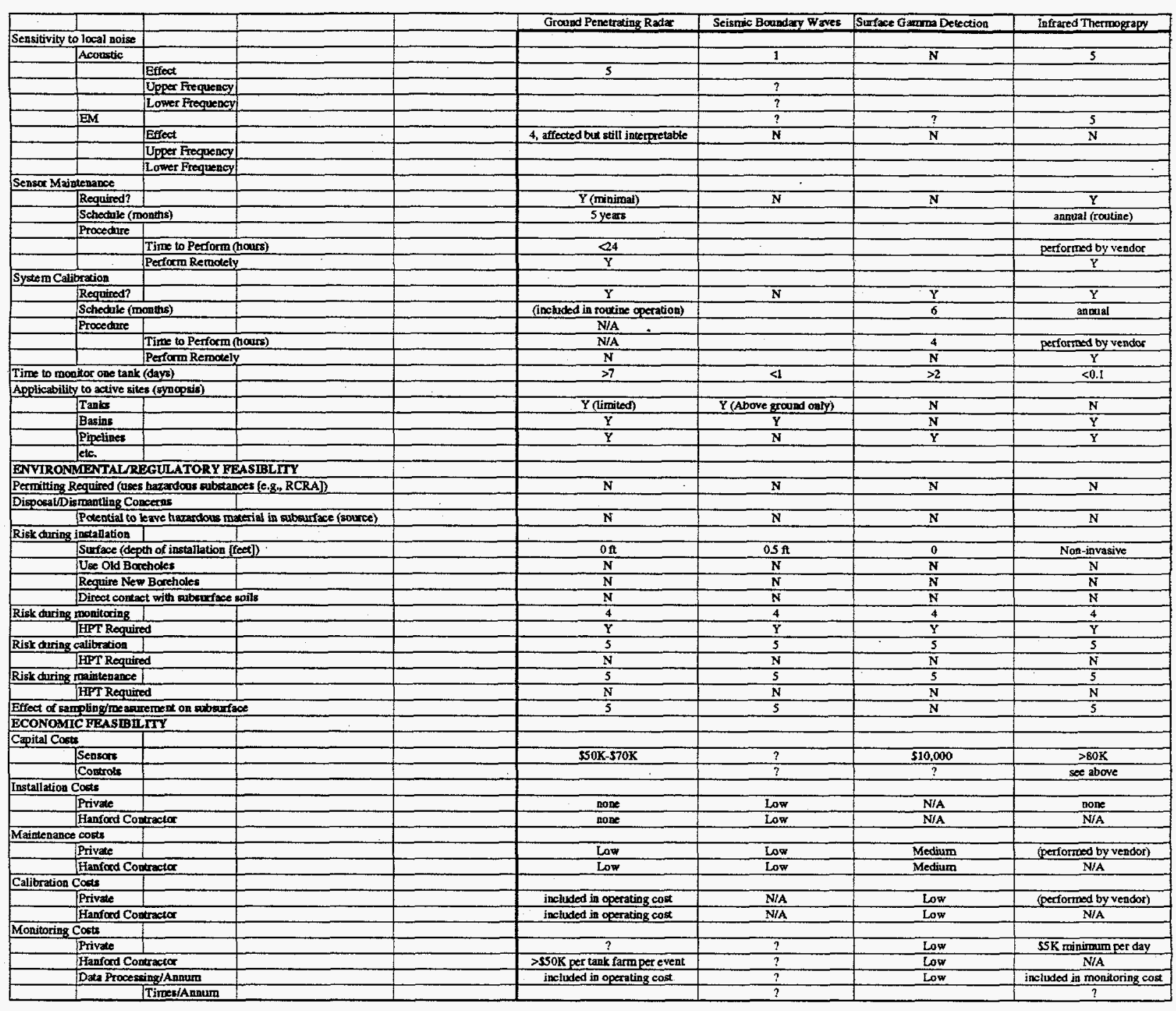


Table A.3. Borehole-Borehole Geophysical Systems

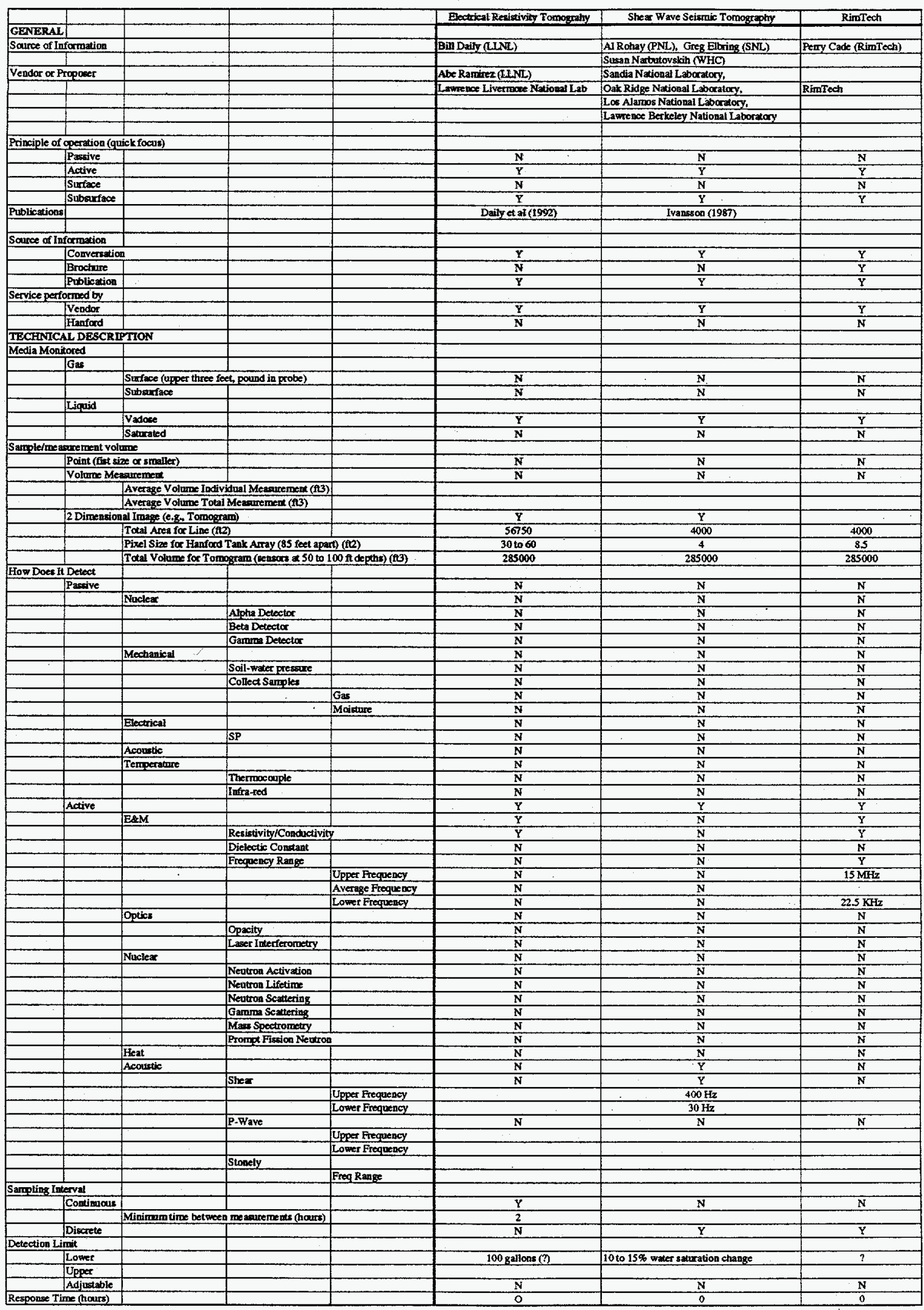




\section{Table A.3. Borehole-Borehole Geophysical Systems}

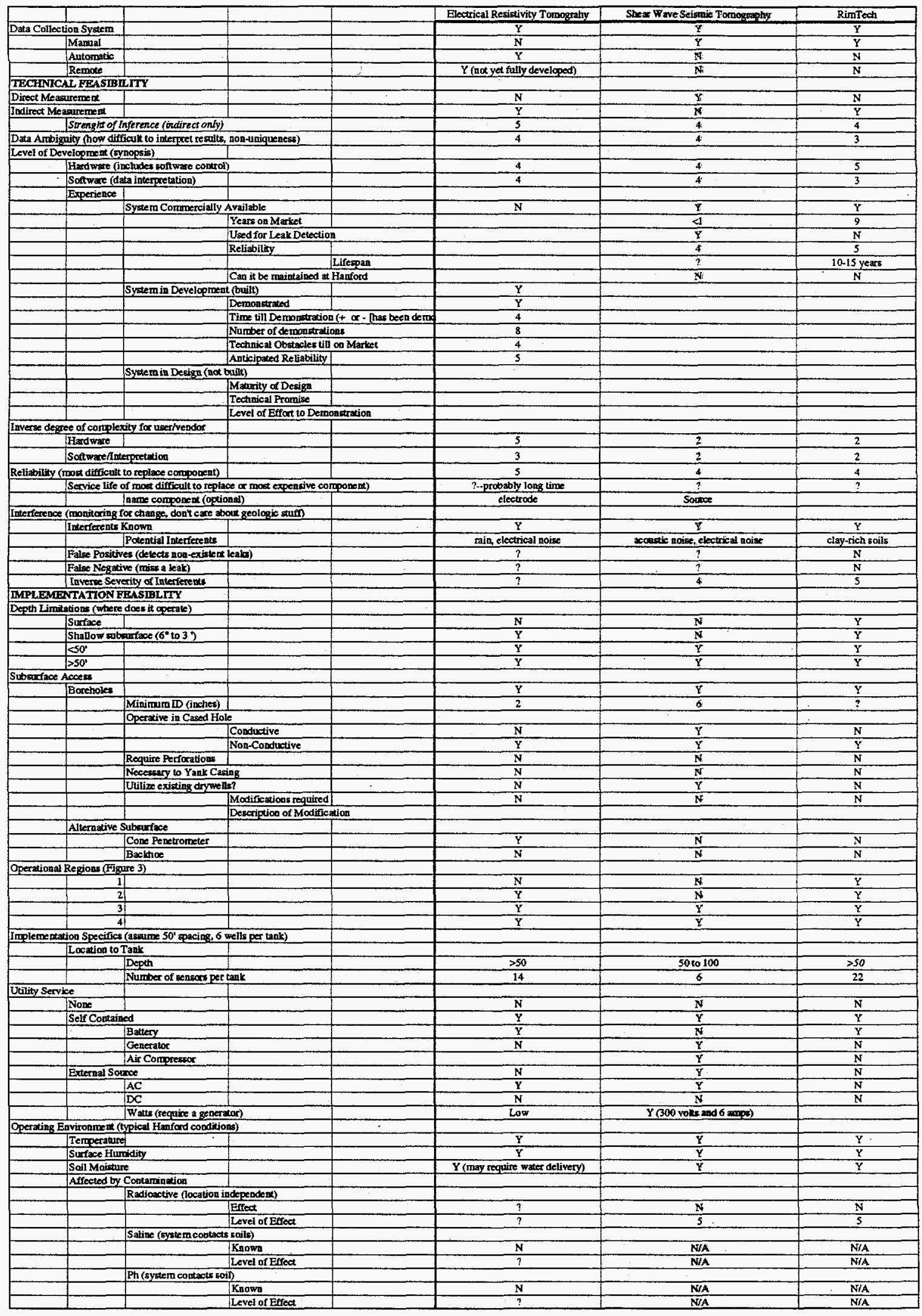


Table A.3. Borehole-Borehole Geophysical Systems

\begin{tabular}{|c|c|c|c|c|c|c|c|}
\hline & & & & & Electrical Resigtivity Tomograthy & Shear Wave Seismic Tomograghy & Rimirech \\
\hline \multicolumn{8}{|c|}{ Sensitivity to local noise } \\
\hline & Acoustic & & & & $\mathbf{N}$ & $\mathrm{Y}$ & $\mathbf{N}$ \\
\hline & & Eiffect & & & & 4 & \\
\hline & & Upper Frequency & & & & $?$ & \\
\hline & & Lower Froguency & & & & $?$ & \\
\hline & EM & & & & $\bar{Y}$ & $y$ & $\bar{Y}$ \\
\hline & & Effect & & & $?$ & 5 & 4 \\
\hline & & Upper Frequency & & & $?$ & $?$ & $?$ \\
\hline & & Lower Frequency & & & $?$ & $?$ & $?$ \\
\hline \multicolumn{8}{|c|}{ Sensor Majntenance } \\
\hline & Required? & & & & $Y$ (\$rader delivery) & $?$ & $?$ \\
\hline & \multicolumn{2}{|c|}{ Schectule (months) } & & & $?$ & $?$ & $?$ \\
\hline & Procedulue & & & & & & \\
\hline & & \multicolumn{2}{|l|}{ Time to Perform (hourn) } & & $?$ & $?$ & $?$ \\
\hline & & Perform Remotely & & & $\mathbf{N}$ & N & $\mathrm{N}$ \\
\hline \multicolumn{8}{|c|}{ System Calibration } \\
\hline & Required? & & & & $\bar{Y}$ & $?$ & $?$ \\
\hline & \multicolumn{2}{|c|}{ Scheciule (months) } & & & 12 & $?$ & $?$ \\
\hline & Procedune & & & & & & \\
\hline & & \multicolumn{2}{|l|}{ Time to Perform (hours) } & & 4 & $?$ & $?$ \\
\hline & & Perform Remoiely & & & $\mathbf{N}$ & $\bar{N}$ & $\bar{N}$ \\
\hline \multicolumn{3}{|c|}{ Tirze to monitor one tank (days) } & & & $<0.1$ & B to 10 wreeks & $7(?)$ \\
\hline \multicolumn{8}{|c|}{ Applicability to active sites (synqperis) } \\
\hline & Tanks & & & & $\mathrm{Y}$ & $\bar{Y}$ & $\mathrm{Y}$ \\
\hline & Basins & & & & $\bar{Y}$ & 8 & $\mathbf{Y}$ \\
\hline 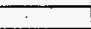 & Pipelibes & & & & $\mathrm{Y}$ & $\bar{Y}$ & $\mathrm{Y}$ \\
\hline \multirow{2}{*}{\multicolumn{8}{|c|}{\begin{tabular}{|c|c|c} 
ete. & \\
\end{tabular}}} \\
\hline & & \multicolumn{2}{|c|}{ ENVIRONMENTALREGULATORY HEASIBLITY } & & & & \\
\hline \multicolumn{4}{|c|}{ Permitting Required (uses hazardous anbstances $[0,8$, RCRA $]$ ) } & & $\bar{N}$ & $\mathbf{N}$ & $\mathbf{N}$ \\
\hline \multirow{2}{*}{\multicolumn{4}{|c|}{\begin{tabular}{|l|l} 
DisposalD ismantling Concerus & | \\
Potential to kave hazardous material in subserface (source)
\end{tabular}}} & & & & \\
\hline & & & & & N & $\bar{N}$ & $\overline{\mathbf{N}}$ \\
\hline \multicolumn{4}{|c|}{ 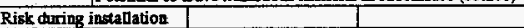 } & & & & \\
\hline & Surface (dep) & perh of installation [feetl] & & & 50 & $50+$ & $a_{+}$ \\
\hline & Use Old Bar & rehoies & & & $\mathbf{N}$ & $\mathrm{Y}$ & $\mathbf{N}$ \\
\hline & Reguire Net & w Bareholes & & & $\mathbf{Y}$ & $\mathrm{N}$ & $\mathrm{Y}$ \\
\hline & Direct corta & ct vith sabsurface soils & & & $\mathrm{Y}$ & $\mathbf{N}$ & $\bar{N}$ \\
\hline Risk during : & monitaring & & & & 5 & 4 & 4 \\
\hline & HPT Requin & & & & $\mathrm{N}$ & $\bar{Y}$ & $\mathrm{Y}$ \\
\hline Risk during & calibretion & & & & 5 & 5 & 5 \\
\hline & FPT Requir & & & & $\mathrm{N}$ & $\mathrm{N}$ & N \\
\hline Risk duting & maintentance & & & & 5 & 5 & 5 \\
\hline & TEPT Requin & & & & $\mathbf{N}$ & $\mathrm{N}$ & $N$ \\
\hline Effect of $\operatorname{san}$ & opling/measen & irement on sobourface & & & $\mathrm{N}$ & $\mathbf{N}$ & $N$ \\
\hline ECONOMI & IC FEASIBII & LITY & & & & & \\
\hline Capital Cost & & & & & & & \\
\hline & Sentore & & & & $\$ 14$ & High & Medium \\
\hline & Controls & & & & $\$ 40,000$ & Medium & Mediurt \\
\hline Installation & Costs & & & & & & \\
\hline & Private & & & & N/A & Low & Low \\
\hline & Franford $\mathrm{Cor}$ & intractor & & & High & N/A & N/A \\
\hline Maintenance & $=$ & & & & & & \\
\hline & Private & & & & Low & Low & Low \\
\hline & Hanford $\mathrm{Col}$ & Ditrectax & & & Low & N/A & N/A \\
\hline Calibration & Costs & & & & & & \\
\hline & Private & & & & Low & Law & Low \\
\hline & Hanfond Co & intractor & & & Low & N/A & N/A \\
\hline Monitoring & Costs & & & & & & \\
\hline & Private & & & & Low & High & Modium \\
\hline & Hanford $\mathrm{Co}$ & idtractar & & & Low & N/A & N/A \\
\hline & Data Proces & ging/Annum & & & $?$ & High & $?$ \\
\hline & & Tirres/Annum & & & $?$ & $?$ & $?$ \\
\hline
\end{tabular}


Table A.4. Soil Moisture Sensors (Part 1)

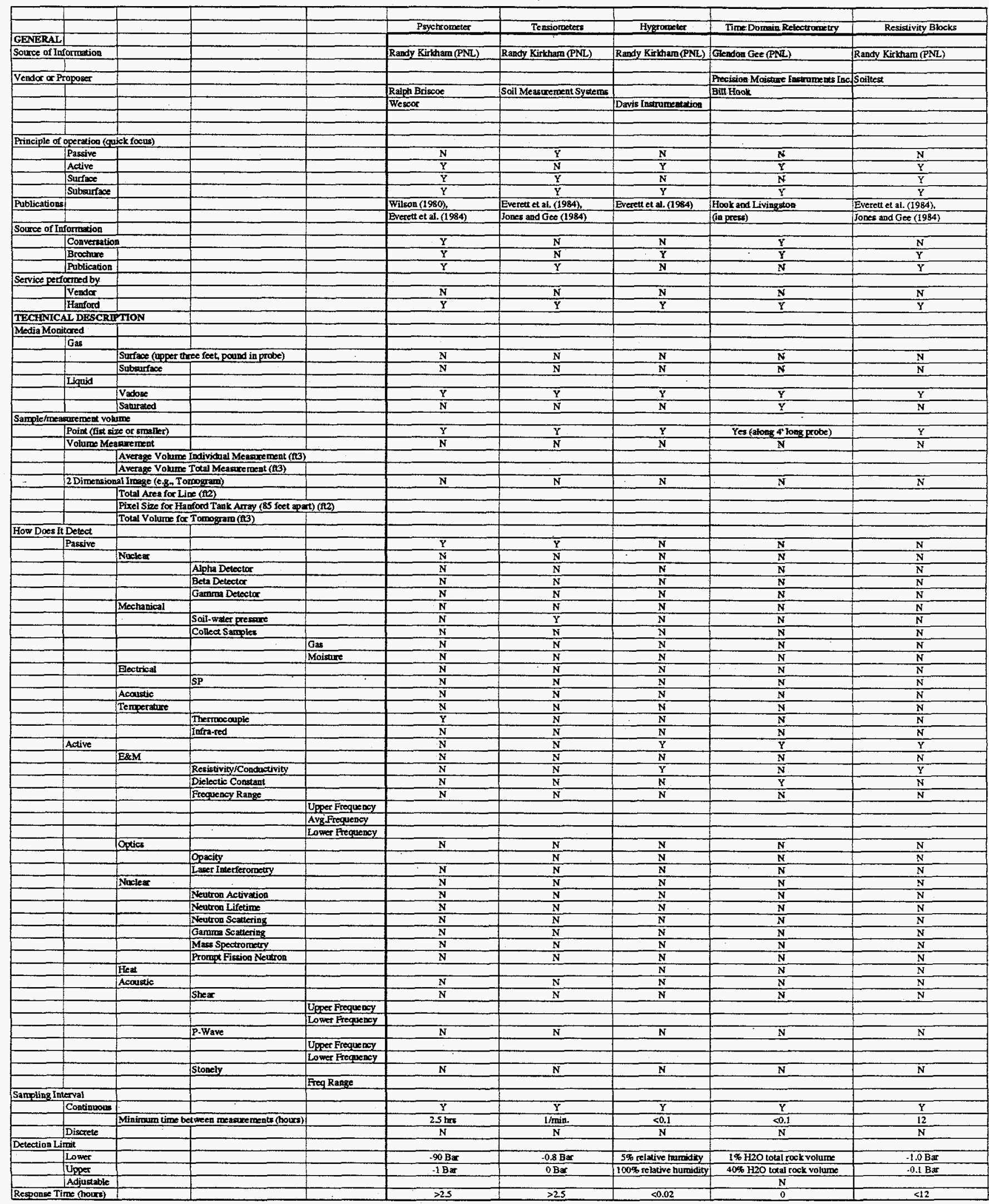


Table A.4. Soil Moisture Sensors (Part 1)

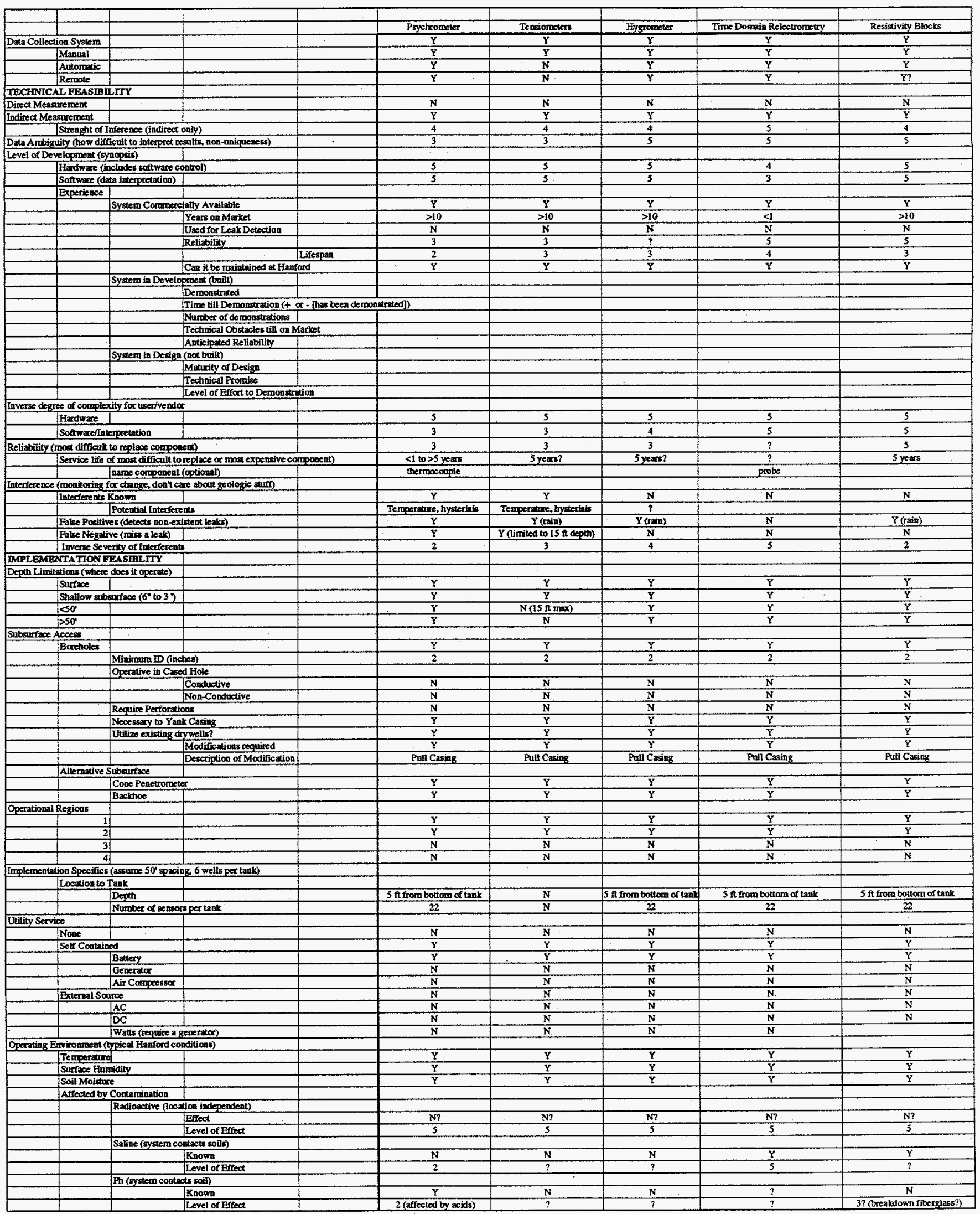


Table A.4. Soil Moisture Sensors (Part 1)

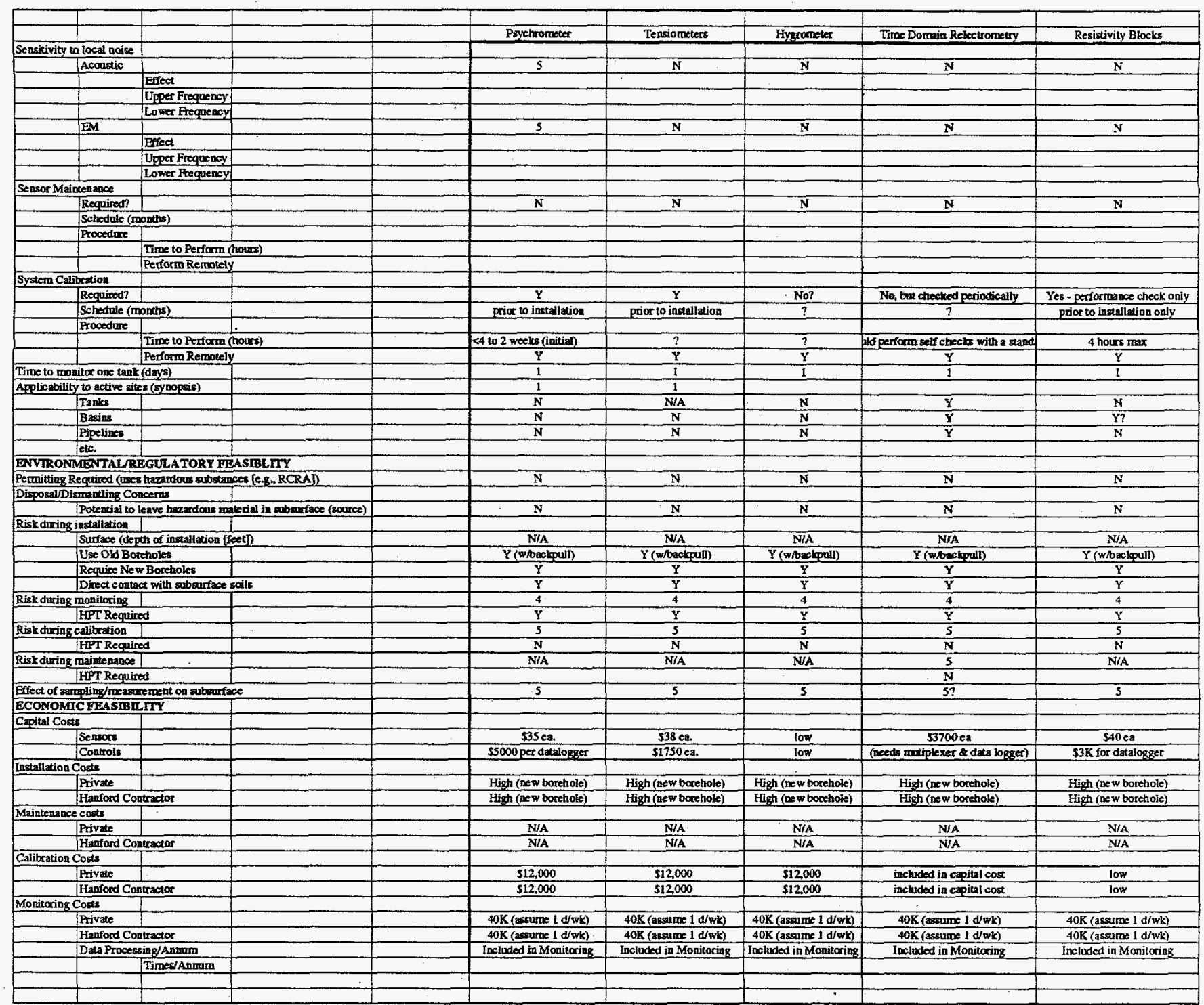


Table A.4. Soil Moisture Sensors (Part 2)

\begin{tabular}{|c|c|c|c|c|}
\hline & & & & \\
\hline & & & & \\
\hline GENERAL & & & & \\
\hline Source of inf & formation & & & \\
\hline & & & & \\
\hline Vendar or $\mathrm{Pr}$ & troposer & & & \\
\hline & & & & \\
\hline & & & & \\
\hline & & & & \\
\hline Fripciple of 0 & operation (gui & ick focus) & & \\
\hline & Passive & & & \\
\hline & Active & & & \\
\hline & Surfine & & & \\
\hline & Substurface & & & \\
\hline Publications & & & & \\
\hline & & & & \\
\hline Source of $\operatorname{tinf}$ & formanion & & & \\
\hline & Conversation & & & \\
\hline & Becochure & & & \\
\hline & Publication & & & \\
\hline Servioe perfo & armed by & & & \\
\hline & Vendoc & & & \\
\hline & Hanford & & & \\
\hline TECHNICA & AL DESCRP & PTION & & \\
\hline Media Monit & tored & & & \\
\hline & Gas & & & \\
\hline & & Surface (uppert & ree feet, pound in proc & \\
\hline & & Subsurface & & \\
\hline & Liguid & & & \\
\hline & & Vadose & & \\
\hline & & Saturated & & \\
\hline Sarmplefmeas & sarement volu & & & \\
\hline & Point (filst si & ze or smallker) & & \\
\hline & Volurne Mea & asurement & & \\
\hline & & Average Vohum & Individual Measurem & $\frac{1}{\operatorname{ent}(f(3))}$ \\
\hline & & Average Vohm & Total Meaamement (ft & \\
\hline & 2Dimension & gal Image $(e, g, ., T$ & roogrant) & \\
\hline & & Total Area for I & de (fi2) & \\
\hline & & Pixel Size for $\mathrm{H}$ & ford Tank Array (35) & feet apart) (iti2) \\
\hline & & Total Volume f & Tornogram (fi3) & \\
\hline How Does in & Detset & & & \\
\hline & Passive & & & \\
\hline & & Nucleax & & \\
\hline & & & Alpha Detoetor & \\
\hline & & & Beta Detector & \\
\hline & & & Gamma Detoctor & \\
\hline & & Mechanical & & \\
\hline & & & Soil-water pressure & \\
\hline & & & Collect Sampkes & \\
\hline & & & & Gas \\
\hline & & & & Moicture \\
\hline & & Electrical & & \\
\hline & & & SP & \\
\hline & & Acoustic & & \\
\hline & & Temperause & & \\
\hline & & & Thermocouple & \\
\hline & & & Infra-ted & \\
\hline & Active & & & \\
\hline & & E\&M & & \\
\hline & & & Resistivity/Conductiv & \\
\hline & & & Dielectic Constant & \\
\hline & & & Frequency Range & \\
\hline & & & & Upper Frequency \\
\hline & & & & Average Frequency \\
\hline & & & & Lower Frequency \\
\hline & & Optics & & \\
\hline & & & Opacity & \\
\hline & & & Laser Interferometry & \\
\hline & & Nuclear & & \\
\hline & & & Neutron Activation & \\
\hline & & & Neutron Lifetirne & \\
\hline & & & Neutron Scattering & \\
\hline & & & Gamm Scattering & \\
\hline & & & Mass Spectrometry & \\
\hline & & & Pramot Fission Neutr & \\
\hline & & Heat & & \\
\hline & & Acoustic & & \\
\hline & & & Shea & \\
\hline & & & & Upper Freguency \\
\hline & & & & Lower frequency \\
\hline & & & P-Wave & \\
\hline & & & & Upper Frequency \\
\hline & & & & Lower Frequency \\
\hline & & & Stonely & \\
\hline & & & & Freg Range \\
\hline Sampling Int & terval & & & \\
\hline & Contimuots & & & \\
\hline & & Minimbing time & etween meanurements & (hours) \\
\hline & Diserete & & & \\
\hline Detection Lir & imit & & & \\
\hline & Lower & & & \\
\hline & Upper & & & \\
\hline & Adjustable & & & \\
\hline Response Tir & ime (hours) & & & \\
\hline
\end{tabular}


Table A.4. Soil Moisture Sensors (Part 2)

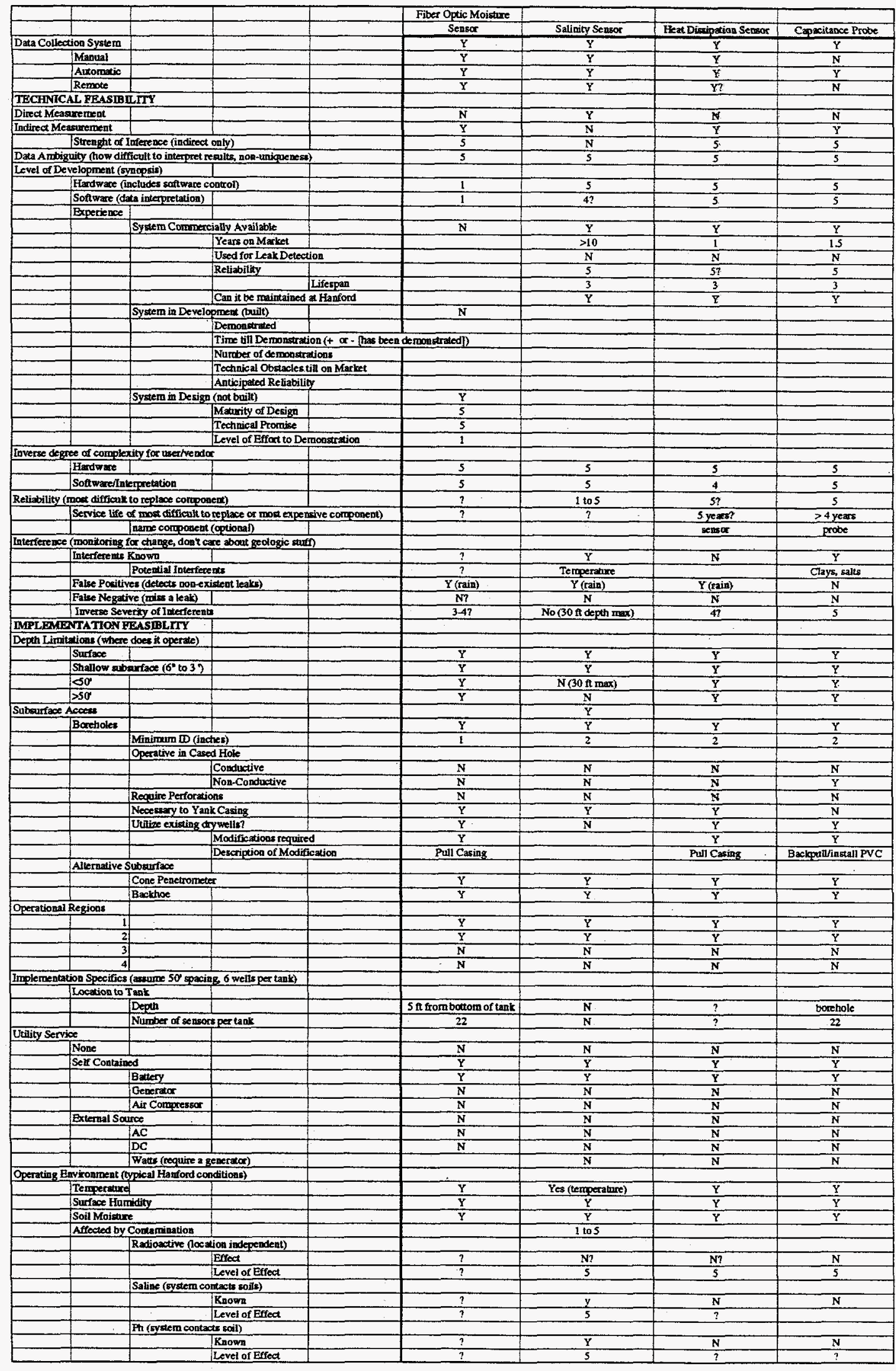


Table A.4. Soil Moisture Sensors (Part 2)

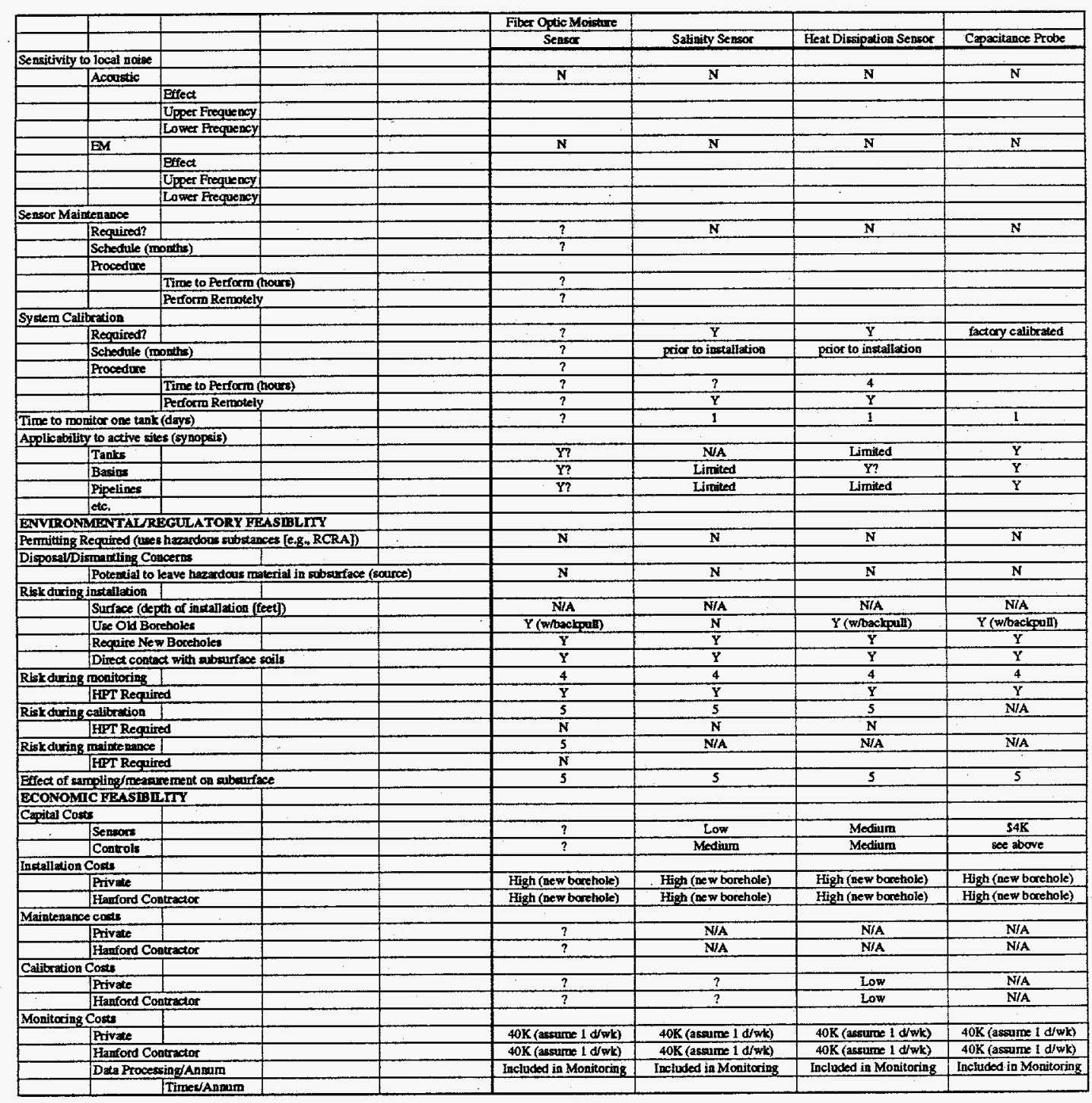


Table A.5. Insitu Sensors

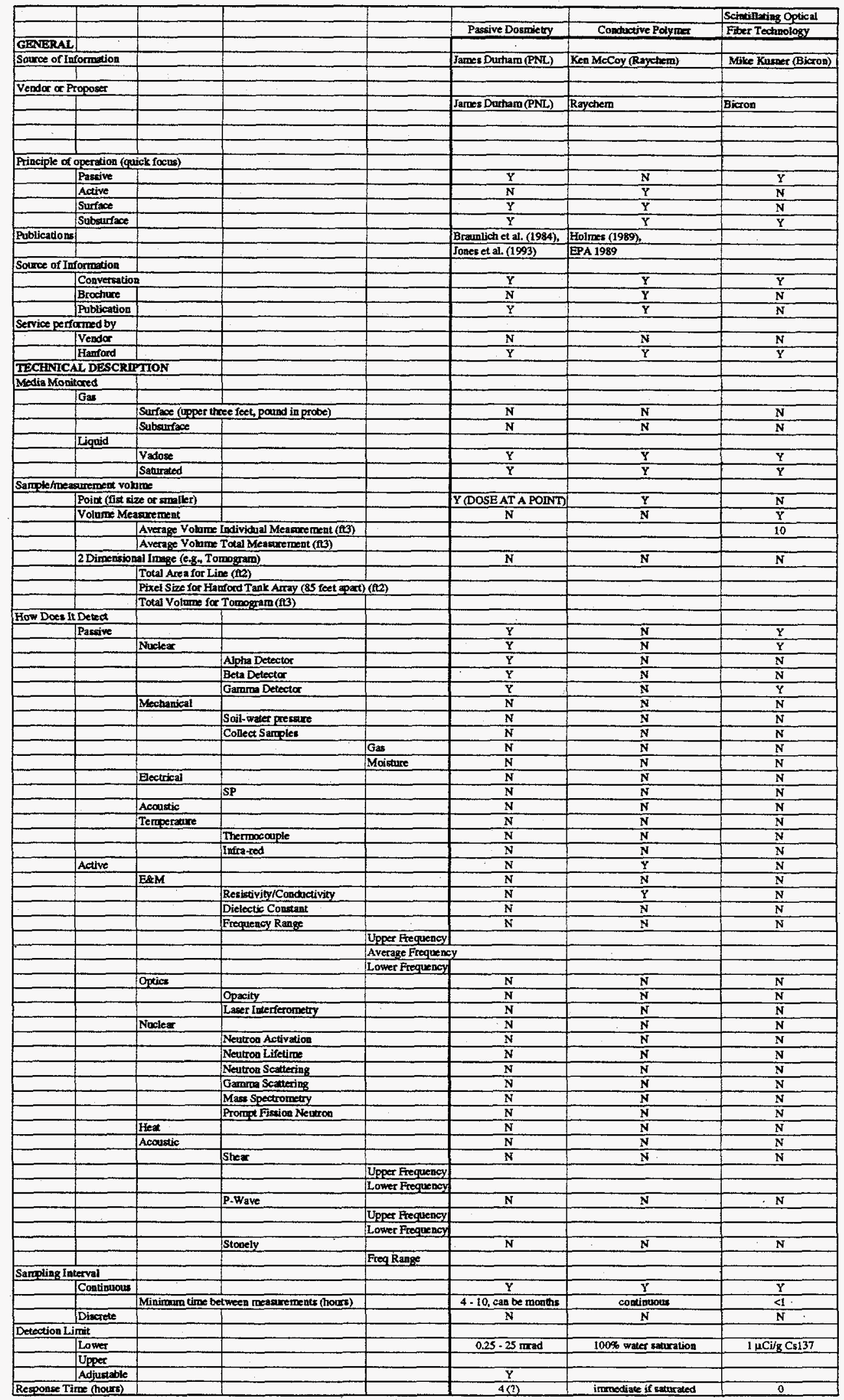


Table A.5. Insitu Sensors

\begin{tabular}{|c|c|c|}
\hline & & \\
\hline & & \\
\hline Data Coilecti & ioa System & \\
\hline & Manual & \\
\hline & Axtomacic & \\
\hline & Remole & \\
\hline TECFNICA & LEFASIBII & LITY \\
\hline Direct Meass & wement & \\
\hline Indirect Meas & strement & \\
\hline & Strenght of In & nference (indirect o \\
\hline Data Ambigu & aity (how diffi & icult to interpret set \\
\hline Level of Dev & relopinent (sy) & mopris) \\
\hline & Hoxdware (in & cludes soft ware $\mathrm{CD}$ \\
\hline & Softwaxe (dat & a inferpretation) \\
\hline & Experience & \\
\hline & & \begin{tabular}{|l|} 
System Cormoenci \\
\end{tabular} \\
\hline & & \\
\hline & & \\
\hline & & \\
\hline & & \\
\hline & & \\
\hline & & Sysem in Develof \\
\hline & & \\
\hline & & \\
\hline & & \\
\hline & & \\
\hline & & \\
\hline & & System in Design \\
\hline & & \\
\hline & & \\
\hline & & \\
\hline Inverse degre & $x$ of conpliesi & iify for userive idac \\
\hline & Handware & \\
\hline & Softwac/inte & enpretation \\
\hline Reliability (II & mose difficol $x$ & to replace compons \\
\hline & Service life of & onost difficult tor \\
\hline & & name cortponent \\
\hline Interference | & (monitoring fo & ot change, dont ca \\
\hline & Interferentes $\mathrm{K}$ & Known \\
\hline & & Potential Interficen \\
\hline & False Positive & $x \in$ (delecens non-exi) \\
\hline & False Negativ & ve (mist a leak) \\
\hline & Inverse Sever & erity of Interferents \\
\hline IMPLEMFA & STATION FE & EASWLITY \\
\hline Depth Limita & tions (where of & does fit operute) \\
\hline & Sinface & \\
\hline & Shallow exbs & sorface $\left(6^{\prime}\right.$ to 3$)$ \\
\hline & $50^{\circ}$ & \\
\hline & $>50$ & \\
\hline Subsuriace A & teces & \\
\hline & Boreholes & \\
\hline & & Minirtoum D (inch \\
\hline & & Operative in Caed \\
\hline & & \\
\hline & & \\
\hline & & Require Peforatio \\
\hline & & Neceseng to Yan \\
\hline & & Utilize exioting do \\
\hline & & \\
\hline & & \\
\hline & Allemative $\mathrm{S}$ : & subaurfioge \\
\hline & & Cone Penetronete \\
\hline & & \begin{tabular}{|l|} 
Backhoce \\
\end{tabular} \\
\hline Operational I & Regions & \\
\hline & & \\
\hline & 2 & \\
\hline & 3 & \\
\hline & 4 & \\
\hline Imptementat & Lon Specifics & (assurne $50^{\circ} \mathrm{apacin}$ \\
\hline & Loc ation to $T$ & Tank \\
\hline & & Depth \\
\hline & & Nunber of sensors \\
\hline Utility Servis & & \\
\hline & None & \\
\hline & Self Containe & \\
\hline & & Battery \\
\hline & & Gemerator \\
\hline & & \begin{tabular}{|l|l} 
Air Compressor \\
\end{tabular} \\
\hline & External Sout & \\
\hline & & AC \\
\hline & & $D C$ \\
\hline & & Watts (require a \\
\hline Operating En & aviroment (c) & Ypical Hanford con \\
\hline & Ternperatume & \\
\hline & Surface Hom & nidity \\
\hline & Soil Moirture & \\
\hline & Affocted by & Contamination \\
\hline & & Radioactive floca \\
\hline & & \\
\hline & & \\
\hline & & Satine (cystern co \\
\hline & & \\
\hline & & \\
\hline & & Ph (fystem contac \\
\hline & & \\
\hline & & \\
\hline
\end{tabular}


Table A.5. Insitu Sensors

\begin{tabular}{|c|c|c|c|c|c|c|}
\hline & & & & & & Sciocillating Optical \\
\hline & & & & Passive Dosmicty & Conductive Polymer & Fiber Techinology \\
\hline \multicolumn{7}{|l|}{ Sensitivity to local noise } \\
\hline Acoulsic & & & & $\mathrm{N}$ & N & $\mathbf{N}$ \\
\hline & Efieat & & & & & \\
\hline & Upper Frequency & & & & & \\
\hline & Lower Frequency & & & & & \\
\hline EM & & & & $?$ & $\mathbf{N}$ & F \\
\hline & Eified & & & & & \\
\hline & Upper Frequency & & & & & \\
\hline & Lower Frequency & & & & & \\
\hline \multicolumn{7}{|l|}{ Sensor Maincepance } \\
\hline Required? & & & & $\mathbf{N}$ & $\mathbf{Y}$ & $\mathrm{N}$ \\
\hline \multicolumn{2}{|c|}{ Schedple (months) } & & & & \multicolumn{2}{|c|}{ (replace cable affer exposure to a leakit). } \\
\hline Procedure & & & & & N/A & \\
\hline & \multicolumn{2}{|c|}{ Time to Perform (hours) } & & & N/A & \\
\hline & \multicolumn{2}{|c|}{ Perform Rernotely } & & & N/A & \\
\hline \multicolumn{7}{|l|}{ Sygrem Calibration } \\
\hline Required? & & & & $Y$ far reader only & Yes-performenece check ouly & $\mathbf{Y}$ \\
\hline \multicolumn{2}{|c|}{ Schedule (mooths) } & & & $?$ & prior to installation onily & \\
\hline Procodune & & & & & & \\
\hline & \multicolumn{2}{|c|}{ Time to Pertorm (hours) } & & & 2 & $?$ \\
\hline & \multicolumn{2}{|c|}{ Pefform Remotely } & & $\mathbf{Y}$ & $\mathbf{Y}$ & $\mathbf{N}$ \\
\hline \multirow{2}{*}{\multicolumn{2}{|c|}{\begin{tabular}{|l|} 
Time to moniter one tank (days) \\
Applicability to active sites (synopsin)
\end{tabular}}} & & & 0.15 to 30 & 0.1 & $>1$ \\
\hline & & & & & & \\
\hline \multicolumn{3}{|c|}{\begin{tabular}{|c|} 
Tanks \\
\end{tabular}} & & $\underline{Y}$ & $\mathbf{N}$ & $Y$ \\
\hline Basins & & & & $\bar{Y}$ & $Y($ secondary) & $Y$ \\
\hline Pipelines: & & & & $\mathrm{Y}$ & $Y$ (seconday) & $\mathbf{Y}$ \\
\hline \multirow{2}{*}{\multicolumn{3}{|c|}{\begin{tabular}{|l|l|l|} 
etc. & & \\
ENVRONMENTALABEGLATORY FEASIBLITY \\
\end{tabular}}} & & & & \\
\hline & & & & & & \\
\hline \multicolumn{3}{|c|}{ Permitting Required (uses hazandours substauces $[$ (e.8., RCRA] $)$} & & $\mathbf{N}$ & $\mathbf{N}$ & $\mathrm{N}$ \\
\hline Disposal/Dismantling $\mathrm{Cor}_{\mathrm{f}}$ & acerns & & & & & \\
\hline Potential to 1 & leave hazindous ma & erial in subsurface (source) & & $\mathbf{N}$ & $N$ & $\mathbf{N}$ \\
\hline Risk during installation & & & & & & \\
\hline Surface (dep & th of installation [f & & & & & \\
\hline Use old Bor & retroles & & & $\bar{Y}$ & Maybe & $\bar{Y}$ \\
\hline Require Ner & Boreholes & & & $Y$ (alpha beta) & $\mathbf{Y}$ & $\mathbf{N}$ \\
\hline Direct contar & at with sthauf 300 & & & Y(alpha, beta) & $\mathbf{Y}$ & $\overline{\mathbf{N}}$ \\
\hline Riskduring moaitoring & & & & 4 & 5 & 5 \\
\hline IHIT Require & & & & $\bar{Y}$ & $N$ & $\mathbf{N}$ \\
\hline Risk ducing califbeation & & & & 5 & & 4 \\
\hline FHPT Require & & & & $\mathbf{N}$ & & $Y$ \\
\hline Riskduring maine eanoce & & & & N/A & N/A & 4 \\
\hline THET Reguire & & & & & & $\mathbf{Y}$ \\
\hline Effect of arnoting/meani & rement on aboutra & & & 5 & 5 & 5 \\
\hline ECONOMTC HEASIBI & LTYY & & & & & \\
\hline Capital Cass & & & & & & \\
\hline Senseors & & & & S20 for dosimeter & mediunn & $\$ 4,000$ \\
\hline Controle & & & & $\$ 45,000$ for reader & medium & Uaknown \\
\hline Installacios Cont: & & & & & & \\
\hline Privale & & & & & High (requires boreholes & \\
\hline Hanford Con & ntractor & & & low & High (requires boreholes & Low \\
\hline Maiplenance coets & & & & & & \\
\hline Ptivate & & & & $N / A$ & N/A & N/A \\
\hline Haufond Con & Aremax & & & \$1000/yeariceader & toone & Low \\
\hline Calibration Costs & & & & & & \\
\hline Privale & & & & N/A & $N / A$ & N/A \\
\hline Haafford Con & atractor & & & N/A & low & Low \\
\hline Monitoring Coss & & & & & & \\
\hline Rivisic & & & & N/A & N/A & N/A \\
\hline Fanford Con & atractor & $\cdot$ & & Low & $40 \mathrm{~K}$ (aspum $1 \mathrm{~d} / \mathrm{wh})$ & Low \\
\hline Data Process & sing/Anturn & & & & inetuded in moniloring cos & \\
\hline & TimeE/Anmom & & & & incloded in monitoring cost. & \\
\hline
\end{tabular}


Table A.5. Moisture Removal and Analysis

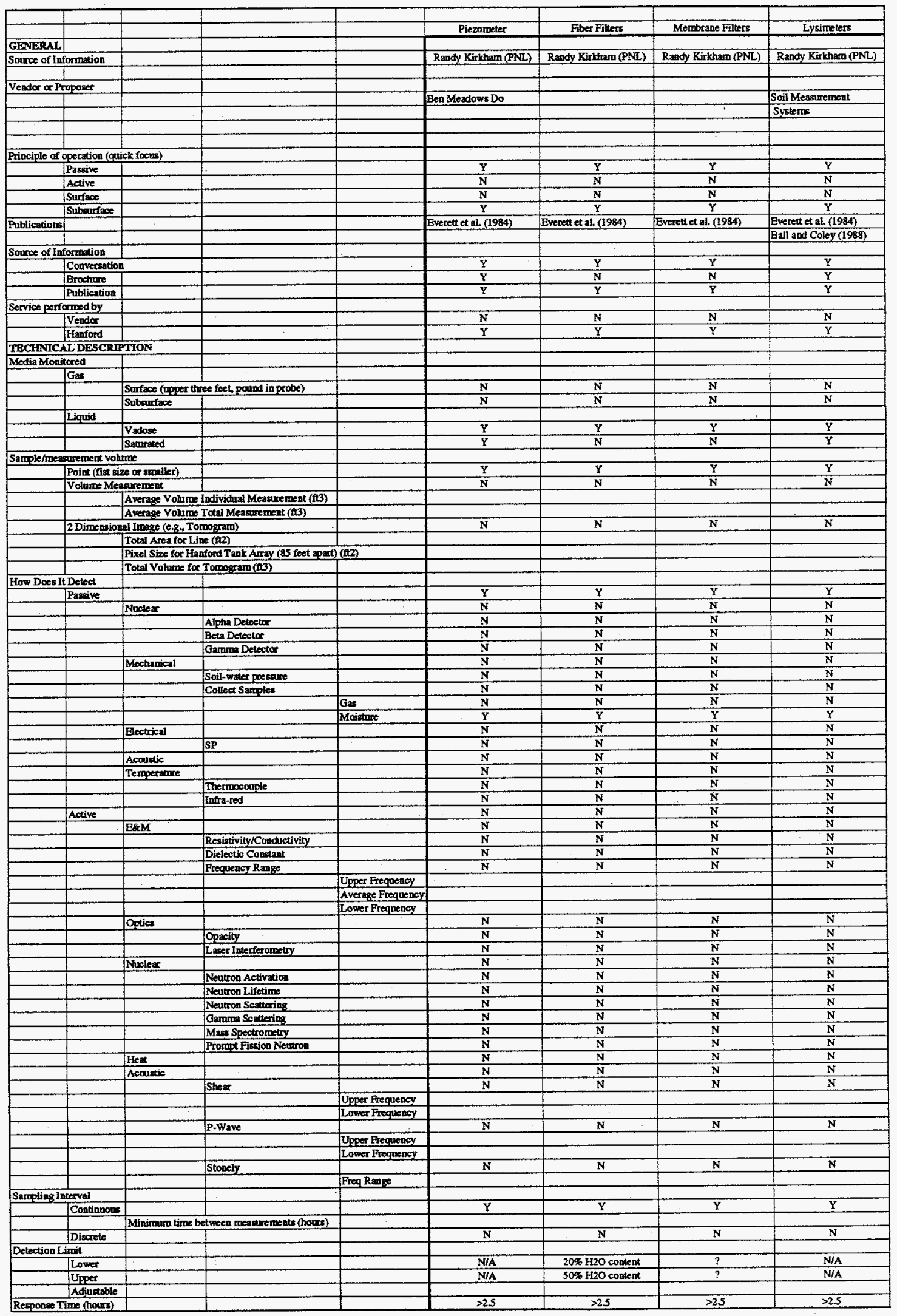


Table A.5. Moisture Removal and Analysis

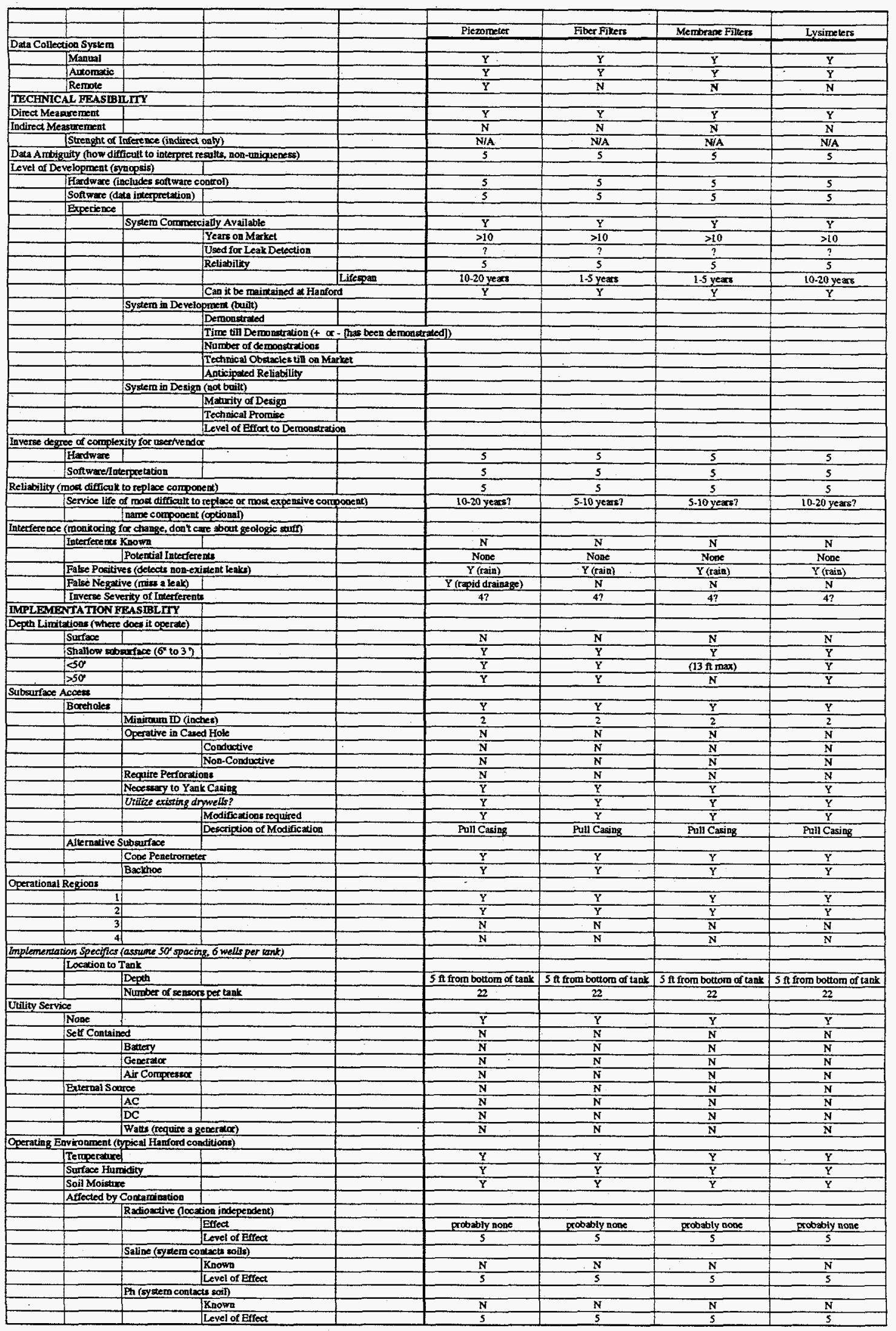




\section{Table A.5. Moisture Removal and Analysis}

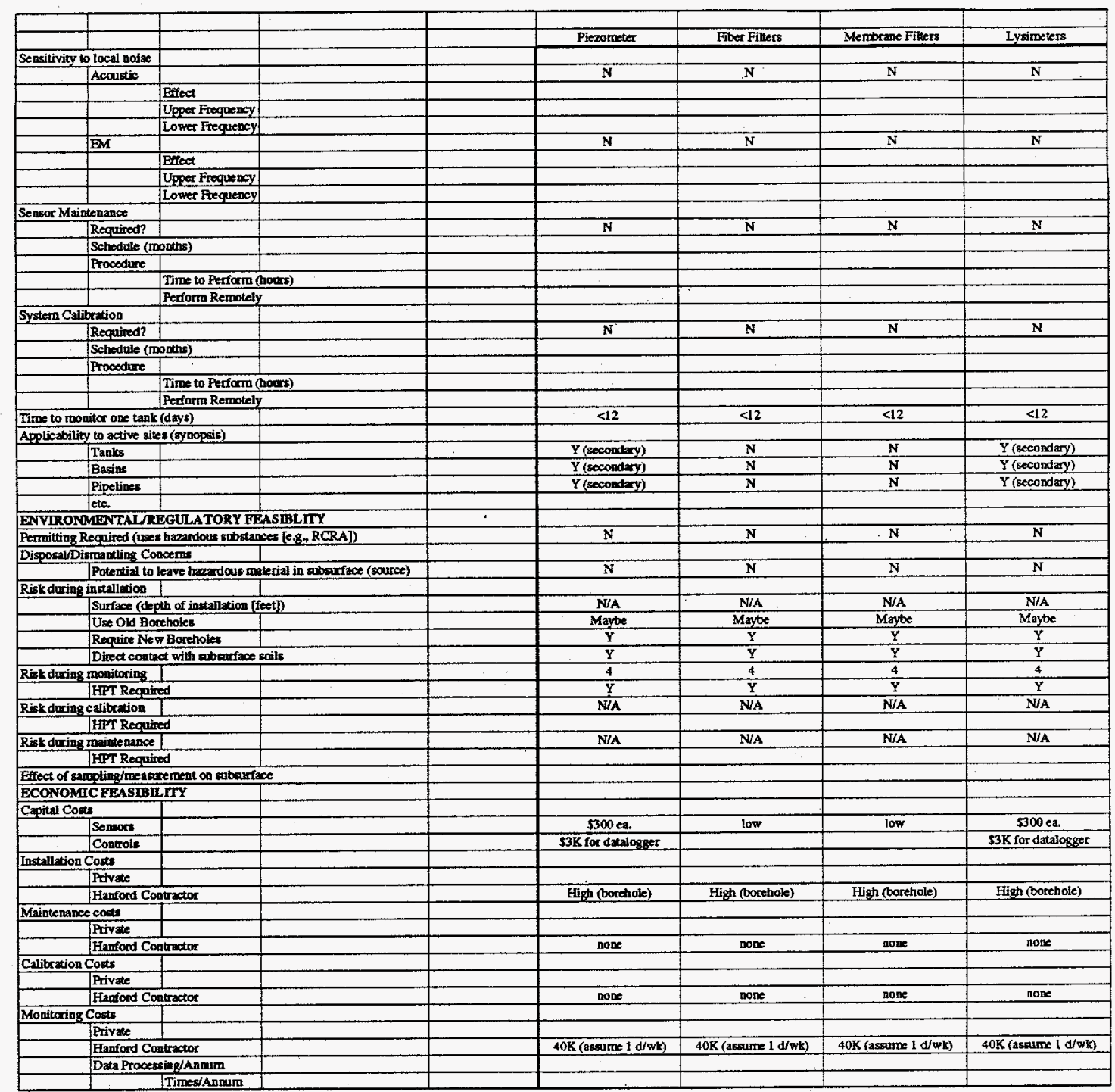


Table A.6. Vapor Extraction and Analysis

\begin{tabular}{|c|c|c|c|c|}
\hline & & & & \\
\hline & & & & \\
\hline GENERAL & & & & \\
\hline Souce of In & formation & & & \\
\hline & & & & \\
\hline Vendoc or $P$ & roposer & & & \\
\hline & & & & \\
\hline & & & & \\
\hline & & & & \\
\hline Principle of & operabion (qui] & jick focus) & & \\
\hline & Passive & & & \\
\hline & Active & & & \\
\hline & Surface & & & \\
\hline & Subarriace & & & \\
\hline Fubtications & & & & \\
\hline & & & & \\
\hline Source of In & formeation & & & \\
\hline & Conversation & & & \\
\hline & Brochure & & & \\
\hline & Publication & & & \\
\hline Service perf & formed by. & & & \\
\hline & Vendar & & & \\
\hline & Hanford & & & \\
\hline TECANIC & AL DESCRIP & PTION & & \\
\hline Media Moni & itoced & & & \\
\hline & Gas & & & \\
\hline & & Surfaxe (coper it) & ree feet, pound in probe) & \\
\hline & & Subsourface & & \\
\hline & Liquid & & & \\
\hline & & Vastase & & \\
\hline & & Saturated & & \\
\hline Samplefmea & wrement volu & & & \\
\hline & Poix (Îst siz & ze or smaller) & & \\
\hline & Yolume Mea & aurement & & \\
\hline & & Average Votame & Indivicual Measurerneat (fitis) & \\
\hline & & Average Volume & Total Measurement (ft3) & \\
\hline & 2Dimemsion & ali linage $\left(e . g_{n} T_{0}\right.$ & mogram) & \\
\hline & & Total Area for L & ine (iD) & \\
\hline & & Pixel Size for $\mathrm{Ht}$ & ford Tank Aray (35 feet apart & $(122)$ \\
\hline & & Total Volume fo & Tomogram (f(A3) & \\
\hline How Does I & totect & & & \\
\hline & Pastive & & & \\
\hline & & Nuclear & & \\
\hline & & & Alpha Detector & \\
\hline & & & Beta Detectox & \\
\hline & & & Gampa Detector & \\
\hline & & Mechanical & & \\
\hline & & & Soil-water pressure & \\
\hline & & & Collect Samples & \\
\hline & & & & Gas \\
\hline & & & & Moisture \\
\hline & & Electrical & & \\
\hline & & & SP & \\
\hline & & Acoustic & & \\
\hline & & Temperature & & \\
\hline & & & Thermocouple & \\
\hline & & & Infra-red & \\
\hline & Active & & & \\
\hline & & E\&M & & \\
\hline & & & Resistivity/Conductivity & \\
\hline & & & Dielectic Constant & \\
\hline & & & Frequency Ravge & \\
\hline & & & & Upper Frequency \\
\hline & & & & Average Frequencic \\
\hline & & & & Lower Frequency \\
\hline & & Ootics & & \\
\hline & & & Opscity & \\
\hline & & & Laser Interferoluetry & \\
\hline & & Nuciear & & \\
\hline & & & Nentron Activation & \\
\hline & & & Nenutron Lifetime & \\
\hline & & & Neutron Scattering & \\
\hline & & & Gamm Scatiering & \\
\hline & & & Mass Spectronktry & \\
\hline & & & Proment Fission Neutron & \\
\hline & & Hese & & \\
\hline & & Acoustic & & \\
\hline & & & Shear & \\
\hline & & & & Upper Frequency \\
\hline & & & & Lower Frequency \\
\hline & & & P-Wave & \\
\hline & & & & Upper Frequency \\
\hline & & & & Lower Frequency \\
\hline & & & Stonely & \\
\hline & & & & Freq Range \\
\hline Sampling In & terval & & & \\
\hline & Continuous & & & \\
\hline & & Mfinimporn time $b$ & retween meagrements fhours) & \\
\hline & Discrete & & & \\
\hline Detection Li & & & & \\
\hline & Lower & & & \\
\hline & Uppex & & & \\
\hline & Adjustable & & & \\
\hline Response $\mathrm{Ti}$ & ine (hourts) & & & \\
\hline
\end{tabular}




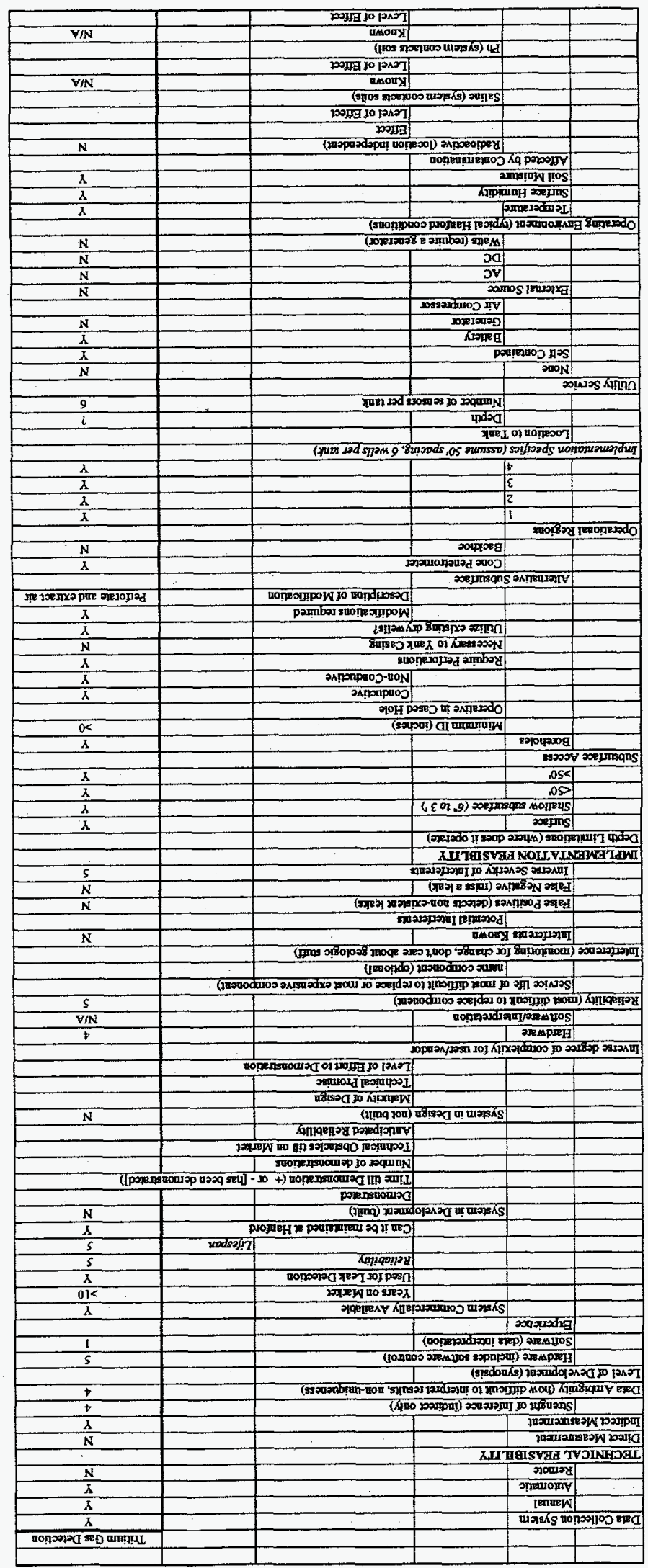


Table A.6. Vapor Extraction and Analysis

\begin{tabular}{|c|c|c|c|c|c|}
\hline & & & & & \\
\hline & & & & & Tritiom Gas Detection \\
\hline \multicolumn{6}{|c|}{ Sensitivity to local noise } \\
\hline & Acoustic & & & & $\mathbf{N}$ \\
\hline & & Effect & & & \\
\hline & & Upper Frequency & & & \\
\hline & & Lower Frequency & & & \\
\hline & EM & & & & $\mathrm{N}$ \\
\hline & & Effect & & & \\
\hline & & Upper Frequency & & & \\
\hline & & Lower Frequency & & & \\
\hline \multicolumn{6}{|c|}{ Sensor Maintenance } \\
\hline & Required? & & & & $\mathbf{N}$ \\
\hline & \multicolumn{5}{|c|}{ Schedule (months) } \\
\hline & Procedure & & & & \\
\hline & & \multicolumn{4}{|c|}{ Time to Rerform (hours) } \\
\hline & & \multirow{2}{*}{\multicolumn{4}{|c|}{ Perform Remotely }} \\
\hline \multicolumn{2}{|c|}{ Sysem Calibration } & & & & \\
\hline & Reguined? & & & & $\bar{Y}$ \\
\hline & \multicolumn{2}{|c|}{ Scheotule (months) } & & & 12 \\
\hline & Procedure & & & & \\
\hline & & \multicolumn{2}{|c|}{ Time to Perform (noluss) } & & 4 \\
\hline & & \multicolumn{2}{|c|}{ Pedorm Remotely } & & $\mathbf{N}$ \\
\hline \multicolumn{6}{|c|}{ Time to moniter one tank (days) } \\
\hline \multicolumn{6}{|c|}{ Appolicability to active sites (synopsis) } \\
\hline & Tanks & & & & Y (if tricinm is preseex) \\
\hline & Basings & & & & Y(if tritium is pesesent) \\
\hline & Pipelines & & & & $Y$ (if tritiom is peesent) \\
\hline \multicolumn{6}{|c|}{\begin{tabular}{|l|l|l} 
etc. & - & \\
\end{tabular}} \\
\hline \multicolumn{6}{|c|}{ ENVIRONMENTALREGULA TORY FEAS IBLTYY } \\
\hline \multicolumn{4}{|c|}{ Permituing Required (Leses hasartous subetances (e.g. RCRA) } & & $\mathrm{N}$ \\
\hline \multicolumn{6}{|c|}{ Disposald Dismantling Concerns } \\
\hline & Potential to k & leave hazandous ma & exial in subsurface (source) & & $\mathbf{N}$ \\
\hline Risk dering & installation & & & & \\
\hline & Surface idep & th of inctallation (ff & & & NIA \\
\hline & Use OVd Bor & retholes & & & $Y$ (if perforate) \\
\hline & Reguire New & o Boreholes & & & $\frac{N}{N}$ \\
\hline & Direct contac & ct with sabsurface: & & & $\mathrm{N}$ \\
\hline Riskduring: & monitoring & & & & 2 \\
\hline & TFPT Require & & & & $\bar{Y}$ \\
\hline Riskduring & calibretion & & & & 5 \\
\hline & IFFT Require & & & & $\mathbf{N}$ \\
\hline Riskduring & mainlenance & & & & 5 \\
\hline & HPT Require & & & & $\bar{N}$ \\
\hline Efiect of gan & mplinglumeanr & rerment on pubsurfes & & & 2 \\
\hline ECONOM & IC FEASIBL & LITY & & & \\
\hline Casital Coste & & & & & \\
\hline & Sensoont & & & & Low \\
\hline & Controls & & & & Low \\
\hline Installation C & $\cos s$ & & & & \\
\hline & Privas: & & & & \\
\hline & Hanfond Con & ntractor & & & Medium to High \\
\hline Mainterance & econts & & & & \\
\hline & Frivate & & & & \\
\hline & Flanford Con & nurator & & & Low \\
\hline Calitrotion C & Corts & & & & \\
\hline & Privas: & & & & \\
\hline & Hanford Con & ntractor & & & Low \\
\hline Monitaing & Costs & & & & \\
\hline & Private & & & & \\
\hline & Hanford Con & ntractor & & & Low to Medium \\
\hline & Data Process & sing/Andurm & & & s. \\
\hline & & Tines/Annum & & & 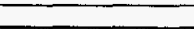 \\
\hline
\end{tabular}


PNL-10176

UC-606

\section{DISTRIBUTION}

No. of

Copies

\section{OFFSITE}

12 DOE/Office of Scientific and Technical Information

\section{ONSITE}

2 DOE Richland Operations Office

R.D. Hildebrand

W.R. Wrzesinski

7 Westinghouse Hanford Company

G.D. Bazinet

R.C. Bolden

L.A. Fort

D.F. Iwatate (3)

J.G. Propson

20 Pacific Northwest Laboratory

R.E. Engelman

G.W. Gee

G.V. Last

R.E. Lewis (5)

P.E. Long

S.S. Teel (3)

Publishing Coordination

Technical Report Files (5)

\section{Routing}

R.M. Ecker

M.J. Graham

P.M. Irving

S.A. Rawson

P.C. Hays (last)

Distr. 1 